\title{
Marketing knowledge and competencies in co-creation relationships
}

Citation for published version (APA):

Noordhoff, C. S. (2007). Marketing knowledge and competencies in co-creation relationships. [Doctoral Thesis, Maastricht University]. Maastricht University Press. https://doi.org/10.26481/dis.20080118cn

Document status and date:

Published: 01/01/2007

DOI:

$10.26481 /$ dis.20080118cn

Document Version:

Publisher's PDF, also known as Version of record

\section{Please check the document version of this publication:}

- A submitted manuscript is the version of the article upon submission and before peer-review. There can be important differences between the submitted version and the official published version of record.

People interested in the research are advised to contact the author for the final version of the publication, or visit the DOI to the publisher's website.

- The final author version and the galley proof are versions of the publication after peer review.

- The final published version features the final layout of the paper including the volume, issue and page numbers.

Link to publication

\footnotetext{
General rights rights.

- You may freely distribute the URL identifying the publication in the public portal. please follow below link for the End User Agreement:

www.umlib.nl/taverne-license

Take down policy

If you believe that this document breaches copyright please contact us at:

repository@maastrichtuniversity.nl

providing details and we will investigate your claim.
}

Copyright and moral rights for the publications made accessible in the public portal are retained by the authors and/or other copyright owners and it is a condition of accessing publications that users recognise and abide by the legal requirements associated with these

- Users may download and print one copy of any publication from the public portal for the purpose of private study or research.

- You may not further distribute the material or use it for any profit-making activity or commercial gain

If the publication is distributed under the terms of Article $25 \mathrm{fa}$ of the Dutch Copyright Act, indicated by the "Taverne" license above, 


\title{
MARKETING KNOWLEDGE
}

\author{
AND COMPETENCIES IN
}

\section{Co-Creation RELATIONSHIPS}


Marketing Knowledge and Competencies in Co-Creation Relationships

\section{(C) 2007, Corine Noordhoff, Den Haag}

All rights reserved. No part of this publication may be reprinted or utilized in any form or by any electronic, mechanical or other means, now known, or hereafter invented, including photocopying and recording, or in any information storage or retrieval system, without permission from the copyright owner.

ISBN: 978-90-5278-681-0

Cover Design: Rosemarie Hofmann-Noordhoff

Printed by: Datawyse Maastricht 


\title{
MARKETING KNOWLEDGE
}

\author{
AND COMPETENCIES IN
}

\section{Co-Creation Relationships}

\author{
PROEFSCHRIFT
}

ter verkrijging van de graad van doctor

aan de Universiteit Maastricht,

op gezag van de Rector Magnificus, prof. mr. G. P. M. F. Mols

volgens het besluit van het College van Decanen,

in het openbaar te verdedigen

op vrijdag 18 januari 2008 om 14:00 uur

door

Corine Simone Noordhoff

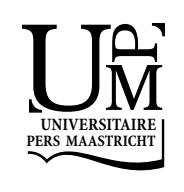


Promotor:

Prof. dr. ir. B.G.C. Dellaert (Erasmus University Rotterdam)

Copromotores:

Dr. K. Kyriakopoulos (ALBA Graduate Business School)

Dr. P. Pauwels

Beoordelingscommissie:

Prof. dr. J.C. de Ruyter (voorzitter)

Prof. dr. G M. Duysters (Eindhoven University of Technology)

Prof. dr. C. Moorman (Duke University) 
LIFE IS TOO IMPORTANT TO BE TAKEN SERIOUSLY

- OsCAR WILDE - 



\section{ACKNOWLEDGEMENTS}

Though there's just one name on the spine of this dissertation, it has been by no means a solitary activity. I am grateful to many people who have traveled with me on my $\mathrm{PhD}$ journey and equipped me with the necessary luggage. This work could not have been done without their help, support, and compassion.

First, I would like to thank my supervisors Benedict Dellaert, Kyriakos Kyriakopoulos, and Piet Pauwels. Not many PhD students have been blessed by a group of supervisors so diverse in personality and opinion. You have proven to be a wonderful team. All of you possess your own unique skills and competencies that complemented each other very beautifully and have been essential during the process.

I would also like to take this opportunity to thank the members of my dissertation committee, prof. dr. Ko de Ruyter, prof. dr. Geert Duysters and prof. dr. Christine Moorman, for their constructive and valuable comments. A special note goes to Christine Moorman who gave very generously of her time to provide useful feedback on my research in general. Moreover, she is a wonderful source of inspiration and her great eye for detail has kept me on my toes.

I am also grateful to my former colleagues in Maastricht who have always created a pleasant working environment. Jos Lemmink and Gaby OdekerkenSchröder are thanked for stimulating and inspiring me to apply for a $\mathrm{PhD}$ position. Vera Blažević deserves my special thanks for being such a positive and energetic person and for the many enjoyable coffee breaks we have shared.

My current colleagues at the Vrije Universiteit in Amsterdam are thanked for their support in finishing the last parts of this dissertation. The fact that you have welcomed me so warmly in the department has made the transition to a job in the "big city" very smooth and easy.

Furthermore, I would like to thank the members of the Marketing Department of the Carlson School of Management at the University of Minnesota for their hospitality and support. I greatly enjoyed visiting you. During my stay in Minnesota a number of people have deeply advanced my knowledge on how to combine seriousness and fun in research. Rajesh Chandy, Jaideep Prabhu, Paola Cillo and Om Narasimhan: Thanks for teaching me this!!

I am grateful for the financial support from MSI (Marketing Science Institute) and NWO (Nederlandse Organisatie voor Wetenschappelijk Onderzoek) 
for the data collection of my dissertation research and my half-year stay in the USA.

I would also like to express special thanks to my "Maastricht-buddies"; Dave and Crista, Joost and Sjoukje, Harm and Floor, and Wim and Lea. Together we have experienced some true moments of la joie de vivre... Our get-togethers were great to relax and get my mind away from the dissertation.

Another group of friends from "the south" (i.e., below the rivers) has contributed seriously also in terms of distraction from the dissertation and keeping my head cool in times of worry. The nights out in the pub, weddings and many other activities that "the Brabo's" and I have jointly undertaken have definitely brightened up the weekends!

To my never-boring family -immediate, extended and "adopted"- I cannot be grateful enough for helping me to become who I am today. Thanks for your endless support, for all the stories about the most awkward and amazing things that happen to you and for not paying too much attention to my moments of despair and stress. Rosemarie, thanks a ton for developing the beautiful cover of my dissertation!

And last, but not least, I extend my most heartfelt gratitude to the one who means so much to me. Jeroen, you were always there to cheer me up and stood by me through all highs and lows. Thank you for giving me the chance to do what needed to be done. For a lack of adequate words, I thank you with all my heart. You've made the difference!

Corine Noordhoff, Den Haag 2007 


\section{TABLE OF CONTENTS}

CHAPTER 1: INTRODUCTION 1

1.1 RESEARCH PROBLEM 2

1.2 CO-CREATION RELATIONS 5

1.3 THEORETICAL FOUNDATION 6

1.4 OBJECTIVES 8

$\begin{array}{ll}1.5 \text { DisSERTATION OUTLINE } & 10\end{array}$

CHAPTER 2: MARKETING INNOVATION IN VERTICAL CO-CREATION: THE MULTIFACETED ROLE OF RELATIONAL TIES 13

2.1 INTRODUCTION 14

2.2 CONCEPTUAL FRAMEWORK AND HYPOTHESES 15

2.3 RESEARCH METHOD 21

2.4 ANALYSIS AND RESULTS 27

2.5 DisCUSSION AND IMPLICATIONS 32

CHAPTER 3: BUILDING NEW COMPETENCIES THROUGH CO-CREATION RELATIONS: THE ROLE OF KNOWLEDGE REDUNDANCY AND MEMORY 37

3.1 INTRODUCTION 38

3.2 LITERATURE REVIEW 40

3.3 HYPOTHESES

3.4 RESEARCH METHOD $\quad 47$

3.5 RESULTS $\quad 52$

3.6 DISCUSSION AND IMPLICATIONS

CHAPTER 4: CO-CREATION KNOWLEDGE TRANSFERABILITY: THE ROLE OF KNOWLEDGE TYPE, TIE STRENGTH, AND TURBULENCE $\quad 61$

4.1 INTRODUCTION 62

4.2 CO-CREATION KNOWLEDGE TRANSFERABILITY 63

4.3 CONCEPTUAL FRAMEWORK $\quad 65$

4.4 RESEARCH METHOD $\quad 70$

4.5 RESUlTS 76

4.6 DisCUSSION AND IMPLICATIONS 80 
CHAPTER 5: CONCLUSION

5.1 INTRODUCTION

5.2 DisCUSSION 86

5.3 PERSPECTIVES ON FURTHER RESEARCH 90

APPENDICES 92

REFERENCES 101

NEDERLANDSE SAMENVATTING 114

CURRICULUM VITAE 118 
CHAPTER 1: INTRODUCTION 


\subsection{Research Problem}

Contemporary firms increasingly pay attention to understanding organizational learning processes and managing their knowledge bases (Noble et al. 2002; Vorhies and Morgan 2005; Zheng Zhou et al. 2005). Such increased interest is driven largely by the role of knowledge in explaining firm success across different disciplines (e.g., Kessler et al. 2000; Nonaka 1994). The resource-based view (RBV) of the firm considers knowledge a resource that is frequently inimitable and therefore of strategic value (Barney 1991), and the knowledge-based view of the firm, an extension of the RBV, even claims that knowledge is the prime resource of firms (Grant 1996; Hill and Deeds 1996). Furthermore, literature on market orientation emphasizes the need for market knowledge to stimulate creativity and achieve superior financial performance (e.g., Han et al. 1998; Im and Workman 2004), and research on organizational memory promotes the importance of knowledge in generating novel outcomes in changing environments (e.g., Moorman and Miner 1997).

Most marketing studies that focused on knowledge development are conducted in new product development contexts. This is particularly relevant because new product development requires firms to proceed through all stages of organizational learning: information acquisition, dissemination, and utilization (Day 1994; Moorman and Miner 1997; Nonaka and Takeuchi 1995). The outcome of this learning process - the new product- physically represents the successful integration and application of (new) knowledge acquired by the firm (Kessler et al. 2000; Nonaka 1994).

The complexities, expenses, and risks involved in integrating information (i.e., learning) through new product development (NPD) have led to discussions about the potential risks and benefits of intra- versus interfirm NPD. Firms (e.g., competitors or channel members) may combine their competencies and resources (e.g., for reasons of risk-sharing and knowledge acquisition) to deliver superior customer value and gain competitive advantages. Moreover, interfirm interactions add to the richness of the knowledge base and decrease the observability of causeand-effect relationships (Mowery et al. 1996); in turn, the associated processes and routines become less imitable for competitors, and switching costs for the partner increase (Perks 2004). Hence, the knowledge resulting from these partner interactions must be, at least in part, unique to the relationship (Jap 2001). However, a number of risks have been identified also. Amongst these are the dangers of opportunistic behavior, (tacit) knowledge leakage, and imitation of 
firm-specific capabilities (Anderson and Jap 2005; Dutta and Weiss 1997; Lorenzoni and Lipparini 1999).

We study the benefits and risks of one particular form of interfirm relations: vertical co-creation relations. In a vertical co-creation relation, a supplier and its business customer join forces to develop a new product. In these relationships, the supplier and its business customer (hereafter customer) may bundle unique resources and competencies from their differing functional areas and use them to "create access to critical resources that enable superior value in the marketplace" (Jap 2001, p. 21). In contrast with other forms of interfirm interactions, co-creation relations are not only driven by a need for resources that are unavailable within the firm but also by a shift in the view of a market (Prahalad and Ramaswamy 2004). Increasingly, the market represents a locus of value creation and extraction, instead of the firm itself (Lusch and Vargo 2006). This shift results in increasing degrees of interactions between firms and their customers (Lilien et al. 2002; Prahalad and Ramaswamy 2004).

Considering the growing importance of connecting customers and suppliers (Marketing Science Institute 2006), social relations should play an important role in marketing decision making in general and knowledge management in co-creation relations more in particular. This dissertation therefore expands on the emerging understanding that "learning is a social process, with new benefits and liabilities that are underappreciated in a framework that views learning solely from the perspective of cognition or past organizational experiences" (Uzzi and Lancaster 2003, p. 397, italics added). Therefore, a focus on the interplay of knowledge and relationship factors ${ }^{1}$ contributes to a richer portrait compared to previous literature focusing on only one of these aspects. The overall aim of this dissertation thus is to examine the (firm and relationship) determinants and (firmlevel) consequences of knowledge development and competencies in co-creation relations.

The next chapter, Chapter 2, examines the moderating role of relational embeddedness on the effective deployment of partners' learning abilities (supplier proactive market orientation and customer lead-user status) to generate marketing innovations, which consist of knowledge developed during co-creation efforts that challenges existing mental market models. Therefore, this chapter answers the following research questions: (1) What are the effects of customer and supplier

\footnotetext{
${ }^{1}$ In our context of co-creation relationships, relationship factors are by definition measured at the interfirm level.
} 
learning abilities on supplier marketing innovation? (2) How does relational embeddedness affect the relationship between partner learning abilities and supplier marketing innovation?

In Chapter 3, we focus on the effect of firm memory on new competence development. We specifically examine the moderating role of the knowledge redundancy of co-creation partners in unlocking firm memory for developing new competencies. In turn, this chapter answers the following research questions: (1) Does firm memory help or hinder new competence development? (2) Does knowledge redundancy affect the potential of firm memory for developing new competencies?

In Chapter 4, we address the value of co-creation knowledge in situations beyond the co-creation relation itself. More specifically, Chapter 4 examines the following questions: (1) Does co-creation knowledge have the potential to be transferred to situations outside the co-creation relation? (2) Does relational embeddedness affect co-creation knowledge transferability? (3) Does environmental turbulence affect co-creation knowledge transferability?

The three empirical chapters contribute to existing research in several important ways. First, they respond to calls for insights into the advantages and liabilities involved in interactive forms of value creation (Marketing Science Institute 2006; Lusch and Vargo 2006; Prahalad and Ramaswamy 2004). By studying knowledge development and competencies with partners in co-creation relations, they extend current interfirm literature that centers on knowledge acquisition from partners. Thus, we generate insights in those factors critical in emergent forms of collaboration and recent views of the locus of value creation. Second, these studies advance existing research by integrating both intra- and interfirm literature rather than treating them separately. Incorporating both firm and relationship factors in the empirical studies untangles the mixed findings in existing literature and provides a richer view of the benefits and costs of learning in different relational conditions. Third, this dissertation complements existing literature that thus far merely assumes future rents derived from interfirm collaborations by empirically examining the transferability of new knowledge from collaborative relations to individual firms' products, projects, processes, and relations (for an exception, see Mowery et al. 1996). 


\subsection{Co-Creation Relations}

Interfirm relations embrace a variety of collaborative forms (Grant and BadenFuller 2004), including (equity) joint ventures, joint development agreements, licensing agreements, and supplier-buyer partnerships (Mowery et al. 1996). The collaborative form studied herein is the co-creation relation, defined as a vertical NPD project that involves two financially independent firms - a business customer and a supplier- which both actively and directly cooperate from at least the development stage of the NPD process onward (regardless of the degree of the formality of this cooperation). The role of the two participating companies depends on their relative positions in the dyadic relationship. Thus, though a company could function as both a customer and a supplier in the value chain, it only fulfills one of these roles in the dyadic relations under study. Horizontal collaborations and vertically integrated supply chain collaborations are not included in this study.

Results from the community innovation survey (CIS) show that vertical co-creation relations are prevalent (Eurostat 2002). No less than $34 \%$ of all Dutch innovations come from collaborations between suppliers and business customers. In addition, Knudsen (2007) uses the CIS to investigate the importance of interfirm relations for explaining NPD success. According to her sample of seven European countries (including the Netherlands), between $47 \%$ and $63 \%$ of collaborations occur with customers (in different industries), and collaboration with suppliers ranges between $42 \%$ and $52 \%$.

Co-creation relations are characterized by early customer involvement. Joint value creation thus is central to such relationships (Prahalad and Ramaswamy 2004). Other forms of interfirm relations typically do not impose requirements on the scope and intensity of interaction between partners. Similar to von Hippel (1986; 1988; 1998; 2002), who examines the effect of interactions with sophisticated customers on radical new product innovations, this dissertation acknowledges that such cooperation can serve as a need-forecasting laboratory, a source of valuable and creative new ideas, and a platform for radical NPD. Unlike von Hippel, however, the focus here is not exclusively on business customers that represent the leading edge of the market; instead, we focus on a broad range of customers with varying degrees of lead-user characteristics.

Moreover, co-creation relations are unique in terms of purpose, in that they form to create knowledge with the partner (Prahalad and Ramaswamy 2004; von Hippel 1988), whereas typical interfirm relations form to acquire knowledge 
from the partner (Grant and Baden-Fuller 2004; Mowery et al. 1996). Capitalizing on the knowledge of a parent firm or partner serves as the typical driver of interfirm collaborations, which generally results in competitive learning races between (alliance) partners (Khanna et al. 1998). Therefore, such alliances normally involve contractual agreements (e.g., licensing agreements, R\&D contracts) and ownership links (e.g., joint ventures) (Grant and Baden-Fuller 2004; Rindfleisch and Heide 1997). In contrast, co-creation relations consist of financially independent entities and no requirements are imposed on the degree of formalization.

\subsection{Theoretical Foundation}

One of the major objectives of this dissertation is to show that marketing knowledge and competencies can be explained by (the interaction of) firm knowledge characteristics and (social) relationship characteristics. Consideration of both these characteristics portrays a more complete and potentially more accurate picture of knowledge development. Hence, we assert that firms engaged in interfirm collaborations and interactive value creation (e.g., during joint new product development projects) can benefit from insights derived from empirical work considering these two aspects. A number of theories have served a dominant role in the development of the research models in this dissertation. We briefly describe these theories and their interconnections hereafter.

In outlining firms' potential for developing and transferring marketing knowledge, we draw on organizational learning theory. Though the idea of organizational learning has been present in the literature for decades, it has gained increased attention only in the 1990s as a consequence of its (commercial) value witnessed by scholars and companies (Easterby-Smith and Araujo 1999). Because theories on organizational learning have received interest from scholars from a number of disciplines, the field has become conceptually fragmented (Parkhe 1991; Huber 1991). Therefore, we explicitly emphasize that organizational learning is studied in this dissertation from an output perspective rather than a process perspective. This implies that knowledge development (i.e., learning) is measured by the degree to which companies have learned to do things better or differently rather than by measuring the effectiveness of information acquisition, dissemination and interpretation.

Learning by organizations has previously been studied both at the intrafirm as well as the interfirm level (e.g., Lukas et al. 1996 and Selnes and Sallis 2003, respectively). We follow the stream of authors (including, for example, 
Lukas et al. 1996 and Kohli and Jaworski 1990) that measures knowledge development at the intrafirm level rather than the interfirm level.

To capture the effect of (social) relationships in this dissertation, we draw upon the social network theory with a focus on the strength-of-ties literature. Whereas traditional sociological studies focused on the effect of characteristics of the individual actor (e.g., firm), social network theory argues that relationships between social actors (e.g., interfirm linkages) are instrumental in explaining realworld phenomena (see, for example, Hansen 1999; McEvily and Zaheer 1999). Strength-of-ties studies typically focus on the impact of social actors' relational embeddedness and their degree of overlap in knowledge bases on information sharing activities (e.g., Granovetter 1973; Rindfleisch and Moorman 2001; Uzzi 1999). We use these two dimensions of embeddedness to illustrate the impact of relationships on firm knowledge and competence development

The social nature of interfirm relationships not only affects firm knowledge and competence development, but also the degree to which collaborative partners can deploy their assets to extract strategic value from it. Hence, and in addition to organizational learning theory, we draw on the resource based view of the firm (RBV) as a tool to evaluate firm resources for their potential to generate sustained competitive advantages. The RBV claims that resources have strategic potential when they are 1) valuable, 2) rare, 3) imperfectly imitable, and 4) imperfectly substitutable (Barney 1991). The knowledge based view of the firm an extension of the RBV-argues that firm knowledge is the most strategically significant firm resource because it is tacit and socially complex in nature (e.g., Grant 1996).

In sum, we mainly deploy organizational learning theory, social network theory and the resource based view of the firm in developing the conceptual frameworks in each of the chapters. Combining these theories allows us to make predictions for the (joint) impact of both (firm) knowledge characteristics and (social) relationship characteristics. This, in turn, generates a more comprehensive overview of the consequences of these characteristics in terms of knowledge creation and transferability. 


\subsection{Objectives}

This dissertation revolves around knowledge creation and transferability, as well as competence development, in vertical co-creation relations. To provide comprehensive insights into several issues that enable firms to achieve returns on their co-creation efforts, we conduct three empirical studies. The glue that holds these studies together relates to the overall focus on the impact of both knowledge-related aspects of the firm and aspects associated with social relationships between supply chain partners. Figure 1.1 provides an overview of the integrative framework of the empirical chapters in this dissertation. Chapter 1 analyzes the multifaceted role of relational embeddedness when suppliers and customers deploy their learning abilities to generate marketing innovations, whereas Chapter 2 focuses on the effect of firm memory and knowledge redundancy between partners on new competence development. Finally, Chapter 3 examines the usefulness of co-creation knowledge outside the co-creation context. The next section briefly introduces the three studies and their objectives.

\section{Figure 1.1 INTEgRative Framework}

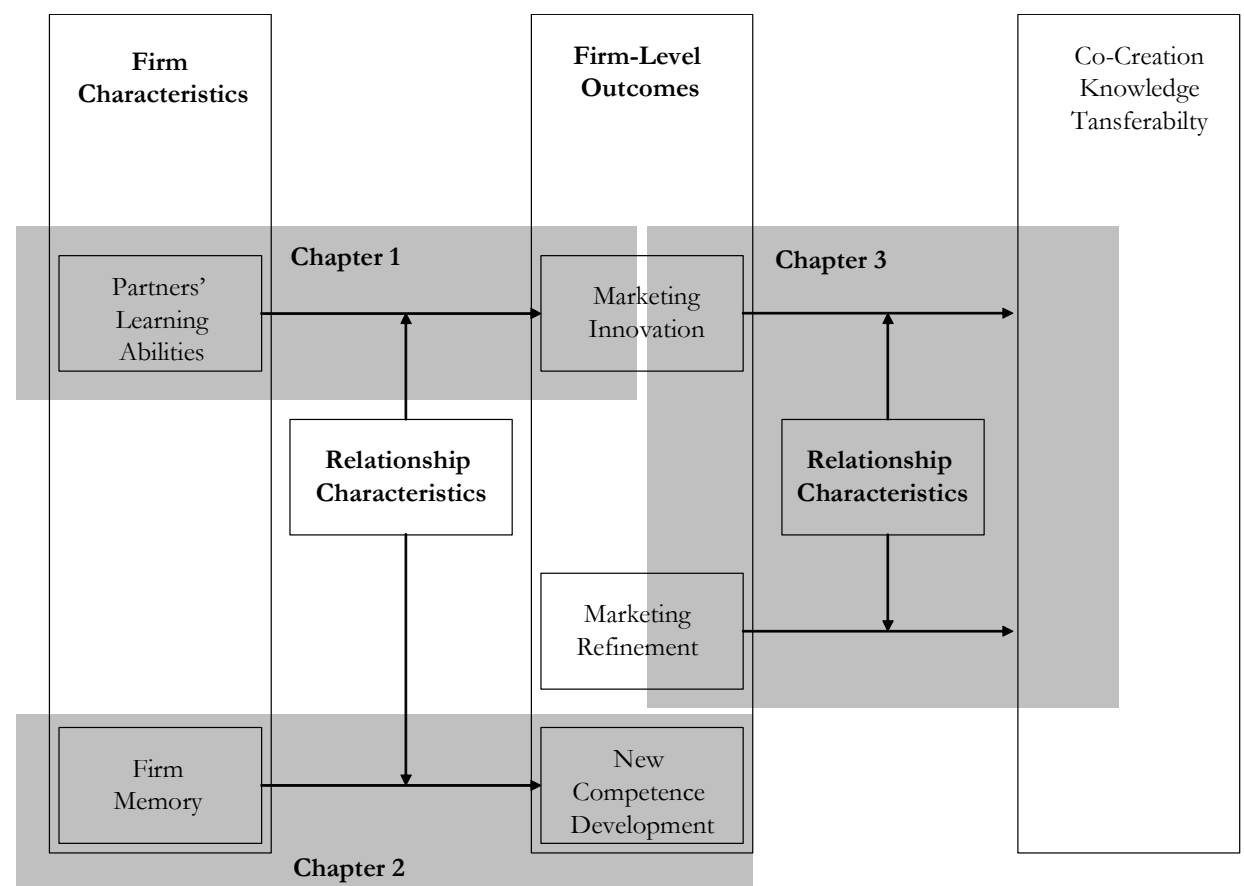




\subsubsection{Chapter 2 Objectives}

Chapter 2 addresses firms' need to understand the drivers of successful cocreation efforts. Although co-creation represents an increasingly common innovation strategy, many partnerships tend to fail (Sivadas and Dwyer 2000), because the strategy requires firms to build their own learning skills and also seek partnerships with customers that possess valuable knowledge. Deep relational ties can help the firm by increasing the likelihood of effective knowledge transfer between parties, but these same ties can lay the foundation for opportunistic behavior by the customer or the loss of diversity vital to learning.

Therefore, this chapter examines how a firm should manage various firm, partner, and relational learning strategies to maximize the returns on its cocreation efforts. Specifically, we aim to assess how the supplier's learning ability, in the form of a proactive market orientation, and the customer's learning ability, in the form of lead-user status, affect the supplier's level of marketing innovation. Although the learning abilities of the co-creators are important, we pay particular attention to the potentially multifaceted role of relational ties in marketing innovation. To address these objectives, we use a quantitative, cross-sectional design that surveys 157 Dutch manufacturing firms that recently participated in co-creation activities.

\subsubsection{Chapter 3 Objectives}

Chapter 3 examines the role of firm memory on new competence development in co-creation relations. This research idea stems from the debate about whether memory helps or hinders firm renewal (Denrell and March 2001; Kogut and Zander 1992). Although firm memory constitutes a necessary ingredient, its associated filters and routines can reduce the generation of novel ideas and hurt new competence development. To overcome this problem, firms frequently enter into relationships with supply chain partners, because the vertical partner operates in different knowledge domains and thus offers new perspectives. Next to the access to different knowledge, however, the focal firm may need knowledge that is similar to that of its supply chain partner in order to be able to integrate the novel perspectives effectively with its existing internal knowledge. Therefore, the objective of this chapter is twofold: To examine the effect of firm memory on new competence development and to study the moderating role of the knowledge redundancy of co-creators. We attempt to achieve these objectives by analyzing cross-sectional survey data from 246 firms in the Dutch manufacturing industry that recently participated in co-creation activities with their supply chain partners. 


\subsubsection{Chapter 4 Objectives}

According to existing arguments, knowledge from collaborative relationships is valuable for the partners involved because of its reapplication potential after the relationship ends (Argote and Ingram 2000; Hamel 1991). Thus, it follows that the knowledge a firm develops during the course of a co-creation relation (i.e., cocreation knowledge) should have intrafirm value beyond the specific outcome of the relationship (i.e., the new product). The extent to which firms benefit from such transfer processes does not appear in existing empirical research. Therefore, this chapter concentrates on the transferability of knowledge from co-creation relations to the individual partners' products, projects, processes, and relations, rather than just knowledge transfer within the partnership. We build on the premise that knowledge generated by interfirm interactions is not automatically qualified for transfer outside the relationship, let alone sustained success (Grant and Baden-Fuller 2004). Chapter 4, then, examines whether the transfer potential of co-creation knowledge plays out differently in conditions of strong versus weak ties and varying levels of turbulence. We obtain data from a cross-sectional survey of 246 Dutch manufacturing firms that recently participated in a co-creation relation. With these data, we address the potential to transfer co-creation knowledge beyond the relationship, as well as the moderating impact of relational embeddedness and environmental turbulence.

\subsection{Dissertation Outline}

This dissertation contains three empirical studies on the (intra- and interfirm) determinants and (intrafirm) consequences of knowledge development and competencies in co-creation relations. The data for these studies are collected in the Dutch manufacturing industry. Table 1.1 offers a summary of the outline of the chapters. 
Table 1.1 Overview of Chapters

\begin{tabular}{|c|c|c|c|c|}
\hline Chapter & Study & Objective & $\begin{array}{l}\text { Estimation } \\
\text { Method }\end{array}$ & $\begin{array}{l}\text { Research } \\
\text { Context }\end{array}$ \\
\hline 1 & Introduction & & & \\
\hline 2 & $\begin{array}{l}\text { Study 1: Marketing } \\
\text { innovation in } \\
\text { vertical co-creation: } \\
\text { The multifaceted } \\
\text { role of relational ties }\end{array}$ & $\begin{array}{l}\text { Explore the } \\
\text { moderating role of } \\
\text { relational ties on the } \\
\text { effect of partner } \\
\text { learning abilities on } \\
\text { marketing } \\
\text { innovation. }\end{array}$ & 3SLS & $\begin{array}{l}157 \text { participants } \\
\text { in a co-creation } \\
\text { relationship in } \\
\text { the } \\
\text { manufacturing } \\
\text { industry }\end{array}$ \\
\hline 3 & $\begin{array}{l}\text { Study 2: Building } \\
\text { new competencies } \\
\text { through co-creation } \\
\text { relations: The role of } \\
\text { knowledge } \\
\text { redundancy and } \\
\text { memory }\end{array}$ & $\begin{array}{l}\text { Examine whether } \\
\text { knowledge } \\
\text { redundancy } \\
\text { unleashes the } \\
\text { potential of firm } \\
\text { memory in } \\
\text { developing new } \\
\text { competencies. }\end{array}$ & 3SLS & $\begin{array}{l}246 \text { participants } \\
\text { in a co-creation } \\
\text { relationship in } \\
\text { the } \\
\text { manufacturing } \\
\text { industry }\end{array}$ \\
\hline 4 & $\begin{array}{l}\text { Study 3: Co-creation } \\
\text { knowledge } \\
\text { transferability: The } \\
\text { role of knowledge } \\
\text { type, tie strength, } \\
\text { and turbulence }\end{array}$ & $\begin{array}{l}\text { Explore the future } \\
\text { value of co-creation } \\
\text { knowledge for } \\
\text { individual firms in } \\
\text { situations outside } \\
\text { the relationship. }\end{array}$ & OLS & $\begin{array}{l}246 \text { participants } \\
\text { in a co-creation } \\
\text { relationship in } \\
\text { the } \\
\text { manufacturing } \\
\text { industry }\end{array}$ \\
\hline 5 & Conclusion & & & \\
\hline
\end{tabular}




\title{
Chapter 2: MARKeTING INNOVATION IN VERTICAL Co-CrEATION:
}

\author{
The Multifaceted Role of Relational Ties
}

Co-creation is an increasingly common innovation strategy for business-to-business firms that requires the firms to build their own learning skills and seek partnerships with lead users. Deep relational ties can help the firm by increasing the likelihood of effective knowledge transfer between parties. However, these same ties may lay the foundation for opportunistic behavior by the customer or the loss of diversity vital to learning. How should a firm manage these various firm, partner, and relational learning strategies to maximize the returns on its co-creation efforts? We examine 157 co-creation business-to-business relationships between Dutch manufacturing firms and their customers to answer this question. Specifically, we assess how the supplier's own learning ability, in the form of proactive market orientation, and the customer's learning ability, in the form of lead-user status, affect the supplier's level of marketing innovation. To this discussion, we add the moderating and potentially multifaceted role of relational ties between co-creators. The results indicate that both supplier and customer learning abilities increase the likelihood of marketing innovation. Although strong relational ties reduce the effectiveness of a customer's leaduser status on marketing innovation, they increase the positive impact of the supplier's own proactive market orientation. These results paint a more complex portrait of the value of relational ties in the context of interfirm learning and point to several relevant managerial and theoretical implications.

This chapter is based on joint work with Christine Moorman. 


\subsection{Introduction}

Co-creation relations with customers mark a shift in marketing from learning from to learning with customers to innovate (Day 1999; Lane and Lubatkin 1998; Vargo and Lusch 2004; von Hippel and Katz 2002). Such relations have become increasingly common as firms attempt to reduce costs and increase the effectiveness of their innovation efforts. In business-to-business (B2B) marketing, co-creation relations consist of vertical relationships that involve two financially independent firms - a business customer and a supplier- that cooperate from the early stages of and throughout the development process (Vargo and Lusch 2004; von Hippel 1986). A survey of the European Community reveals that $34 \%$ of all Dutch product and process innovations result from co-creation relations (Eurostat 2002), but only $30 \%$ of these relations are successful in terms of helping firms innovate (Sivadas and Dwyer 2000).

Why do so many efforts fail? Co-creation fundamentally involves managing relationships to innovate, and we therefore argue that failures typically are rooted in a lack of attention to managing both the learning and the relational aspects of these partnerships (Uzzi 1999; Uzzi 1997). In turn, we seek to integrate literature on learning and relational ties to gain insights into the success of cocreation efforts.

Beginning with learning, we examine two research streams: literature on lead users and that on market orientation. Foundational research by von Hippel $(1986$; 1988) indicates that the lead-user status of a firm's customers is critical for helping the firm generate new insights about its markets. Equally critical is the firm's own learning ability in searching for and absorbing novel insights about the market (Day 1994; Jaworski and Kohli 1993; Narver et al. 2004).

Although the learning abilities of these partners are important, we also argue that the closeness of their relationship catalyzes innovation. In advancing this thesis, we build on two divergent views of relational ties. Traditionally, relational theorists have argued that embedded interfirm relationships build on commitment and reciprocity to facilitate the exchange of tacit knowledge about customer needs. Accordingly, prior work establishes the beneficial effects of relational ties on the ease of knowledge transfer (Hansen 1999; Reagans and McEvily 2003). In contrast, other research observes a dark side of close relations and argues specifically that opportunism and cognitive convergence tend to result from close relations, which then hampers information exchange (Anderson and Jap 2005; Christensen and Bower 1996; Grayson and Ambler 1999). 
Recent work thus suggests a complex and even contingent role for the strength of ties in interfirm relations. Although we build on them, we depart from these perspectives in two ways. First, we focus on the effect of tie strength on innovation, not information diffusion. Second, though we acknowledge the direct effect of relational ties, we consider how such ties influence the effectiveness of the partners' aforementioned learning abilities on innovation. That is, our approach unites two distinct literature streams -tie strength and organizational learning- and expands on an emerging understanding that "learning is a social process, with new benefits and liabilities that are underappreciated in a framework that views learning solely from the perspective of cognition or past organizational experiences" (Uzzi and Lancaster 2003, p. 397, italics added).

The next section begins with an overview of literature on marketing innovation and the effect of the learning abilities of partners in B2B relationships. Then, we discuss how relational ties between partners influence the impact of supplier and customer learning abilities on innovation. We continue with an empirical test of our ideas in a sample of customer-supplier co-creation relations in the Dutch manufacturing industry. Finally, we conclude with a discussion of the implications of our findings for pertinent literature and further research.

\subsection{Conceptual Framework and Hypotheses}

This section examines the relationship among marketing innovation, partners' learning abilities, and partners' relational embeddedness. Figure 2.1 summarizes our predictions. We begin by defining marketing innovation, then describe the main effect relationships between the partners' learning abilities and marketing innovation. We finish by examining the moderating role of relational embeddedness on these main effect relationships.

\subsubsection{The Nature of Marketing Innovation}

Our focus centers on marketing innovation, which includes product-market decisions such as targeting, segmentation, and positioning, as well as decisions related to the marketing mix. Marketing innovation differs from the related concept of product innovation (O'Connor 1998), in that whereas the latter pertains to the degree of departure from prior technologies, marketing innovation focuses on the degree of departure from a dominant market model (Slater and Narver 1995), or what others call strategic innovation (Markides 1999) or value innovation (Kim and Mauborgne 1999). For example, Canon's market leadership in the photo copier industry was driven not by any substantial technological 
Figure 2.1 ConCEPTUAL Framework

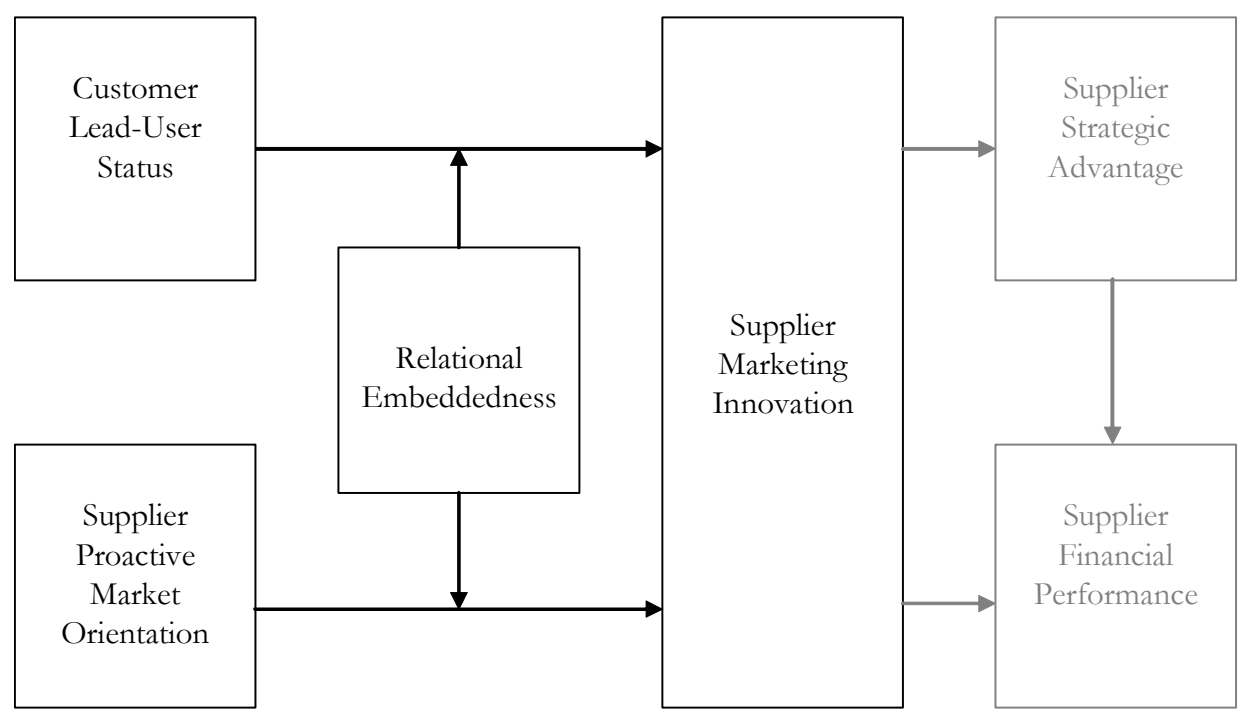

breakthrough but rather by its segmentation of end users according to dealer networks instead of volume (Markides 1999). This method enabled Canon to create new market spaces by challenging the established quality-price trade-off that other incumbents (e.g., Xerox, IBM, Kodak) had taken for granted. Similar to product innovations, marketing innovations can result in financial success when the firm achieves a novel position (Cirque de Soleil positioned at the intersection of theatre and the circus) or targets a market that historically has not been associated with its product or service (e.g., blue jeans for youth, not just blue-collar workers).

\subsubsection{The Effects of Customer and Supplier Learning Abilities on Supplier Marketing} Innovation

We follow the literature by suggesting that partner learning abilities should increase the incidence of marketing innovations. In this section, we explain why customer lead-user status and a supplier's proactive market orientation represent crucial learning abilities for marketing innovation.

Customer lead-user status. Building on research by von Hippel and associates (Morrison et al. 2000; Thomke and von Hippel 2002; von Hippel and Katz 2002), we define lead-user status as the extent to which a customer is on the 
leading edge of marketing trends and adopts new inputs and ideas offered by the supplier in novel ways to satisfy the latent needs of its own market. The motivation of lead users to participate in the innovation efforts of the supplier depends on the expected benefit of an early solution to their latent needs, which may give customers an important advantage in their own markets (Urban and von Hippel 1988).

Lead-user status tends to increase marketing innovation for three important reasons. First, as experts on leading-edge marketing trends, lead users can focus the supplier's search process by providing the most detailed and timely information on customer needs and solutions (von Hippel 1988). Specifically, lead users are familiar with future conditions (Urban and von Hippel 1988; von Hippel 1986) and therefore serve the role of a "need-forecasting laboratory for marketing research" (von Hippel 1986, p. 791).

Second, working with lead users early in the development process gives suppliers the opportunity to develop, test, and improve their concepts and strategies prior to going to market (von Hippel and Katz 2002). A key benefit of this early involvement is the opportunity for the customer and supplier to exchange tacit knowledge. Need-related information often is difficult for typical customers to articulate, so typical types of passive (acquire knowledge through seminars, consultants, market studies) and active (benchmarking, competitor intelligence) learning may not be the real keys to innovation. Rather, working closely with lead users, particularly through actual interfaces with strategies, should offer suppliers greater access to the types of tacit knowledge that may spark innovations.

Third, lead users can reduce emotional barriers associated with the inherently risky nature of innovation. Specifically, innovation efforts can stumble as anxiety gathers about experimenting with new marketing strategies that prompt uncertain results (Eisenhardt and Tabrizi 1995). Co-creation relations with lead users can, in part, mitigate this risk by increasing the supplier's confidence that its innovative activities are in sync with customer needs that will spread throughout the market later. For all three reasons, we propose:

$\mathrm{H}_{1 \mathrm{a}}$ : Customer lead-user status has a positive effect on supplier marketing innovation.

Supplier proactive market orientation. Although lead users are important for early, tacit knowledge about latent needs, it is equally important that the partner (here, the supplier) firm has the ability to understand and assimilate 
this knowledge (Cohen and Levinthal 1990). One way to conceive of this ability is to determine whether the supplier firm has a proactive market orientation.

Market orientation is a firm-level belief that emphasizes serving the customer; a specific set of organization-wide processes (generation of, dissemination of, and responsiveness to market intelligence) are instrumental for learning about and meeting customer needs (Day 1994; Jaworski and Kohli 1993). Within this broad framework, literature distinguishes between proactive (i.e., focus on customers' latent needs, future customers) and responsive (i.e., focus on expressed needs, current customers) market orientations or market-driving versus market-driven firms (Day 1998; Jaworski et al. 2000). We build on the recent work of Narver et al. (2004) to focus on proactive market orientation, which exhibits two features: a set of values associated with risk tolerance and entrepreneurship (Hamel 1991; Slater and Narver 1995) and market information processes that uncover and meet latent, not articulated, market needs. These features constitute two key abilities that foster marketing innovation. We discuss each in greater detail.

First, because a proactive market orientation is associated with risk tolerance and entrepreneurship, it likely increases employees' motivation to deviate from existing marketing knowledge to generate new ideas (Im and Workman 2004; von Hippel 1986). A fundamental entrepreneurial activity involves detecting opportunities to satisfy unarticulated customer needs. Despite the high-risk undertaking, proactive firms tend to reward employees for the opportunities it creates (not for mistakes avoided), which also removes barriers to creativity (Hamel 1991).

Second, because proactive firms are good at engaging in experiments and creative problem solving with customers (Slater and Narver 1995; Thomke et al. 1998; von Hippel 1994), these firms are more likely to tap the unarticulated needs of lead users for marketing innovations. As opposed to expressed needs, which frequently are aligned to what the customer has experienced in the past, latent needs require firms to think outside the box and innovate (Narver et al. 2004). We therefore propose:

$\mathrm{H}_{1 \mathrm{~b}}$ : Supplier proactive market orientation has a positive effect on supplier marketing innovation. 


\subsubsection{The Moderating Effect of Relational Embeddedness}

In addition to these direct effects of partners' learning abilities, we suggest that the effects are influenced by the nature of the partners' relationship. Specifically, building on tie strength literature, we argue that relational embeddedness moderates the aforementioned hypotheses. Tie strength literature offers a fundamental foundation for explaining how embedded relations may affect information exchanges among individuals and organizations (Granovetter 1973). In this chapter, we focus on an important dimension of strength of ties, namely, the role of relational embeddedness, which we define as the degree of reciprocity and closeness between a customer and a supplier in a co-creation relationship (Rindfleisch and Moorman 2001). As such, the degree of relational embeddedness is indicative of the motivation of the partners to engage in information sharing activities (Rindfleisch and Moorman 2001).

A central thesis in tie strength literature posits that strong ties advance the sharing of complex, sensitive, and tacit information, whereas weak ties promote the exchange of codified and diverse information (Granovetter 1973; Hansen 1999; Uzzi and Lancaster 2003). Understanding of the deleterious effects of embedded relations, referred to as "dark side behaviors," also is emergent (Anderson and Jap 2005; Grayson and Ambler 1999). We explore these conflicting views by delineating two different effects of embeddedness on the relationship between partner learning abilities and marketing innovation.

Perspective 1: Close relationships and information exchange effects. Close relationships facilitate the exchange of two types of information. First, close partners are less concerned about the loss of proprietary information (Rindfleisch and Moorman 2001; Uzzi 1999), which decreases coordination costs because no contracting is necessary (Nielsen 2005), facilitates the exchange of sensitive information such as customer data, and increases learning potential (Smith et al. 1995). Second, embedded relationships allegedly facilitate the exchange of complex, tacit information as a result of the closeness between the customer and the supplier (Moorman et al. 1992). According to Nielsen (2005), close partners develop relationship-specific heuristics, so they can transfer "sticky" knowledge more effectively and efficiently.

Why does the exchange of sensitive, complex, and tacit knowledge increase the likelihood that supplier and customer learning abilities result in marketing innovations? Each party provides knowledge that should, according to $\mathrm{H}_{1 \mathrm{a}}$ and $\mathrm{H}_{1 \mathrm{~b}}$, facilitate innovation. However, suppliers and customers form relationships because they expect that the exchange of information will promote 
an even more effective understanding of market opportunities and, hence, an increased likelihood of innovation. In turn, relational embeddedness and its associated information exchange should fuel the conversion of partners' learning abilities into innovative approaches to managing the relevant market. In the absence of such an exchange, learning abilities should have a weaker effect on innovation. Thus:

$\mathrm{H}_{2 \mathrm{a}}$ : Relational embeddedness strengthens the effect of customer lead-user status on supplier marketing innovation $\left(\mathrm{H}_{1 \mathrm{a}}\right)$.

$\mathrm{H}_{2 \mathrm{~b}}$ : Relational embeddedness strengthens the effect of supplier proactive market orientation on supplier marketing innovation $\left(\mathrm{H}_{1 \mathrm{~b}}\right)$.

Perspective 2: The dark side of close relationships. Although highly embedded relationships may create mutual benefits for the parties involved, evidence also suggests these relationships do not always generate the expected payoffs. The general thrust behind these arguments states that embedded relations may dampen the beneficial effects of information exchange.

First, in close relationships, firms may come to believe their partners "have become stale or too similar to them in their thinking and therefore have less value to add" (Moorman et al. 1992, p. 323). Because close partners develop relationship-specific heuristics (Uzzi 1997) and specialized language (Argote et al. 2003) to facilitate common understanding, partners naturally converge in their thinking. This convergence reduces the likelihood that partners expose each other to novel information (Grayson and Ambler 1999). Wary of these dangers, firms often break away from long relationships with service providers (Dowling et al. 1994) to combat "institutionalized creativity" (Halinen 1997, p. 280) and access new pools of knowledge and skills.

Second, close partnerships tend to open the door for opportunistic behavior (Anderson and Jap 2005). According to Zahra et al. (2006, p. 552), "strong social bonds often discourage network members from questioning each other's motives or from sounding the alarm even when ethical violations occur." Anderson and Jap (2005) extend these arguments by noting that closeness plants the seeds of vulnerability, because information sharing creates an opportunity for parties to use disclosed information for their own self-interests (see also Moorman et al. 1992). These concerns can lead firms to behave cautiously and refrain from sharing knowledge vital to the success of marketing innovation projects (Zahra et al. 2006). Therefore, according to the dark side view, close relationships reduce the likelihood that partners share novel or proprietary information with each other. 
These arguments imply lead users should have a weaker effect on supplier marketing innovation when the supplier and customer share a closely tied relationship, because the strong relationship reduces the likelihood that customers expose suppliers to new marketing knowledge and skills, which is vital to marketing innovation. Similarly, relational embeddedness dampens the effect of proactive market-oriented suppliers on marketing innovation, because the suppliers make weaker use of their own learning abilities in response to their concerns about opportunism and the lower likelihood they receive novel information. Therefore, proactive market-oriented firms that seek marketing innovations may have greater success in weakly tied relationships than in strongly tied relationships with customers. Thus:

$\mathrm{H}_{3 \mathrm{a}}$ : Relational embeddedness attenuates the effect of customer lead-user status on supplier marketing innovation $\left(\mathrm{H}_{1 \mathrm{a}}\right)$.

$\mathrm{H}_{3 \mathrm{~b}}$ : Relational embeddedness attenuates the effect of supplier proactive market orientation on supplier marketing innovation $\left(\mathrm{H}_{1 \mathrm{~b}}\right)$.

Although it is not central to our research question, Figure 2.1 and our model test include the effect of marketing innovation on various strategic and financial performance implications for the supplier, because prior research indicates the importance of innovation for firm performance (e.g., Auh and Menguc 2005; Chandy and Tellis 2000; Han et al. 1998; Sorescu et al. 2003). Moreover, a test of the strategic and financial consequences of marketing innovation validates the intrinsic quality of the effects captured by $\mathrm{H}_{1}-\mathrm{H}_{3}$. Finally, if marketing innovation influences firm performance, it increases the importance of examining how the various supplier and customer factors we consider in our hypotheses influence marketing innovation.

\subsection{Research Method}

The empirical context for this study is co-creation relations between suppliers and customers (i.e., business customers) in the manufacturing industry. We test the model using a cross-sectional survey methodology that involves key informants.

\subsubsection{Sample}

We used Dun \& Bradstreet's Market Direct database to obtain the telephone numbers of all Dutch manufacturing firms with more than 50 employees, which resulted in a list of 3,146 companies. We required participants to be engaged in 
joint product development with their customers from at least the development stage onward. Telephone interviews indicated whether the companies met the sample requirements, requested participation in the research, and verified respondents' mailing address. After excluding companies that did not fulfill the sample requirements $(n=1,376)$ or could not be contacted for other reasons (e.g., independent subdivisions of parent companies with central product development departments, bankruptcy, outdated telephone numbers) ( $\mathrm{n}=910$ ), we were left with a sampling frame for the final survey of 860 companies.

We mailed surveys to product development team leaders, to whom we promised a customized report that compared their scores with the sample average. In total, 246 firms responded, for a response rate of $28.6 \%$. Of the sample, 157 respondents (18.3\% of the sampling frame) were suppliers engaged in a new product development project with a customer and qualified for our study.

We examined nonresponse bias by comparing early respondents (ER) and late respondents (LR) (Armstrong and Overton 1977) and find no differences in terms of the variables in the model ${ }^{2}$. Using the same test on objective firm characteristics, we examined the number of employees in the respondent's business unit $\left(\mathrm{ER}=3.86, \mathrm{LR}=3.74, \mathrm{t}_{(131)}=.60\right.$, n.s.) and again find no differences. Finally, in terms of external validity, the percentage response per industry (i.e., two-digit standard industrial classification [SIC] code) is similar to the percentage of Dutch companies operating in the industries.

The targeted key informants were new product development team leaders in the supplier firms, whom early interviews indicated were in the best position to report on marketing innovations arising from co-creation relationships in $\mathrm{B} 2 \mathrm{~B}$ firms. We observed that B2B firms typically do not form separate relationships or groups to investigate marketing innovations but instead that such innovations typically arise from product development efforts. Our analysis of these informants indicates they have high levels of experience with the firm and partner relationship. Informants reported longstanding relationships with customers (mean $=12$ years, $\mathrm{SD}=12$ years) and high levels of experience in their position as product development team leaders (mean $=9$ years, $\mathrm{SD}=9$ years), which enhances our confidence in the data. Furthermore, informants' involvement in the

\footnotetext{
${ }^{2}$ Customer lead-user status ER $=5.00, \mathrm{LR}=4.85, \mathrm{t}_{(155)}=.82$, n.s.; supplier proactive market orientation $\mathrm{ER}=5.41, \mathrm{LR}=5.44, \mathrm{t}_{(155)}=-.20$, n.s.; relational embeddedness $\mathrm{ER}=5.58, \mathrm{LR}=5.57$, $\mathrm{t}_{(155)}=.11$, n.s.; supplier marketing innovation $\mathrm{ER}=4.76, \mathrm{LR}=4.84, \mathrm{t}_{(155)}=-.47$. n.s.; supplier strategic advantage $\mathrm{ER}=5.25, \mathrm{LR}=5.29, \mathrm{t}_{(155)}=-.23$, n.s.; supplier financial performance $\mathrm{ER}=$ 4.89, $\mathrm{LR}=4.65, \mathrm{t}_{(155)}=.70$. n.s.
} 
relationship was high, with an average score of $6.0(\mathrm{SD}=1.28)(1=$ no involvement, $7=$ high involvement). Finally, to reduce problems associated with memory decay, we asked the informants to report only on joint development efforts that had been launched not more than two years ago.

\subsubsection{Measure Development}

In addition to a thorough literature review, we performed a series of pretests, including five exploratory field interviews, six survey pretests, six follow-up interviews, and a panel with 10 researchers, to corroborate the measurement scales. We describe our measures in detail and provide full scales for all variables in Appendix A.

Supplier marketing innovation. To measure marketing innovation, we use an established scale that assesses the degree to which the project develops innovative marketing ideas (Kyriakopoulos and Moorman 2004). Our approach follows standard views of creativity and innovation, which insist on two key features, namely, novelty and usefulness (Amabile 1983; Lubart 1994). Usefulness often appears in conceptualizations of innovation and creativity, because it means the innovation can be utilized in the market and therefore has a pragmatic quality. This requirement is often considered functional in its orientation by critics, but in firms it can be useful for separating the bizarre from the truly innovative.

Given this requirement, suppliers indicated the extent to which their firm had learned to take different and more effective marketing actions as a result of working with their customers. The following marketing actions constitute the final scale: targeting and segmentation, product positioning and differentiation, customer service, distribution, and communication and promotion.

Customer lead-user status. We measure lead-user status with a scale developed to reflect von Hippel's views regarding lead users' key qualities, specifically, the degree to which the customer: (1) tends to conduct thorough research of the available options offered by suppliers to identify new marketing possibilities that could address their own and their customers' needs; (2) has, in the past three years, invested a substantial amount of time and money in identifying leading-edge marketing trends; (3) is positioned at the leading edge of marketing trends and related needs; and (4) has, in the past three years, applied existing solutions in ways not anticipated by suppliers.

Supplier proactive market orientation. Our measure of supplier proactive market orientation is adapted from Narver et al. (2004), who first introduced the concept. Building on their view -that a proactive market 
orientation exhibits risk tolerance values and a set of market information processes for uncovering and meeting latent needs- we retain five items, namely, the extent to which the supplier (1) helps customers anticipate developments in markets; (2) continuously tries to discover additional needs of customers, of which they are unaware; (3) incorporates solutions to unarticulated customer needs in its new products and services; (4) brainstorms about how customers (could) use its products and services; and (5) extrapolates key trends to gain insight into what users in a current market will need in the future.

Relational embeddedness. The moderator used in this study is relational embeddedness, the measure for which we adopt from Rindfleisch and Moorman (2001). Consistent with our conceptualization, the scale items reflect the degree to which partners in co-creation relations are motivated to share close social relationships, so informants rated the relationship using the following items: (1) We feel indebted to our customer for what it has done for us; (2) Our new product development team members share close social relations with our customer's new product development team members; (3) The relationship with our customer can be defined as "mutually gratifying"; and (4) We expect that we will be working with our customer in the future.

Supplier financial and strategic performance. In this study, we use two performance measures. First, the supplier financial performance measure uses four indicators (on a seven-point Likert scale) adapted from Moorman (1995) and pertains to the co-creation relation context. Therefore, the items survey the extent to which the product resulting from the co-creation relation has achieved its objectives, which relate to such issues as market share, sales, return on assets, and profit margin.

Second, supplier strategic advantage refers to the strategic benefits gained as a result of the co-creation relation, compared with competing firms, that enable the supplier to compete more effectively in the market place (Jap 1999). We adapt Jap's (1999) four-item measurement scale to tap how the relationship has benefited the supplier firm from a strategic point of view. An example item is "our firm has gained strategic advantages over our competitors" ( 1 = strongly disagree, $7=$ strongly agree).

Control variables. Our control variables consist of two categories. The first group accounts for relationship characteristics that fall outside our scope of investigation (i.e., effects of tie strength in co-creation relations) but may offer alternative or confounding explanations, according to previous studies in the field. The second group of variables controls for differences in the environmental forces 
that companies face and that affect marketing innovation, according to previous studies.

At the relationship level, we control for goal congruency, because a greater alignment of goals affects the degree to which a dyad forms close relationships and exchanges information (Eliashberg and Michie 1984; Jap 1999). We measure goal congruency with four items on a seven-point Likert scale. In addition, we rely on Sivadas and Dwyer's (2000) measure to control for the level of formalization, because explicit rules between partners affect relationship effectiveness (e.g., Bidault et al. 1998; Sivadas and Dwyer 2000).

We also control for differences in environmental turbulence across the cocreation relations in our sample, because it influences the extent to which firms can absorb new knowledge and expand their existing knowledge set (Cohen and Levinthal 1990; Cyert and March 1963). To operationalize these measures, we adapt Kohli and Jaworski's (1993) market turbulence and technological turbulence measurement scales.

\subsubsection{Construct Validation}

To assess measure validity, we ran two confirmatory factor models-one for the predictor variables (learning abilities, relational embeddedness, and control variables) and one for the dependent variables (marketing innovation, financial performance, and strategic advantage). Each of the observed indicators loads significantly on the intended latent constructs, thus indicating convergent validity among the items of the latent construct (Campbell and Fiske 1959). Several items were deleted based on their low factor loadings and/or high modification indices. The subsequent fit indices provide support for the predictor model $\left(\chi^{2}=354.54\right.$, nonnormed fit index $[\mathrm{NNFI}]=.94$, confirmatory fit index $[\mathrm{CFI}=.95$, square root mean residual $[\mathrm{SRMR}]=.07$, root mean square error of approximation [RMSEA] $=.04)$ and the outcome model $\left(\chi^{2}=58.08, \mathrm{NNFI}=.99, \mathrm{CFI}=.99, \mathrm{SRMR}=.05\right.$, RMSEA $=.03)$. According to Bagozzi and Yi (1988), composite reliability should at least be .60; each factor fulfills this requirement (see Table 2.1).

We evaluate discriminant validity using two different approaches. As a first test of discriminant validity, we compare the average variance extracted (AVE) of each construct with the squared correlation between constructs. Discriminant validity exists if the items of the latent variable share more common variance with their respective variable than any variance that this variable shares with other variables (Fornell and Larcker 1981). Therefore, the AVE for any variable should be higher than the squared correlation between that variable and 


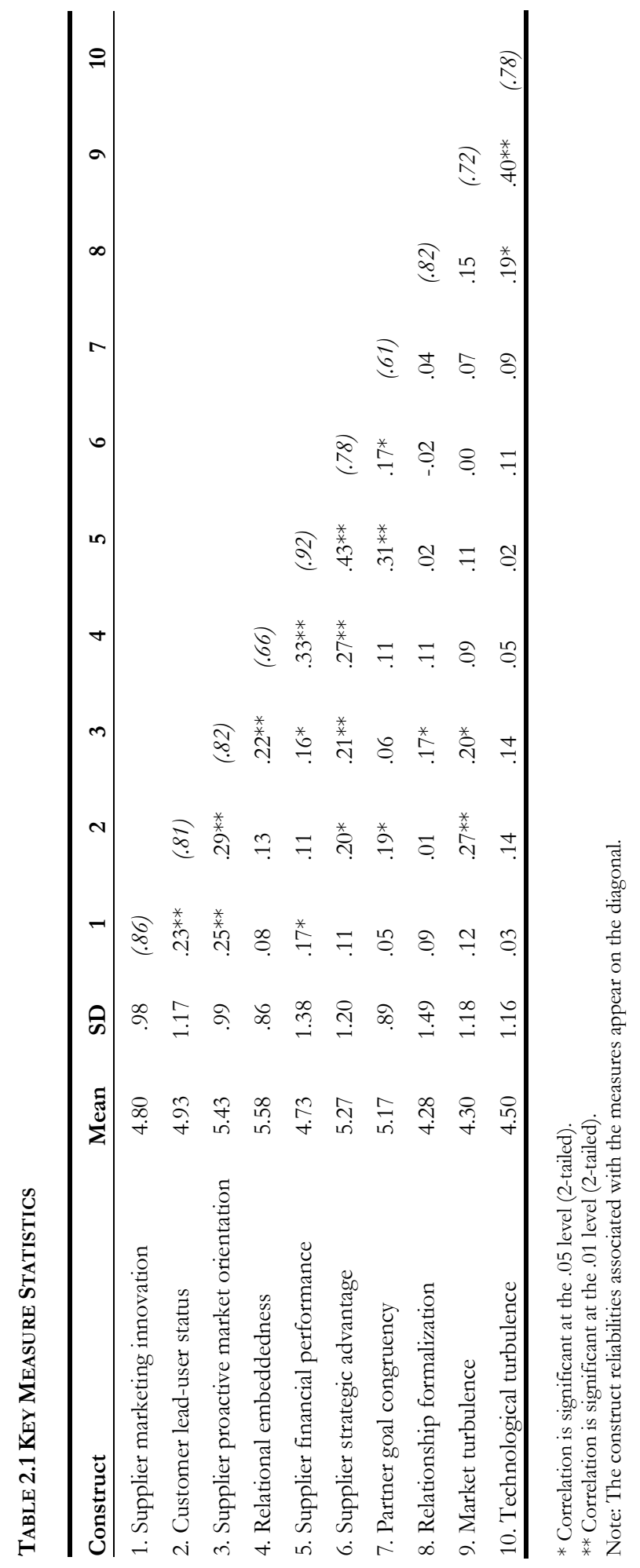


all other variables (Koufteros 1999). The data confirm that discriminant validity exists, with positive differences between AVE and the squared correlations ranging between .02 and .47 . To achieve further evidence of discriminant validity, we construct baseline measurement models and constrained models for all possible pairs of latent variables, then compare the models with a chi-square difference test for each pair. All chi-square differences are significant (i.e., minimum chi-square difference $=29.93, p<.001,1 \mathrm{df}$ ) and confirm discriminant validity between the constructs.

\subsubsection{Common Method Bias Test}

When the dependent and independent variables come from a single key informant, common method bias can be a problem. We therefore examine the extent of this bias using Harman's one-factor test. According to Podsakoff and Organ (1986), common method variance is not a problem when the first factor does not account for the majority of the variance, there is no general factor in the unrotated factor structure, and several factors can be identified. Consistent with our measurement model, the results of the principal components factor analysis reveal 10 factors with eigenvalues greater than 1.0 that explain $68 \%$ of total variance. Furthermore, the first factor accounts for less than the majority of the variance explained, and we do not find a general factor in the unrotated factor score. Consequently, common method variance does not appear to be a concern.

\subsection{Analysis and Results}

To examine the role of partner learning abilities and relational embeddedness on marketing innovation in co-creation relations, we model a system of three equations, outlined next, in 3SLS. We estimate the model with 3SLS for several reasons. First, it considers the endogeneity of marketing innovation in the model equations, whereas for such a system of equations, ordinary least square (OLS) estimates can be inconsistent, because they ignore the distinction between marketing innovation as a criterion and as a predictor variable (Greene 2002). Second, this estimation method yields efficient parameter estimates if the errors between the independent variables are correlated (Greene 2002).
(1) $\mathrm{MI}=$
$\mathrm{c}_{1}+\beta_{1}(\mathrm{CLU})+\beta_{2}(\mathrm{SPMO})+\beta_{3}$
$(\mathrm{RE})+\beta_{4}(\mathrm{RE} * \mathrm{CLU})+\beta_{5}$
$(\mathrm{RE} * \mathrm{SPMO})+$ control variables $+\varepsilon_{1}$,
(2) $\mathrm{FIN}=$
$\mathrm{c}_{2}+\beta_{6}(\mathrm{MI})+\beta_{7}(\mathrm{STRAT})+\mathrm{control}$ variables $+\varepsilon_{2}$, and 
(3) $\operatorname{STRAT}=\mathrm{c}_{3}+\beta_{8}(\mathrm{MI})+$ control variables $+\varepsilon_{3}$,

where

$\mathrm{c}=$ constant,

$\mathrm{MI}=$ supplier marketing innovation,

$\mathrm{CLU}=$ customer lead-user status,

SPMO = supplier proactive market orientation,

$\mathrm{RE}=$ relational embeddedness,

FIN = supplier financial performance,

STRAT $=$ supplier strategic advantage, and

$\varepsilon=$ disturbance terms.

As suggested by Aiken and West (1991), we mean-center the variables in the equations that comprise the interaction terms (relational embeddedness $\mathrm{x}$ customer lead-user status, relational embeddedness $\mathrm{x}$ supplier proactive market orientation) to facilitate the interpretation of our results. Variance inflation factors (VIFs) below 2 obtained from a set of three OLS estimations provide no indication of multicollinearity (Neter et al. 1985). We present a summary of the results in Table 2.2.

\subsubsection{Tests of Hypotheses}

Hypothesis 1 suggests that the higher the learning abilities of the co-creation partners, the higher the degree of marketing innovation will be. The results in Table 2.2 show that both customer lead-user status and supplier proactive market orientation relate positively to marketing innovation $(\beta=.13, p \leq .05 ; \beta=.21, p \leq$ .01 , respectively). Given that these variables are mean-centered and part of an interaction term, these are simple effects indicating that there is support for $\mathrm{H}_{1 \mathrm{a}}$ and $\mathrm{H}_{1 \mathrm{~b}}$ at the mean level of relational embeddedness (here zero). Therefore, we also tested the significance of these two effects at -1 SD and $+1 \mathrm{SD}$ around the mean level of the moderator (Preacher et al. 2006). The results of these tests show that lead-user orientation becomes less significant when the value of the moderator increases $(\beta=.22, \mathrm{p} \leq .01$ at $-1 \mathrm{SD}$ and $\beta=.04$, ns at $+1 \mathrm{SD})$. Thus, $\mathrm{H}_{1 a}$ is supported for relatively low values of relational embeddedness. For proactive market orientation, we find a positive but insignificant effect for low ($1 \mathrm{SD})$ relational embeddedness $(\beta=.10, p \geq .05)$ and a positive significant effect for high $+1 \mathrm{SD})$ relational embeddedness $(\beta=.33, p \leq .01)$. 
$\mathrm{H}_{1 \mathrm{~b}}$ is thus supported for relatively high values of relational embeddedness ${ }^{3}$.

We hypothesize that both these main effects are moderated by relational embeddedness. The hypothesized strengthening effect of relational embeddedness on customer lead-user status is not observed. Thus, there is no support for $\mathrm{H}_{2 \mathrm{a}}$. In contrast, and in support of the dark side perspective represented in $\mathrm{H}_{3 \mathrm{a}}$, relational embeddedness attenuates the effect of customer lead-user status $(\beta=-.10, p \leq .05)$ on supplier marketing innovation. We provide a graphical representation of the moderating effect, following procedures recommended by Aiken and West (1991), in Figure 2.2 which shows the effect of customer lead-user status on supplier marketing innovation at low and high levels of relational embeddedness (low $=1$ $\mathrm{SD}$ below the mean, high $=1 \mathrm{SD}$ above the mean). High relational embeddedness indeed has very little effect on the relationship between customer lead-user status and marketing innovation, but low levels of relational embeddedness produce the greatest supplier marketing innovation when customers are lead users.

In contrast, the hypothesized strengthening effect of relational embeddedness on supplier proactive market orientation is significant and positive $(\beta=.14, p \leq .05)$, which prompts us to accept $\mathrm{H}_{2 \mathrm{~b}}$ at the expense of $\mathrm{H}_{3 \mathrm{~b}}$. Figure 2.3 plots this moderating effect and reveals that high levels of close relationships produce the highest supplier innovation payoffs when supplier proactive market orientation is high. However, high levels of close relationships produce poor innovation payoffs in the absence of a supplier with a strong proactive orientation. This finding is consistent with the first perspective on relational embeddedness, which states that close relationships help the supplier innovate ${ }^{4}$.

\subsubsection{The Effect of Marketing Innovation on Firm Performance}

Although our focus is not on the impact of marketing innovation on firm performance, our model accounts for these important effects, so we provide an overview of the results. Using the 3SLS estimates reported in Table 2.2, we observe that supplier marketing innovation has a direct positive effect on supplier strategic advantage $(\beta=1.42, p \leq .01)$ but a direct negative effect on supplier financial performance $(\beta=-2.44, p \leq .01)$. In addition, supplier strategic

\footnotetext{
${ }^{3}$ We also calculated the exact region of values for which the simple slopes are significant: The slopes of customer lead-user orientation are significant for values of relational embeddedness ranging from -3.57 to -.04 . The slopes of supplier proactive market orientation are significant for values ranging from -.42 to 1.43 . The range of observed values for relational embeddedness is between -3.57 and 1.43.

${ }^{4}$ We also test for interaction effects between the learning abilities of partners. Because these effects are not significant, we drop them from the model for parsimony.
} 


\begin{tabular}{|c|c|c|c|c|c|c|}
\hline \multirow[b]{5}{*}{ Independent Variables } & \multicolumn{6}{|c|}{ Dependent Variables } \\
\hline & \multirow{3}{*}{\multicolumn{2}{|c|}{$\begin{array}{c}\text { Supplier } \\
\text { Marketing } \\
\text { Innovation }\end{array}$}} & \multirow{3}{*}{\multicolumn{2}{|c|}{$\begin{array}{c}\text { Supplier } \\
\text { Financial } \\
\text { Performance }\end{array}$}} & \multirow{3}{*}{\multicolumn{2}{|c|}{$\begin{array}{c}\text { Supplier } \\
\text { Strategic } \\
\text { Advantage }\end{array}$}} \\
\hline & & & & & & \\
\hline & & & & & & \\
\hline & Coeff. & SE & Coeff. & SE & Coeff. & SE \\
\hline Customer lead-user status & $.13^{* *}$ & .07 & .09 & .14 & -.04 & .11 \\
\hline Supplier proactive market orientation & $.21 * * *$ & .08 & $.26^{*}$ & .16 & -.08 & .12 \\
\hline Relational embeddedness & .09 & .07 & & & & \\
\hline \multicolumn{7}{|l|}{ Customer lead-user status } \\
\hline$\times$ relational embeddedness & $-.10^{* *}$ & .05 & & & & \\
\hline \multicolumn{7}{|l|}{ Supplier proactive market orientation $\times$} \\
\hline relational embeddedness & $.14^{* *}$ & .06 & & & & \\
\hline Supplier marketing innovation & & & $-2.44 * * *$ & .37 & $1.42 * * *$ & .24 \\
\hline Supplier strategic advantage & & & $1.94 * * *$ & .26 & & \\
\hline \multicolumn{7}{|l|}{ Control Variables } \\
\hline Partner goal congruency & .02 & .07 & & & & \\
\hline Relationship formalization & -.02 & .04 & & & & \\
\hline Market turbulence & .04 & .08 & $.44 * * *$ & .15 & -.12 & .11 \\
\hline Technological turbulence & -.04 & .08 & $-.35^{* *}$ & .15 & .16 & .11 \\
\hline \multicolumn{7}{|l|}{$\begin{array}{l}* p \leq .10 . \\
* * p \leq .05 . \\
* * * p \leq .01 .\end{array}$} \\
\hline \multicolumn{7}{|c|}{$\begin{array}{l}\text { advantage has a direct positive effect on supplier financial performance }(\beta=1.94 \text {, } \\
p \leq .01) \text {. Using these estimates, we calculate the total impact of the direct and } \\
\text { indirect (through strategic advantage) effects of marketing innovation on financial } \\
\text { performance. }\end{array}$} \\
\hline
\end{tabular}


Figure 2.2 How Relational Embeddedness Influences the Customer LEAD-User MARKETING INNOVATION RELATIONSHIP

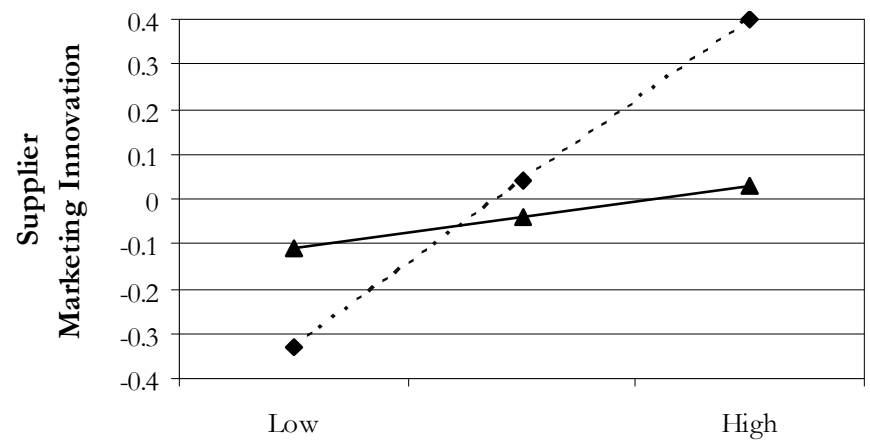

Supplier Proactive Market Orientation

... High relational embeddedness

$\longrightarrow$ Low relational embeddedness

Figure 2.3 How Relational Embeddedness Influences the Supplier Learning MARKETING INNOVATION RELATIONSHIP

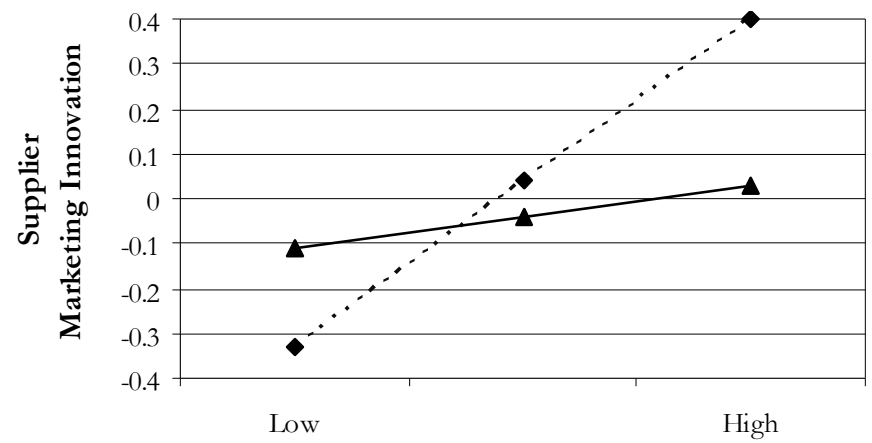

Supplier Proactive Market Orientation

-. - - High relational embeddedness

$\longrightarrow$ Low relational embeddedness 
The results indicate a positive total effect of marketing innovation on financial performance $(.31)^{5}$, consistent with previous research (e.g., Kyriakopoulos and Moorman 2004; Sorescu et al. 2003). However, the relationship between marketing innovation and financial performance is more complex than previous research has suggested. Our results reveal that the negative direct effect of marketing innovation on financial performance is suppressed by the positive indirect effect of marketing innovation (through strategic advantage) on financial performance (Shrout and Bolger 2002, p. 431). Thus, the total effect of marketing innovation on financial performance cannot be explained by simply decomposing it into two additive positive effects with the same sign, as would be the case in typical mediated processes. Instead, our findings support the view that innovation may involve (short-term) financial costs, despite its positive strategic advantage (Auh and Menguc 2005; Inkpen 1996).

As a final test of the proposed mediating role of strategic advantage on the relationship between marketing innovation and financial performance, we conduct a Sobel test (Sobel 1982; 1986), the results of which provide strong evidence of a significant mediating effect of strategic advantage on the relationship between marketing innovation and financial performance $(z=4.60, p \leq .001)$.

\subsection{Discussion and Implications}

Whereas prior research has focused on knowledge transfer from partners, we examine the role of a marketing innovation in the context of co-creation relations with customers. Specifically, our model examines the antecedents of marketing innovation -partners' learning abilities and relational ties- as well as its outcomes. We test our model using a Dutch sample of 157 co-creation relations between suppliers and their customers. The most pronounced result reveals that relational ties differentially moderate the positive effect of the customer's lead-user status and the firm's own proactive market orientation on marketing innovation. Our findings thus have important implications for literature on interfirm learning, lead

\footnotetext{
5 The total effect of marketing innovation is computed by summing the indirect and direct paths. We compute the indirect effect by multiplying the regression coefficient of the relationship between marketing innovation and supplier strategic advantage (1.42) with the regression coefficient of the relationship between supplier strategic performance and financial performance (1.94), for an indirect effect of $1.42 \times 1.94=2.75$. The direct effect (mediator constant) of marketing innovation on financial performance is -2.44 . When we add the direct and indirect effect, the expected positive total effect is $2.75-2.44=.31$. This positive total effect also explains the positive correlation coefficient between marketing innovation and financial performance in Table 2.1.
} 
users, and innovation. We discuss these implications, suggest some future research directions, and describe several limitations associated with our study.

\subsubsection{Implications for Interfirm Learning Research}

A review of the literature on learning points to its emphasis on either knowledge or social factors. Firms with resources are viewed as having more stocks of knowledge, whereas firms with capabilities supposedly have more flows of knowledge, which create and replenish stocks (Barney 1991; Day 1994). From a social perspective, the focus has tended to be on how relationships foster knowledge-related activities. For example, Moorman (1995) finds that clan cultures, characterized by high trust and support, foster a high level of knowledge utilization across the market. Uzzi and Lancaster (2003) view learning as a social process that helps solve problems associated with knowledge transfer and learning in markets. Similarly, Selnes and Sallis (2003) find that relational trust promotes relationship performance in terms of lower costs, better quality, more new products, and better marketing, and Rindfleisch and Moorman (2001) find that embedded relations promote more information acquisition and utilization in an alliance.

By harnessing the knowledge (supplier proactive market orientation and customer lead-user status) and the social characteristics (relational embeddedness) that are part of most interfirm relationships, we develop a richer view of the benefits and costs of learning when the relationship is strong versus weak. What we discovered frankly surprised us and points to a much more complex and multifaceted view of relational ties. In addition, we hope these findings offer greater insight to address the Marketing Science Institute's (2006) recent research priorities, namely, to examine the effects of customer engagement in new product development.

On the positive side, our findings indicate that strong ties between suppliers and customers strengthen the effect of supplier learning skills, in the form of a proactive market orientation, on supplier marketing innovation. On the negative side, these very same strong ties attenuate the effect of customer learning skills, in the form of customer lead-user status, on supplier marketing innovation. In other words, a strong relationship enables the supplier to use its own learning skills more effectively but disrupts its ability to use its customer's learning skills for innovation.

Why do we find these differential effects? We offer several speculations that further research should consider. Beginning with a discussion of why 
proactive market-oriented suppliers perceive greater innovation payoffs on their own knowledge investments in close relationships with customers, we offer the following ideas. First, a close relationship with a customer may increase a firm's confidence in its own knowledge and innovation skills. Thus, strong customer involvement would not improve innovation by transmitting knowledge as much as it improves innovation by increasing confidence in current supplier knowledge and skills.

Second, strong customer involvement helps the supplier gain greater innovation returns from its own knowledge by forcing the supplier to evoke stored and even tacit knowledge related to the customer. Without the customer pushing the supplier on with its needs and ideas, the supplier may not delve as deep in considering what it knows. Hence, strong customer involvement can improve innovation by forcing the supplier to unearth important, but hard to retrieve, insights.

Third, strong customer involvement may motivate the supplier to work harder to meet the customer's needs. According to this view, a strong customer relationship motivates the supplier to innovate; without a strong relationship, the supplier can slip back into its current technologies or focus on a production, rather than a customer, view of strategy, which might hamper marketing innovation of the type we study herein.

Turning now to why suppliers perceive the innovation returns from leaduser customers as lower in stronger relationships than in weaker relationships, we offer the following speculations. In strong relationships, suppliers can learn more quickly and more effectively about what their customers know and thus may be more likely to discount customer contributions to marketing innovations. This possibility refers to one of the problems of close relationships in knowledge-based partnerships (Grayson and Ambler 1999; Moorman et al. 1992), and we find evidence of it in our sample.

Another reason may be more specific to marketing innovation. Recall that most marketing innovations are, by definition, process innovations that improve positioning, targeting, segmentation, or distribution. Therefore, and given that the customer is a firm that is part of the supplier's value chain, concerns about opportunistic behavior may be even more profound than those affiliated with product innovations, which typically enjoy patent or trademark protection. This proposition is consistent with alliance literature, which suggests market knowledge flows more easily to allies than does manufacturing know-how (Hamel 1991). Such opportunism concerns may mean that a close relationship does not prompt the 
type of supplier disclosure to the customer that would promote the reciprocal customer sharing so central to supplier innovation.

\subsubsection{Implications for Lead-User Research}

Despite the profound contributions of the idea of lead-user status, we are not aware of prior research that has measured this quality using a general scale. Urban and von Hippel (1988) develop a set of criteria specific to lead users in the PCCAD industry that successfully identifies lead users, and Lilien et al. (2002) find that lead users differ from non-lead users in several ways. First, lead users report high marketing/sales skills, whereas non-lead users report stronger technology skills. Second, lead users report higher extraversion, according to a standard Myers Briggs scales.

We develop a measure of lead-user status by relying on the conceptual foundations of von Hippel (1986) and others. Our measure is well validated and, as expected, has a positive effect on the level of supplier innovation, consistent with Urban and von Hippel (1988), who find that the concepts created by lead users generally are preferable to those created by non-lead users. Our finding is also consistent with Lilien et al. (2002), who indicate lead users tend to produce more novel, original, and breakthrough ideas rather than incremental ideas. Our research extends this literature by providing a measure that can be used across studies to identify lead users and examine the effect of this trait on innovation outcomes.

\subsubsection{Implications for Innovation Research}

Finally, our research has several implications for the study of innovation. First, by studying marketing innovation, rather than product innovation, we provide a unique view of how learning and relationships might work similarly or differently, relative to existing product innovation literature. Second, our findings make clear that marketing innovation achieves its financial objectives primarily through a strategic advantage. This result is remarkably consistent with prior warnings that innovation provides no short-term benefits, which explains the difficulty firms often have in persisting with their innovation efforts. Therefore, managers should base their co-creation evaluations on not only the (short-term) financial performance of the product but also the effect of the new product introduction on the firm's strategic position and the money generated by that.

This value of marketing innovation for strategic competitive advantage echoes a shift in strategy literature from technological to strategic or value 
innovations (Baden-Fuller and Pitt 1996; Kim and Mauborgne 1999; Markides 1999) that deal with non-product innovations. Our study shows that such marketing innovations are being developed in co-creation relationships and that they indeed facilitate competitive advantages.

\subsubsection{Limitations and Future Research Directions}

The limitations of this study offer important opportunities for additional research. First, researchers could argue that partners' different learning abilities (reactive/proactive market orientation, lead-user status) must fit for learning to take place. Additional research investigating this issue could enhance our understanding of this possibility.

Second, we acknowledge a measurement concern, in that we use single informants for both the supplier and the customer. Although we invested significant effort to obtain data from customers directly, suppliers rarely were willing to reveal their identity. Although it is exceptional in marketing and organizational research on co-creation relations, it would clearly be preferred to focus on data sources that allow for the inquiry of both parties involved.

Third, we encourage researchers to examine the extent to which our findings generalize to other countries and industries. Because our sample is limited to a set of Dutch firms, it would be interesting to examine whether our results extend to different cultures. Likewise, there may be industries in which marketing innovation strategies are more prevalent, such as services or retailing. Our results do not necessarily extend to these unique industries, so further research might replicate our approach in these and other industries. 


\section{Chapter 3: Building New Competencies through Co-Creation}

\section{RELATIONS: THE Role OF KNOWLEDGE REDUNDANCY AND MEMORY}

Firm memory is a double-edged sword for firms in developing new competencies; though a necessary ingredient for innovation, its tacit and routine nature can limit novel perspectives and binder new competence development. One way to overcome this problem is to enter co-creation relations with supply chain partners, which operate in different knowledge domains and thus can offer new knowledge perspectives. To realize this potential, however, we argue that the focal firm needs knowledge redundancy with its supply chain partner to understand and integrate novel perspectives into its internal knowledge base. This, in turn, creates the foundation for new competence development. We test these ideas using a sample of 246 firms that recently participated in a co-creation relation. The findings bighlight a contradictory role of firm memory, illustrate the crucial role of knowledge redundancy, and, in general, underscore the importance of vertical cocreation relations in developing new competencies. 


\subsection{Introduction}

Developing new competencies (for example, skills or principles) is of great interest to both researchers and practitioners (Eisenhardt and Martin 2000; Benner and Tushman 2003; Ulrich and Smallwood 2004). New competencies (also known as capabilities) are crucial to firm renewal and success given increasing levels of technological and market turbulence (e.g., McEvily and Marcus 2005). Various fields ranging from organizational learning, resource-based view, networks or strategy have witnessed an explosion of studies on competencies as sources of sustainable competitive advantage (e.g., Barney 1991; March 1991; Powell 1998). Most of this research has studied the rent-generating potential of various capabilities (e.g., Dyer and Singh 1998; Henderson and Cockburn 1994) leaving the question of how firms develop new capabilities (i.e., competencies) relatively unexplored.

Two research streams have sought to shed light on this topic. First, one stream concentrates on internal sources and stresses the path-dependent role of prior skills and knowledge in developing new capabilities (e.g., Cohen and Levinthal 1990; Helfat 2000; Henderson and Clark 1990). Second, a rapidly expanding stream of research assesses how interfirm relations might help a firm develop new competencies by studying embeddedness, joint problem solving, and information sharing (e.g., Gulati 1999; McEvily and Marcus 2005; Rindfleisch and Moorman 2001; Uzzi 1997). These two research streams have operated separately, which has prevented richer insights from the cross-fertilization of different findings.

This study seeks to combine these research streams to understand how firms can use their memory to develop new competencies through vertical cocreation relations. Specifically, we explore new competence development as a function of a firm's internal knowledge (or firm memory) and the knowledge redundancy with its supply chain partner in a co-creation context. Beginning with memory, researchers note that "innovation builds on existing know-how" (Powell and Brantley 1992, p. 368) and firms can derive capabilities by fusing prior knowledge in a creative way known as "combinative capability" (Kogut and Zander 1992). In this latter effort, firms typically fail because entrenched communication routines, problem-solving strategies, and information filters block novel perspectives on existing knowledge (Henderson and Clark 1990). Information filters, for example, prevent firms from understanding the value of recombined knowledge, which prompts them to either discard the new solution or 
misinterpret its value to the market (Cohen and Levinthal 1990). Prior strengths are argued to create path-dependencies leading to competency traps (e.g., Dougherty 1992; Helfat 2000; Leonard-Barton 1992; March 1991). Hence, alone, firm memory is likely to discourage the development of new competencies.

We argue that vertical co-creation relations can remedy this problem because they expose the firm to the divergent knowledge, beliefs, and mental models held by partners ${ }^{6}$. The main thrust of our argument posits that knowledge redundancy with a supply chain partner (i.e., similarities in skills, knowledge, resources, and products) helps the focal firm overcome the challenges of its prior knowledge and recombine its existing knowledge with the partner knowledge to create new competencies.

Although both firm memory and interfirm knowledge redundancy matter, research tends to examine these drivers separately to explain new competence development. For example, research addresses the effects of both memory (Anderson and Tushman 1991; Vlaar et al. 2005) and knowledge redundancy (e.g., Bonner and Walker 2004) on competence development but rarely in conjunction. An exception to this is Lane and Lubatkin's (1998) work in the context of interorganizational learning. However, these authors focus on the relevance of firm memory (to the partner), whereas we focus on the effect of the level of firm memory.

Building on these two research streams, our goal is to investigate (1) the effect of a firm's memory on its competence development and (2) the influence of knowledge redundancy with a supply chain partner during co-creation projects on the main effect between memory and new competence development. This research focus seeks to contribute to existing literature in three ways. First, we enhance theories of organizational memory by examining ways firms may benefit from prior knowledge. Existing theory either hails or condemns a reliance on prior knowledge; while extant research stresses the traps and the potential of memory, we examine knowledge redundancy between supply chain partners as a key way to make memory an asset in pursuing new competencies during co-creation.

Second, we aim to contribute to literature acknowledging the importance of the interplay between intra- and interfirm factors by empirically assessing the (joint) impact of these factors on new competence development. The intuition that firms need to invest in their own knowledge base and skills in order to profit from

\footnotetext{
${ }^{6}$ Horizontal relations, compared with vertical ones, are less effective because firms operate within the same industry and thus tend to converge in their industry recipes and cognitive frameworks.
} 
interfirm collaboration drives our rationale for linking RBV and tie strength research.

Third, we attempt to advance research on interfirm relations and the development of new capabilities. Pertinent literature has examined the direct effect of relational embeddedness (Lane and Lubatkin 1998; Rindfleisch and Moorman 2001) and knowledge complementarities between firms (Sapienza et al. 2004; Sivadas and Dwyer 2000) in various learning processes, such as information or knowledge transfer. We instead focus on the moderating impact of knowledge redundancy as it unlocks prior knowledge in developing new competencies.

The following section reviews the literatures of new competence development, memory, and co-creation relations. We then discuss the potential of knowledge redundancy to overcome the threats of firm memory in the form of formal predictions. We report, then, the method for testing our hypotheses and the results for 246 manufacturing companies that recently participated in a cocreation relation. We conclude with the implications of our findings for theory and practice and the key limitations of our research.

\subsection{Literature Review}

This section discusses the key concepts behind new competence development, firm memory, and knowledge redundancy based on a brief review of pertinent literature.

\subsubsection{New Competence Development}

The resource-based view (RBV) seeks to explain differential rent generation as a function of firm resources, including all assets, capabilities (i.e., competencies), knowledge, and so forth (Barney 1991; Grant 1996; Teece et al. 1997). Assuming that resources are stable over time and heterogeneously distributed across firms, a resource can sustain a firm's competitive advantage when it is (1) valuable, (2) rare, (3) imperfectly imitable, and (4) nonsubstitutable (Barney 1991). This literature stream makes an important distinction between assets and capabilities (Grant 1996), in that capabilities are more enduring sources of competitive advantage that involve idiosyncratic and path-dependent routines or processes that firms use to deploy and combine their assets (e.g., Amit and Schoemaker 1993; Teece et al. 1997). Such routines are based on social interactions that convert tacit and explicit knowledge (Nonaka 1994) and follow an evolutionary, exploitative path, because the past determines the future (Levitt and March 1988; March 1991; Nelson and Winter 1982). 
Recent research also examines how firms can develop new, exploratory competencies (March 1991). New competence development refers to the extent to which firms reach beyond their existing experience to develop new concepts, skills, and knowledge when developing a new product (Gatignon et al. 2002). Developing new competencies is an important organizational challenge as continuous change renders prior skills and competencies obsolete (e.g., Teece et al. 1997). As hardly any innovation is born out of entirely new ideas, most innovations are results of recombining existing knowledge, skills or technologies. Thus, for developing new competencies, firm memory plays a critical and multifaceted role because it affects a firm's ability and willingness to reconfigure this knowledge (Eisenhardt and Martin 2000; Song et al. 2005).

\subsubsection{Firm Memory}

Firm memory represents a repository of experience (Hanvanich et al. 2006) captured in different storage bins or forms: firm memory takes the form of beliefs, behavioral routines, or artifacts, such as product design, product packaging, and logos (Moorman and Miner 1997). Firm beliefs constitute shared norms and values, as well as myths or stories (e.g., Deshpandé et al. 1993). Through learning by doing, firms gain experience that can be encoded in (in)formal behavioral routines, such as standard operating procedures (Winter 1987) or manuals (Nonaka and Takeuchi 1995). Finally, memory appears in objects that embody evidence of prior learning (Madhavan and Grover 1998).

The literature records the multifaceted role of memory. Memory typically filters and interprets new knowledge to increase the efficiency and effective sorting of information selected from the environment (Garud and Rappa 1994; Walsh and Ungson 1991). Researchers note that memory in the form of routines are the primary means by which organizations accomplish much of what they do (e.g., Cyert and March 1963; Nelson and Winter 1982) and ensure efficiency and reliability (Hannan and Freeman 1983). In a dynamic world however, this same mechanism may screen out relevant (market) information because the filters, built over time and embodying prior knowledge, cannot recognize it as relevant (Henderson and Clark 1990). Memory, thus, becomes a source of inertia.

Despite this static view of memory, recent research explicitly recognizes that routines can be a source of flexibility and change (Feldman and Pentland 2003) or mutation, in the parlor of evolutionary theories (Nelson and Winter 1982). Moorman and Miner (1998, p. 712) note that such adaptation can result from "applying pre-existing routines to new contexts, recombining subunits within 
pre-existing routines, and recombining entire routines in new ways." In organizational research, this phenomenon has been referred to as the firm's “combinative capabilities" (Kogut and Zander 1992), because innovations arise from recombining and fusing existing knowledge (e.g., Nelson and Winter 1982; Schumpeter 1939; von Hippel 1988). For example, Henderson and Clark (1990) describe the introduction of portable air fans as an innovation that is based on existing knowledge on the components of the traditional room air fans, although the interactions between the components have altered. It remains unclear, however, what triggers the recombination and how firms can overcome the inertia of memory.

Finally, literature on NPD indicates that product development requires two key types of memory: market- and technology-related (Moorman and Slotegraaf 1999). Although generally addressed separately by scholars, the close connection between these two resources appears more frequently in recent studies (Song et al. 2005). According to Danneels (2002, p. 1104), "it is necessary to address the impact of both [marketing and technology] on product innovation simultaneously". Therefore, this chapter conceptualizes organizational memory as the interplay between marketing and technology memory. Marketing memory, a market-related resource, refers to prior knowledge, insights, and information regarding the marketing aspects of the product category, whereas technology memory encompasses prior knowledge about research and development in the product category. Empirical research has shown that the interplay of these resources is important (Moorman and Slotegraaf 1999; Dutta et al. 1999).

\subsubsection{Co-Creation Relations}

In addition to intrafirm sources, other research examines interfirm relations as a context conducive to developing capabilities (e.g., Dyer and Singh 1998; Hamel 1991; Powell et al. 1996). Research on interfirm learning notes that firms "turn to external knowledge sources in an effort to develop capabilities more divergent from their existing set" (Lane and Lubatkin 1998, p. 462). Likewise, Powell et al. (1996) note that "sources of innovation do not reside exclusively inside firms; instead, they are commonly found in the interstices between firms, universities, research laboratories, suppliers, and customers" (p. 117).

We focus on new competence development -or competence development for simplicity- in vertical co-creation relations. We define these relationships as joint new product development (NPD) projects that involve two financially independent firms, a business customer and a supplier, that actively and directly 
cooperate from at least the development stage of the NPD process onward. Thus, horizontal collaborations and vertically integrated firms are not part of this study. This context is particularly well suited for our investigation because it captures a situation in which two companies (both with their own memory levels) exchange information and accumulate knowledge in pursuit of a new product. In this respect, vertical co-creation relations represent an interactive form of learning from external knowledge, in contrast to passive (e.g., journals, seminars, consultants) and active (e.g., benchmarking, competitive intelligence) external learning (Lane and Lubatkin 1998). Therefore, a key difference of co-creation relations from normal vertical relations commonly studied is that the former represents an interactive form of learning as they allow the partner to capture tacit knowledge because they involve intense, face-to-face interaction in contrast to the latter in which customer input is at best at the concept or product testing stage.

\subsection{Hypotheses}

We begin our hypotheses with a baseline prediction on the direct and joint effect of the two memory types. Then, we develop arguments on the effect of knowledge redundancy on the relationship between firm memory and new competence development. Figure 3.1 provides an overview of the model ${ }^{7}$.

Figure 3.1: CoNCEPTUAL Framework

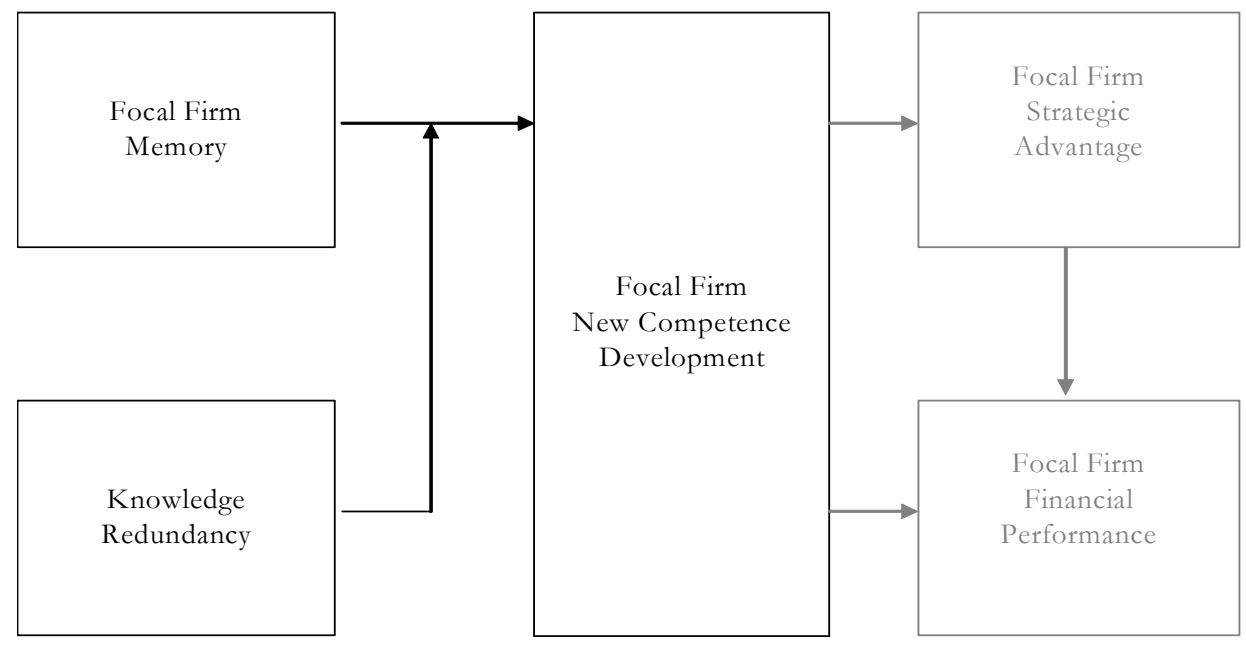

\footnotetext{
${ }^{7}$ As in Figure 3.1, we refer to focal firm traits when addressing intrafirm variables (e.g., firm memory, new competence development, firm financial performance, and firm strategic advantage).
} 


\subsubsection{Firm Memory as a Threat to Competence Development}

Research typically views firm memory as a barrier to creativity, innovation, and new competence development and documents a host of negative effects labeled as "competence traps" (Levitt and March 1988; March 1991) or "core rigidities" (Leonard-Barton 1992). The way in which memory blocks new competence development has been addressed previously by economic, cognitive, or psychological perspectives.

First, from an economic viewpoint, memory blocks new competence development because current routines focus on efficiency, whereas new knowledge requires time to pay off (March 1991). Exploring and integrating new knowledge into the current system requires firms to engage in changes to, for example, current communication channels and adopt new information filters that match the new competence. These demands take time to meet, and the payoffs are uncertain and temporally remote. Therefore, firms tend to prefer to exploit their current success by repeating their standard operating procedures instead of acquiring new competencies.

Second, cognitive or information processing literature suggests that organizational memory develops heuristics and routines, accessed in an unconscious, automatic manner (Kahneman et al. 1982). Because of these "shortcuts" to information processing and decision making, the links between the action and its purpose get disconnected. This disconnection limits firms' creativity in terms of using and applying new knowledge to create new competencies.

Third, organizational psychologists study the relationship between memory and new competence development by examining the fear of cannibalization (Barton et al. 1989; Staw and Ross 1987), which in this context refers to "firms' readiness to reduce the (potential) value of past investments" (Chandy and Tellis 1998, p. 475). Although sunk costs are irrecoverable, people tend to suffer from a "sunk cost effect" and continue to consider past investments because they fear they have invested too much to abandon the strategies, routines, and filters developed so far (Arkes and Ayton 1999). Similarly, firms tend to hold on to prior investments when they build and store organizational knowledge sets, even when an economic evaluation tells them that those investments are no longer profitable (Nijssen et al. 2005).

Our arguments apply to either memory type (marketing or technological). More interestingly, they extend to the interaction of marketing and technology memory which we label firm memory in this chapter. Prior research has taken a strong stand in favor of bridging marketing and $R \& D$ in new product 
development (e.g., Moorman and Slotegraaf 1999). Their arguments, however, are confined to enhancing overall performance (e.g., Song et al. 2005). Though integration of different knowledge bases is important in many instances, this integration is limited to existing worldviews of the firm, and it could be a handicap to building new competencies. Therefore, we begin with three baseline hypotheses:

$\mathrm{H}_{1 \mathrm{a}}$ : Marketing memory has a negative effect on new competence development.

$\mathrm{H}_{1 \mathrm{~b}}$ : Technology memory has a negative effect on new competence development.

$\mathrm{H}_{1 \mathrm{c}}$ : The interaction of marketing and technology memory (i.e., firm memory) has a negative effect on new competence development.

\subsubsection{How Does Knowledge Redundancy with the Supply Chain Partner Unleash the Potential of Firm Memory?}

We define knowledge redundancy as the degree of overlap in the knowledge bases of two social actors (business customer and supplier). We will argue that knowledge redundancy in co-creation relations could be instrumental to unlocking firm memory for recombination with external information and thus spurring competence development. Our argumentation deviates from previous literature that tends to advocate intermediate levels of knowledge redundancy, as a driver of interfirm learning and competence development (Grant 1996; Hitt et al. 2000; Kale and Singh 2000; Mowery et al. 1996). Recall, however, we focus on cocreation relations between suppliers and business customers, and because of the differences in their structural positions, these parties operate in different knowledge domains and possess different knowledge bases (Jap 2001; Rindfleisch and Moorman 2001). Thus, the threat of nearly complete knowledge base overlaps (typical in horizontal relations) is not an issue; the challenge for the co-creation partners is then to have knowledge held in common to enhance the exchange, interpretation, and integration of knowledge in the process of building new competencies (Grant 1996; Sapienza et al. 2004).

We have suggested that memory possessed by the focal firm alone is a necessary but insufficient requirement for competence development, because individual firms cannot break away from their existing routines and procedures to detect the necessary linkages between prior and new knowledge. The risks of competency traps, avoidance of unlearning, and unwillingness to cannibalize past 
investments suggest that organizational memory might hinder new skill development. Therefore, we propose that knowledge redundancy (similarity of or overlap between knowledge of the focal firm and the partner firm) provides the missing link to successful uses of prior existing knowledge. Because combinations of existing and new processes, procedures, behaviors, and artifacts create new knowledge, firms must to be able to assimilate new knowledge and integrate it into their knowledge bases (Eisenhardt and Martin 2000; Kogut and Zander 1992; Liebeskind 1996; Zahra and George 2002). Knowledge redundancy offers partners a means to unlock their memory and thus provides a basis for new competence development. We discuss how knowledge redundancy serves this role in terms of the behaviors required to develop new competencies (Nonaka and Takeuchi 1995).

First, knowledge redundancy overcomes the dangers of organizational memory by boosting knowledge exchange between partners. Behavioral theorists such as Cyert and March (1963) find that firms tend to develop new competencies from similar external knowledge sources, because of a tendency to avoid uncertainty. Knowledge redundancy reduces the causal ambiguity that results from the imperfectly understood idiosyncratic features of the new context in which firms put their knowledge to use (Tyre and von Hippel 1997). Also, similar knowledge bases reduce the tension between existing and new knowledge in co-creation relations because both partners have related experiences with technological and marketing processes or decisions that have worked in the past (Hansen 1999; Uzzi 1997; Uzzi 1996).

Second, similar know-how enhances the mutual understanding of the assumptions that underlie external information and enables the focal firm to relate this information to its previously gained insights (Lane and Lubatkin 1998). Firms with related knowledge can interpret the tacit knowledge of the partner more easily than can firms with unrelated knowledge because they share a common basis which facilitates understanding (Lane and Lubatkin 1998; Nielsen 2005).

Third, knowledge integration between the co-creation relation partners is smoother and faces less resistance (Sapienza et al. 2004). According to several authors (e.g., Grant 1996; Rindfleisch and Moorman 2001), aspects such as common beliefs, common languages, and common knowledge domains spur the efficient integration of knowledge into an existing knowledge base. For example, when applications of the knowledge match the recipient firm's established ideas about their effect, it accepts knowledge much more easily (Sapienza et al. 2004). 
In summary, knowledge redundancy plays a dual positive role in terms of unlocking firm memory to promote new competence development. First, it breaks traditional routines by releasing the potential of existing experience to discover new linkages between old and new pieces of information and highlighting the benefits of unlearning. Second, knowledge redundancy prevents firms from experiencing inefficient communication or suffering a lack of cross-fertilization.

$\mathrm{H}_{2}$ : Knowledge redundancy in vertical co-creation relations positively moderates the relationship between firm memory and new competence development.

\subsection{Research Method}

\subsubsection{Sample and Procedure}

We drew an initial list of all Dutch manufacturing firms with more than 50 employees $(n=3,146)$ from Dun \& Bradstreet's Market Direct Database. To qualify for participation, the business customer and supplier had to have been jointly involved in the project since at least the development stage. To address a potential memory bias, we also required the jointly developed new product to have been launched not more than two years ago. Telephone contacts indicated whether the companies met the sample requirements, requested their participation in the research, and verified the respondents' mailing address. We excluded those companies that did not meet the sample requirements or could not be included in the sample for other reasons $(n=2,286)^{8}$. The frame for the final survey therefore consists of 860 firms, and we received 246 responses for a response rate of $28.6 \%$.

The key informants for this study are new product team leaders, who possess high levels of knowledge about the firm and the relationship with the partner (Bonner and Walker 2004; Olson et al. 1995). To ensure respondent competency, we cross-checked their direct involvement in the co-creation relationship and found an average score of 6 (on a seven-point Likert scale, $1=$ no involvement and $7=$ high involvement) ( $\mathrm{SD}=1.33$ ). Respondents rated the intensity of cooperation in each stage of the process on a scale from 1 (no cooperation) to 7 (intensive cooperation), which guarantees the presence of true co-creation in the sample. The average score across the five stages of the co-

\footnotetext{
8 Of these, 1,376 companies did not engage in a co-creation relationship during the previous two years. We exclude 910 companies for several reasons, including that they are independent subdivisions of parent companies with centralized new product development units, bankruptcy, or outdated contact information.
} 
creation process was 5.1 ( $\mathrm{SD}=1.6)$, with the lowest intensity of cooperation in the launch stage (mean $=4.7$ ) and the highest in the test stage (mean $=5.5$ ). Longstanding relationships with partners (mean $=11$ years, $\mathrm{SD}=12$ years) and the respondents' rich experience in their positions as product development team leaders (mean $=9$ years, $\mathrm{SD}=8$ years) enhance our confidence in the data.

\subsubsection{Measure Development}

To develop the measures, we involve business managers in five exploratory field interviews and six survey pretests. The pretests offer insights into the extent to which potential respondents understand and properly interpret the measurement scales. Although the survey was generally perceived well, some items required wording adaptations. We then discussed these implemented changes during six follow-up interviews with business managers and a panel of 10 researchers to corroborate the measurement scales. The items used in the survey are documented in Appendix B, and we provide overviews next.

New competence development. To measure new competence development, we use Gatignon et al.'s (2002) scale. The items in this scale assess the extent to which the co-creation relation required the firm to integrate existing and new knowledge. Respondents rated the degree to which the vertical cocreation relation (1) involved fundamentally new concepts or principles, (2) required new skills the firm did not possess before the project, (3) required a great deal of retraining, (4) required learning from completely new or different knowledge bases, (5) required adoption of different methods and procedures, and (6) required the development of many new skills. The assessment is specific to the firm, which implies that a new product can demand new competencies of the focal firm but not necessarily other firms.

\section{Focal firm memory: Interaction effect of marketing and technology} memory. Our measure of firm memory is adapted from Moorman's (1995) memory scale. We model organizational memory as the interaction between marketing and technology memory, because these two functional areas have critical importance for NPD (Dutta et al. 1999; Harrison et al. 2001) and may be complementary (Harrison et al. 2001; Song et al. 2005). We adapt the wording of the original scale to capture the marketing/technology memory of the focal firm about the product category internal to the firm prior to the co-creation relation. Both scales consist of four items that use seven-point Likert scales. The items of the two scales tap the levels of (1) knowledge, (2) information and data, (3) 
experience, and (4) insights regarding marketing and technology within the product category.

Knowledge redundancy. The moderator, knowledge redundancy, uses a semantic differential scale adopted from Rindfleisch and Moorman (2001). Consistent with our conceptualization, the items reflect the degree to which the partners possess related NPD knowledge and resources. Respondents therefore rated interfirm knowledge redundancy using the following items: (1) Our partner produces very different/similar products; (2) Our partner has complementary/overlapping new product development skills; (3) Our partner's new product development team members have different/the same knowledge; and (4) Our partner has very different/similar resources.

Firm financial and strategic performance. We employ two performance measures. The first relates to the performance of the new product relative to its objectives, such as market share, sales, return on assets, profit margin, and return on investment (Moorman 1995). In addition, Jap's (1999) fouritem measurement scale captures strategic performance effects, so this second measure assesses the benefits firms receive compared with competing firms as a result of their co-creation relation. An example item is "Our firm has gained strategic advantages over our competitors" $(1=$ strongly disagree, $7=$ strongly agree).

We include five control variables to reduce the possibility of alternative explanations. A set of three variables relates to relationship characteristics. Specifically, (the lack of) an aligned strategic interest and intent between partners may affect the difficulties associated with communication and goal achievement (Dwyer and Oh 1988; Jap 1999). Therefore, we include partner goal congruency to account for this alignment. We also control for the level of co-creation-specific investments, because previous research demonstrates that they can increase commitments to make the relationship work as a result of the lock-in effect of adapting to a partner (Ghosh and John 1999; Rokkan et al. 2003). Such sunk investments also can deteriorate relationship outcomes, because the partner may expropriate part of the value (Rokkan et al. 2003; Williamson 1985). Finally, partners may be more enticed to trust a new knowledge source if they have strong ties (Szulanski and Jensen 2006), so we include relational embeddedness as a control variable. Market and technological turbulence also could affect the degree to which firms resort to external sources of information to increase their chances of survival (Cohen and Levinthal 1990; Cyert and March 1963; Song et al. 2005). Therefore, we employ this set of two environmental variables. 


\subsubsection{Validity and Reliability of the Measurement Model}

Before assessing the research model, we scrutinize the measurement model to determine the reliability of the scales. The measurement scales show satisfactory composite reliability (Bagozzi and Yi 1988): The construct reliability is .86 for new competence development, .96 for marketing memory, .94 for technology memory, .74 for knowledge redundancy, .92 for focal firm financial performance, .78 for focal firm strategic advantage, .64 for partner goal congruency, .81 for co-creationspecific investments, .72 for relational embeddedness, .74 for market turbulence, and .78 for technological turbulence (see Table 3.1).

To establish the unidimensionality of the constructs, we ran a confirmatory factor analysis and deleted several items based on low factor loadings and/or high modification indices. We find absolute and incremental fit indexes above the cut-off levels recommended by Bentler (1992). Therefore, our goodness-of-fit measures $\left(\chi^{2}=1051\right.$, NNFI $=.95$, CFI $=.96$, SRMR $=.05$, RMSEA $=.04)$ satisfy the unidimensionality criterion. Moreover, each of the observed indicators loads significantly on the intended latent constructs, which implies convergent validity among the items (Campbell and Fiske 1959).

We proceeded with our inspection of the measurement model by examining discriminant validity through a series of confirmatory factor analyses. We construct baseline measurement models and constrained models for all possible pairs of latent variables and find significant chi-square differences between all pairs (i.e., minimum chi-square $=36.13, p<.001$, $1 \mathrm{df}$ ), which confirms the discriminant validity between constructs. Alternatively, discriminant validity might exist if the items of the latent variable share more common variance with their respective variable than the variable shares with other variables (Fornell and Larcker 1981). Therefore, the average variance extracted (AVE) for any variable should be greater than the squared correlation between that variable and all other variables (Koufteros 1999). The AVE of all constructs exceeds the squared correlations.

Two issues that frequently emerge in survey research are common method variance and nonresponse bias. We examine the common method variance using Harman's one-factor test, which suggests it is not a problem when (1) several factors can be identified, (2) the first factor does not account for the majority of the variance, and (3) no general factor exists in the unrotated factor structure. The principal components factor analysis shows 11 factors with eigenvalues greater than 1.0 that correspond to the variables included in our model and jointly explain $70 \%$ of total variance. Furthermore, the first factor accounts for less than 


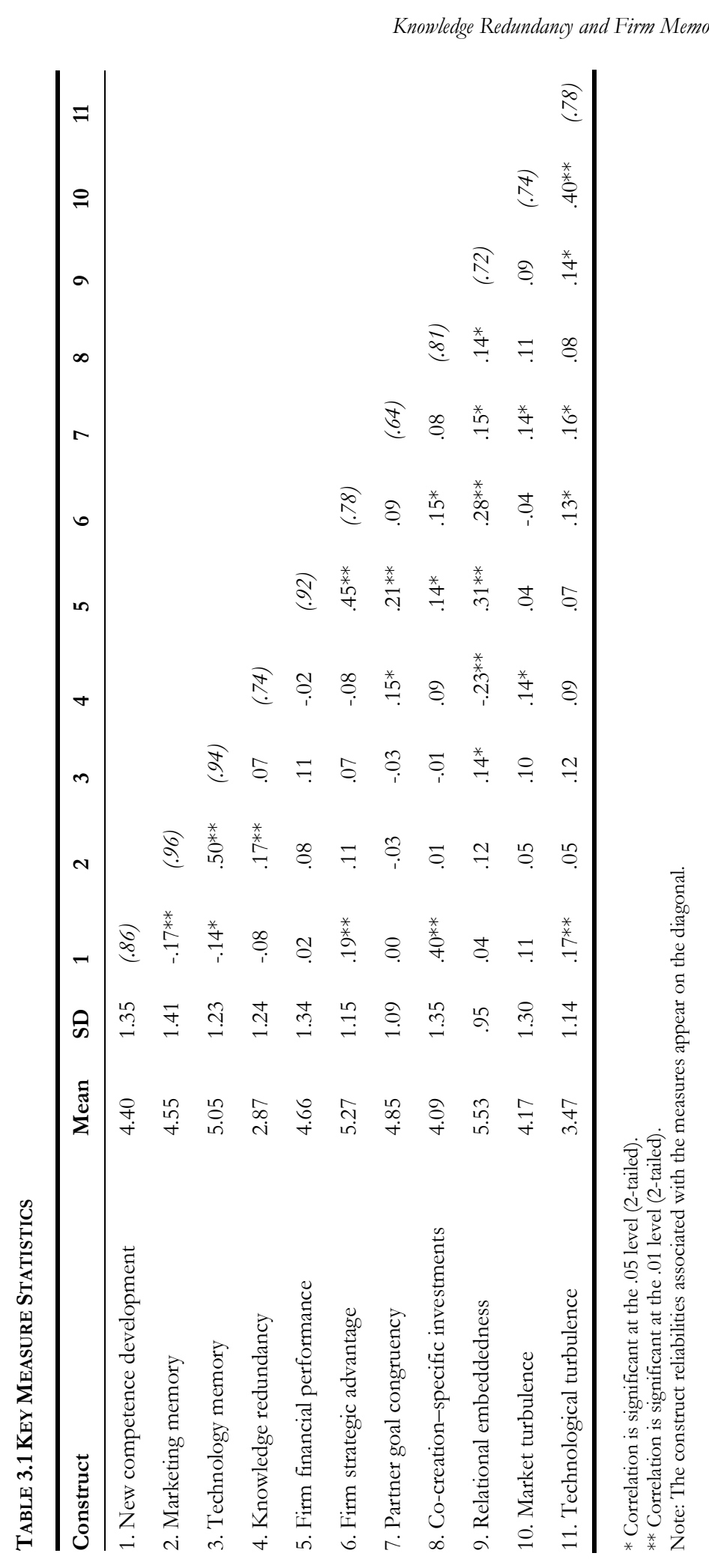


the majority of the variance explained (14\%), and we do not find a general factor in the unrotated component matrix. Therefore, none of the three requirements is violated, so we do not consider common method variance a problem.

We examine nonresponse bias by comparing early (ER) and late (LR) respondents (Armstrong and Overton 1977) on all predictor and criterion variables. In addition, we subject an objective measure, number of employees, to this procedure. The t-tests offer no indication of nonresponse bias?.

\subsection{Results}

To test the system of equations outlined next, we use three-stage least squares (3SLS) analysis, because competence development serves as both a predictor and a criterion variable in the system of equations. Whereas 3SLS estimations are consistent in such conditions, ordinary least square (OLS) estimates tend to produce inconsistent results (Greene 2002). Furthermore, 3SLS yields efficient parameter estimates if the errors of the independent variables are correlated (Greene 2002).

(1) $\mathrm{NCD}=$

$\mathrm{c}_{1}+\beta_{1}(\mathrm{MM})+\beta_{2}(\mathrm{TM})+\beta_{3}(\mathrm{KR})+\beta_{4}\left(\mathrm{MM}^{*} \mathrm{TM}\right)+\beta_{5}$ $(\mathrm{MM} * \mathrm{KR})+\beta_{6}(\mathrm{TM} * \mathrm{KR})+\beta_{7}((\mathrm{MM} * \mathrm{TM}) * \mathrm{KR})+$ control variables $+\varepsilon_{1}$;

(2) $\mathrm{FIN}=\quad \mathrm{c}_{2}+\beta_{8}(\mathrm{NCD})+\beta_{9}($ STRAT $)+$ control variables $+\varepsilon_{2}$; and

(3) $\mathrm{STRAT}=\mathrm{c}_{3}+\beta_{10}(\mathrm{NCD})+$ control variables $+\varepsilon_{3}$,

where

$\mathrm{c}=$ constant,

NCD = new competence development,

$\mathrm{MM}=$ marketing memory,

$\mathrm{TM}=$ technology memory,

$\mathrm{KR}=$ knowledge redundancy,

$\mathrm{MM}^{*} \mathrm{TM}=$ firm memory,

FIN $=$ firm financial performance,

\footnotetext{
${ }^{9}$ New competence development $\mathrm{ER}=4.32, \mathrm{LR}=4.47, \mathrm{t}_{(223)}=-.87$, n.s.; marketing memory $\mathrm{ER}=$ 4.62, $\mathrm{LR}=4.50, \mathrm{t}_{(245)}=.66$, n.s.; technology memory $\mathrm{ER}=5.16, \mathrm{LR}=4.97, \mathrm{t}_{(245)}=1.23$, n.s.; knowledge redundancy $\mathrm{ER}=3.00, \mathrm{LR}=2.76, \mathrm{t}_{(245)}=1.58$, n.s.; firm financial performance $\mathrm{ER}=$ 4.83, $\mathrm{LR}=4.51, \mathrm{t}_{(245)}=1.89$, n.s.; firm strategic advantage $\mathrm{ER}=5.35, \mathrm{LR}=5.20, \mathrm{t}_{(245)}=1.02$, n.s.; partner goal congruency $\mathrm{ER}=4.96, \mathrm{LR}=4.76, \mathrm{t}_{(245)}=1.41$, n.s.; co-creation specific investments $\mathrm{ER}$ $=4.23, \mathrm{LR}=3.98, \mathrm{t}_{(245)}=1.49$, n.s.; relational embeddedness $\mathrm{ER}=5.49, \mathrm{LR}=5.57, \mathrm{t}_{(212)}=-.66$, n.s.; market turbulence $\mathrm{ER}=4.09, \mathrm{LR}=4.25, \mathrm{t}_{(245)}=-.96$, n.s.; technological turbulence $\mathrm{ER}=4.42, \mathrm{LR}=$ $4.52, \mathrm{t}_{(216)}=-.68$, n.s.; number of employees $\mathrm{ER}=4.01, \mathrm{LR}=3.83, \mathrm{t}_{(191)}=1.02$, n.s.
} 
STRAT $=$ firm strategic advantage, and

$\varepsilon=$ disturbance terms.

According to established practice for examining interactions, we enter the main effects associated with the two-way interaction terms into the system of equations. For the same reason, we also include the non-hypothesized two-way interaction effects. To minimize the threat of multicollinearity in equations containing interaction terms, we mean-center the variables (Aiken and West 1991). Moreover, the variance inflation factors (VIF) resulting from OLS estimations provide no indication of multicollinearity; all VIFs are well below the recommended cut-off value of 10 (Neter et al. 1985).

\subsubsection{Regression Results}

We test the hypotheses in this chapter by analyzing the results of the 3SLS estimation. Concerning $\mathrm{H}_{1 a}$ and $\mathrm{H}_{1 b}$, we observe a negative and significant main effect of marketing and technology memory on new competence development ( $\beta$ $=-.14, p \leq .05$ and $\beta=-.17, p \leq .05$, respectively; see Table 3.2) for the mean value of knowledge redundancy ${ }^{10}$. Additional probing as recommended by Preacher et al. (2006) shows an insignificant main effect of marketing memory $(\beta$ $=.05, p \geq .05)$ for low knowledge redundancy $(-1 \mathrm{SD})$ and a significant negative main effect $(\beta=-.33, p \leq .01)$ for high knowledge redundancy $(+1 \mathrm{SD})$. For technology memory, we observe a significant negative effect for low knowledge redundancy $(\beta=-.29, \phi \leq .01)$ and an insignificant negative effect for high knowledge redundancy $\left(\beta=-.05, p \geq .05\right.$ ). Thus, $\mathrm{H}_{1 \mathrm{a}}$ is supported for relatively high values of knowledge redundancy and $\mathrm{H}_{1 \mathrm{~b}}$ is supported for relatively low values of knowledge redundancy. ${ }^{11}$ In support of $\mathrm{H}_{1 \mathrm{c}}$, the results show a negative impact of firm memory (i.e., the interaction of marketing and technology memory) on new competence development $(\beta=-.09, p \leq .05)$. Hence, increases in firm memory inhibit firms from letting go of their existing routines or cannibalizing their previous investments in knowledge development.

10 These variables are mean-centered and part of an interaction term. The results, therefore, represent the simple effects of these variables.

11 The observed values for knowledge redundancy range between -1.87 and 4.13. Given this range, the slopes of marketing memory are significant for all values of knowledge redundancy between -.11 and 4.13 . For technological memory, the range is $[-1.87, .20]$. 
TABle 3.2 3SLS Model Estimation Results

\begin{tabular}{ccc}
\multicolumn{3}{c}{ Dependent Variables } \\
\hline New & Firm & Firm \\
Competence & Financial & Strategic \\
Development & Performance & Advantage
\end{tabular}

Independent Variables

Coeff.

Coeff.

SE Coeff.

SE

\section{Firm Memory}

Firm memory $(\mathrm{MM} \times \mathrm{TM})$

$\begin{array}{llllll}-.09 * * & .04 & -.12^{* *} & .05 & .08^{* *} & .08 \\ -.14^{* *} & .06 & -.15^{*} & .08 & .14^{* *} & .06 \\ -.17^{* *} & .07 & .00 & .09 & .08 & .07\end{array}$

Marketing memory (MM)

$.09 \quad .08$

.07

\section{Knowledge Redundancy}

Firm memory $\times$ knowledge

redundancy $(\mathrm{MM} \times \mathrm{TM} \times \mathrm{KR}) \quad .08^{* *} \quad .03$

Knowledge redundancy $(\mathrm{KR})^{12} \quad-.19^{* *} \quad .07$

$\mathrm{MM} \times \mathrm{KR} \quad-.14 \quad .05$

$\begin{array}{lll}\mathrm{TM} \times \mathrm{KR} & .10 & .06\end{array}$

\section{Firm Outcomes}

New competence development

$\begin{array}{lll}-.20 & .16 & .32 * * * \\ 1.60^{* * *} & .25\end{array}$

Firm strategic advantage

\section{Control Variables}

$\begin{array}{lll}\text { Partner goal congruency } & -.04 & .07\end{array}$

Co-creation-specific investments $\quad .39 * * * \quad .06$

Relational embeddedness $\quad-.06 \quad .09$

Market turbulence $\quad .05 \quad .06$

\begin{tabular}{lllllll} 
Technological turbulence & .12 & .07 & $-.15^{*}$ & .09 & .09 & .07 \\
\hline
\end{tabular}

$* p \leq .10$.

$* * p \leq .05$.

$* * * p \leq .01$.

12 In line with our expectations regarding the non-perfect overlap of knowledge bases between partners, our test of potential U-shaped effects of knowledge redundancy is not significant and therefore dropped from the model. 
Figure 3.2 Effect of Knowledge Redundancy on New Competence Development WHEN FIRM MEMORY IS HIGH

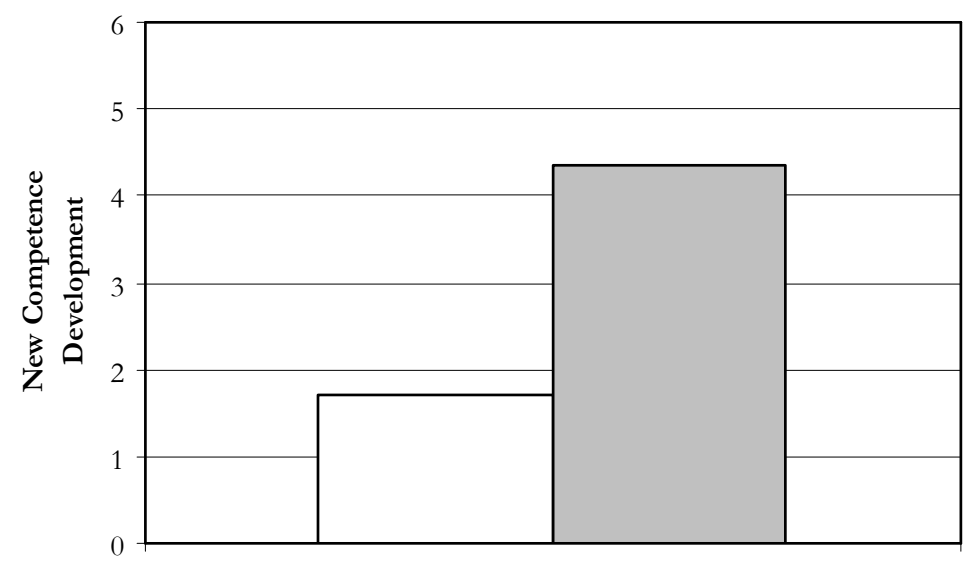

Knowledge Redundancy

$\square$ Low knowledge redundancy $\square$ High knowledge redundancy

Figure 3.3 Effect of Knowledge Redundancy on New Competence Development WHEN FIRM MEMORY IS LOW

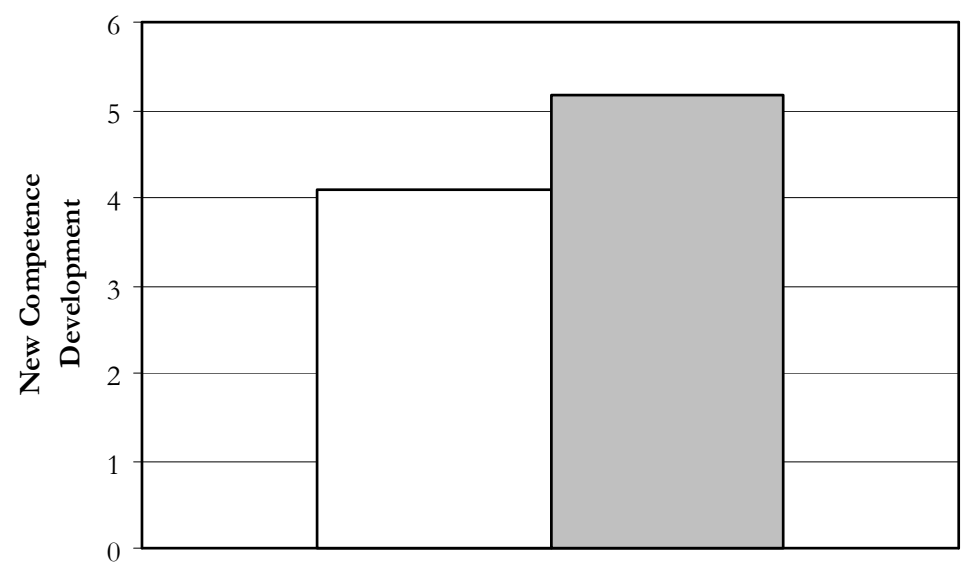

Knowledge Redundancy

$\square$ Low knowledge redundancy $\square$ High knowledge redundancy 
The second hypothesis relates to the moderating impact of knowledge redundancy on the relationship between firm memory and competence development. The results of the 3SLS estimations in Table 3.2 reveal a positive moderating effect ( $\beta$ $=.08, p \leq .05$ ). To provide a deeper understanding on how knowledge redundancy unlocks prior knowledge for new competence development, we ran additional analyses in which we estimate the effects of low knowledge redundancy (2 SD below the mean) and high knowledge redundancy (2 SD above the mean) on new competence development when firm memory is high and all other effects remain constant at their respective means. Figure 3.2 provides a graphical presentation of the outcomes, showing that moving from low to high knowledge redundancy increases the chances of competence development by more than $150 \%$ when firm memory is high. The same procedure is repeated for low levels of firm memory and the outcomes are presented in Figure 3.3. This figure again shows that chances for competence development are higher when partners have redundant (or overlapping) knowledge bases. However, the effect for low levels is not as strong as for high levels of firm memory; partners with high levels of knowledge redundancy have a new competence development score only $26 \%$ higher than that of partners with low knowledge redundancy. These simulations suggest that firms with high levels of firm memory benefit from high levels of knowledge redundancy with their co-creation partner. Moreover, the findings strengthen our confidence in the assertion that firms with high levels of firm memory suffer from inertia and fail to use their existing knowledge to develop new competencies.

We further find that some control variables have significant effects. Cocreation-specific investments have a positive effect on new competence development $(\beta=.39, p \leq .01$ ); apparently, such investments commit firms to engaging in search behavior and reaching outside their existing knowledge stocks to develop new competencies (Rindfleisch and Heide 1997). Furthermore, technological turbulence negatively affects firm financial performance $(\beta=-.15, p$ $\leq .05)$. Finally, we find that market turbulence has a positive effect on firm financial performance $(\beta=.18, p \leq .05)$ but a negative effect on firm strategic advantage $(\beta=-.12, p \leq .05)$. Although the latter findings may seem contradictory, we note that the strong positive effect of strategic advantage on financial performance compensates for the negative effect of market turbulence on strategic advantage. We elaborate on the relationship between strategic advantage and financial performance in the next section. 


\subsubsection{The Effect of New Competence Development on Firm Performance}

Although not explicitly hypothesized, our model accounts for the effects of new competence development on firm performance. The 3SLS estimates in Table 3.2 show that competence development has a direct positive effect on firm strategic advantage $(\beta=.32, p \leq .01)$ and an insignificant direct effect on firm financial performance. Furthermore, we observe a direct positive effect of strategic advantage on financial performance $(\beta=1.60, p \leq .01)$. To test for the proposed mediating role of strategic advantage on the relationship between competence development and financial performance, we conduct a Sobel (1982; 1986) test. Unlike the causal steps approach recommended by Baron and Kenny (1986) for testing mediation, the Sobel test directly estimates the indirect effect and the standard errors of the effects (Preacher and Hayes 2004). The Sobel test equation is as follows (MacKinnon and Dwyer 1993; Sobel 1982):

z-value ${ }^{13}=a^{*} b /$ SQRT $\left(b^{2 *} s_{a}{ }^{2}+a^{2 *} s_{b}{ }^{2}\right)$

The Sobel test returns a $z$-value of $2.46(p=.01)$, which implies that strategic advantage significantly mediates the relationship between competence development and financial performance. This result coincides with previous research, which concludes that the search for and integration of new, external knowledge to develop new competencies takes time before it pays off from a financial point of view, despite the relatively immediate strategic gains (Auh and Menguc 2005; Kaplan and Norton 1996; March 1991).

\subsection{Discussion and Implications}

Our research objective is to examine the ambiguous role of memory in new competence development and the potential effects of the knowledge redundancy of supply chain partners in co-creation relations. Although previous research has addressed the direct effects of relationship factors and organizational memory, the indirect role of knowledge redundancy on the relationship between memory and new competence development has been largely ignored. This study attempts to close this gap, and its findings suggest that knowledge redundancy between business customers and suppliers in co-creation relations unlocks firm memory

\footnotetext{
13 Where a $=$ raw regression coefficient for the association between the independent variable and the mediator, $s_{\mathrm{a}}=$ standard error of $a, b=$ raw coefficient for the association between the mediator and the dependent variable (when the independent variable is also a predictor of the dependent variable), and $s_{\mathrm{b}}=$ standard error of $b$.
} 
useful for new competence development. We therefore discuss our contributions, suggest future research directions, and describe some limitations of this chapter.

\subsubsection{Theoretical Contributions}

We contribute to literature related to the value of prior knowledge for capability development by providing insight into the debated role of memory for competence development; furthermore, we show that firm memory in vertical cocreation relations by itself does not stimulate firms to acquire new knowledge and skills. Rather, both marketing and technology memory separately and jointly hinder the development of new competencies. This finding is consistent with prior research warning about the automatic and tacit nature of memory, especially routines and entrenched worldviews (e.g., Walsh 1995; Walsh and Ungson 1991). Our results also extend prior empirical research that examines the effect of memory on product outcomes (Kyriakopoulos and de Ruyter 2004; Moorman and Miner 1997). We research the effect of memory not on product outcomes but on the ability of a firm to develop new competencies, which is crucial because new competencies are necessary for the success of new product development (e.g., Gatignon et al. 2002).

Our results indicate that firms should engage in vertical co-creation relations that exhibit high knowledge redundancy to overcome the inertia and blind spots of prior knowledge. Specifically, we reconcile opposing views regarding the relationship of memory with new competence development by showing that knowledge redundancy with a partner activates the use of existing knowledge (i.e., firm memory) to stimulate new competence development by the focal company. At least in part, this finding explains why companies increasingly engage in joint NPD projects (Sivadas and Baker-Prewitt 2000).

Our findings also relate to capability research, which focuses mainly on the consequences of capabilities (e.g., Henderson and Cockburn 1994; Moorman and Slotegraaf 1999). We deviate from this focus and examine instead their genesis. We thus join a small group of studies (e.g., McEvily and Marcus 2005) seeking to understand how firms develop new competencies. In addition, whereas previous research emphasizes intrafirm (e.g., Cohen and Levinthal 1990) or interfirm (e.g., McEvily and Marcus 2005) sources of new competencies, we combine both sources in one study and investigate their individual and joint effects.

Yet another implication of our research relates to interfirm literature, which typically deals with ways to benefit from collaborations. Thus, previous research investigates such important issues as the structure of collaborations (e.g., 
Kogut 1988), new product advantage (e.g., Bonner and Walker 2004), cooperative competency (e.g., Sivadas and Dwyer 2000), and the acquisition and use of information (e.g., Rindfleisch and Moorman 2001). However, we attempt to answer, at least in part, Lane and Lubatkin's (1998) call for a focus on with "whom" to partner rather than "how" to partner. Our research affirms that knowledge redundancy represents an important selection criterion for co-creation projects with channel members. Existing knowledge is most likely to be fruitful for new competence development when firms select partners that hold knowledge related to their own.

\subsubsection{Managerial Contributions}

Our findings also have important implications for practice. Managers of NPD projects should be aware of the interaction between organizational memory and knowledge redundancy with their partners. Traditionally, partners holding similar knowledge have been regarded as less attractive parties for new competence development. Our results, however, indicate that knowledge redundancy of supply chain partners helps to unlock firms' prior existing knowledge for recombination and helps them to develop those competencies necessary in the co-creation relation.

Moreover, firms can conclude from this research that fears of knowledge destruction or value depreciation are not justified; our results show that memory is -by itself- harmful for new competence acquisition and consequently the strategic position of the firm. A more beneficial way to reap value of accumulated existing memory in new competence development is to team up with a partner that possesses knowledge related to that of the focal firm.

Finally, firms should not be discouraged by seemingly negligible effects of new competence development on financial performance. Our exploration of the financial and strategic consequences of new competence development points out that new competencies result in relatively immediate strategic advantages, but that it takes time before it pays off from a financial perspective.

\subsubsection{Limitations and Future Research Directions}

Several limitations of this chapter merit discussion. First, we focus on co-creation between customers and suppliers that take different positions in the supply chain, which explains the linear effect of knowledge redundancy. In turn, we expect inverted U-shaped effects of knowledge redundancy on competence development in horizontal collaboration. Partners in such collaborations are, by nature, 
competitors and thus may lack a common knowledge base or have nearly perfect overlap, which would inhibit their competence development. We therefore encourage researchers to examine the extent to which our findings generalize to other co-creation types, such as between competitors. Insights into the differences across these settings could bring greater clarity to the discussion about linear versus inverted U-shaped effects.

Second, our study does not distinguish between basic (i.e., general understanding of traditions and routines related to the new product) and specialized (i.e., knowledge diversity) knowledge (Cohen and Levinthal 1990; Lane and Lubatkin 1998). Further research on the relative effects of these two types of (non)redundant knowledge could improve understanding of how relationship characteristics might overcome the negative effects of memory.

Third, our outcomes derive from the performance of products that were launched no more than two years prior to the study. This decision stems from business managers' remarks that product managers have a better memory of products launched recently. However, because of this approach, our financial performance indicators refer to products that have been on the market for no more than two years, which may help explain why we find that competence development negatively affects financial performance but positively affects strategic advantage. Longitudinal research could eliminate this concern. 


\section{Chapter 4: Co-Creation Knowledge Transferability: The}

\section{ROLE OF KNOWLEDGE TYPE, TIE STRENGTH, AND TURBULENCE}

Knowledge gained from collaborative relationships is claimed to be valuable for partners because of its potential for reapplication in other contexts. Despite this asserted importance, virtually no research examines such potential. Therefore, this chapter considers the transferability of knowledge acquired during collaborative relations to individual partners' own products, projects, processes, and relations rather than knowledge transfer within the partnership or intrafirm transfers of best practices. Data from 246 vertical co-creation projects in the manufacturing industry indicate that co-creation knowledge does not automatically qualify a firm for sustained success. Rather, the transfer potential of co-creation knowledge differs in conditions of strong versus weak ties and varying levels of turbulence. Firms should therefore conduct careful, upfront evaluations of the transferability of knowledge. 


\subsection{Introduction}

Knowledge transfer represents an important area in theories of organizational learning and knowledge management (e.g., Argote et al. 2003; Szulanski and Jensen 2006). Research thus focuses on understanding the factors that affect the success of such transfer (e.g., Simonin 1999b) using two approaches. The first focuses on intra-organizational transfer of firm-specific practices (Szulanski et al. 2004; Winter and Szulanski 2001) and builds on the notion of replication of routines, derived from evolutionary economics (Nelson and Winter 1982). This approach investigates the attributes of knowledge (Winter 1987; Zander and Kogut 1995) that shape the success of its transfer. The second approach focuses on interfirm relations, such as new product alliances or joint ventures, to research interorganizational knowledge transfer (Cohen and Levinthal 1990; Hamel et al. 1989; Mowery et al. 1996; Rindfleisch and Moorman 2001; Song et al. 2005). Existing literature on knowledge diffusion in collaborative settings, for example, examines the social relationship factors and processes that facilitate the transfer of knowledge between partners (Cohen and Levinthal 1990; Lane and Lubatkin 1998; Mowery et al. 1996).

We build on these ideas but take a different perspective. Specifically, though an important theoretical and managerial issue, minimal research empirically examines the actual transferability of new knowledge from collaborative relations to individual firms' own products, projects, processes, and relations. We contribute to existing literature on knowledge transfer by taking a first step in filling the lacuna involving intrafirm transferability of interfirm knowledge. We build on the premise that reapplication or spill-over potential in contexts other than the focal relationship becomes more crucial to achieving competitive advantage than immediate outcomes (e.g., the new product in co-creation relations) (Argote and Ingram 2000; Hamel 1991). This focus unites two disparate fields of research, because we consider the intrafirm transferability of interfirm generated knowledge.

But what makes co-creation knowledge an interesting study context? Because co-creation represents an interactive form of external learning (McEvily and Marcus 2005) compared with other forms (e.g., observation, consulting, competitive benchmarking), its potential value for other intra- and/or interfirm uses may hinge on the relational setting in which it was developed. That is, we argue that the context in which the co-creation knowledge was developed affects not only knowledge transfer within the relationship (e.g., Cross and Sproull 2004; Hansen 1999) but also the firm-specific usefulness of the developed knowledge, 
beyond the co-creation relation. First, we propose that individual partners' opportunities to extract value from co-creation knowledge (i.e., transfer to situations outside the relationship) are functions of the impact of knowledge types. Therefore, we investigate two knowledge types: marketing innovation (knowledge that challenges existing mental market models) and marketing refinement (knowledge that refines existing processes). Although previous research mentions the relevance of both knowledge types for transfers (e.g., Winter and Szulanski 2001), none has empirically examined them simultaneously. Second, we posit that the types of knowledge interact with (1) the closeness of the co-creation relation in which the knowledge initially was developed and (2) environmental turbulence and therefore theorize that both factors affect the transferability of co-creation knowledge.

We conceptualize transferability as the extent to which marketing knowledge developed within a vertical co-creation relation can be used by the partner firms in situations outside their current relationship. In other words, we examine the extent to which knowledge developed in co-creation relations can be transferred by partners to situations (both in- and outside their own firm) outside the co-creation relation. Thus, in contrast to most prior research, we do not study the amount of knowledge acquired from a co-creation relation as the primary outcome of the transfer process; rather, we study it as an input that provides a means to assess transfer potential to other situations, after the co-creation relation ends.

In the next sections, we elaborate on the literature pertaining to knowledge transfer. We also explain our conceptual framework and build a set of testable hypotheses. We empirically test our ideas using a sample of co-creation projects in the Dutch manufacturing industry and conclude with a discussion of the implications of our findings for theory and practice, as well as suggestions for further research.

\subsection{Co-Creation Knowledge Transferability}

In this section, we provide an overview of existing literature related to knowledge transfer and describe the mechanisms by which co-creation knowledge transferability operates.

\subsubsection{Definition}

The concept of knowledge transferability builds on previous notions of replication strategy (Winter 1987; Winter and Szulanski 2001), knowledge transfer (Argote and Ingram 2000), intrafirm diffusion of technology (Cool et al. 1997), and 
interfirm information diffusion (Rindfleisch and Moorman 2001). We define transferability as the extent to which individual partners can use marketing knowledge (here, marketing innovation and marketing refinement) developed during their vertical co-creation relation in situations outside the initial relation. This conceptualization differs from previous research on knowledge transfer in several ways. First, we aim to obtain insights into the reapplication potential of knowledge generated through co-creation relations for future use and therefore study the value of knowledge instead of focusing on specific aspects of the transfer process, such as the speed (Zander and Kogut 1995), accuracy (Szulanski and Jensen 2006), or efficiency (Grant and Baden-Fuller 2004; Winter and Szulanski 2001) of the transfer.

Second, we explicitly recognize that knowledge is socially constructed and therefore potentially dependent on the relational and environmental context in which it gets developed (e.g., Hansen 1999). Specifying the development context is important because that context affects transfer costs differentially (Edmondson et al. 2003; Grant and Baden-Fuller 2004). Typical definitions of knowledge transfer do not detail the context in which the transferred knowledge originated; for example, Argote and Ingram (2000, p. 151) simply define knowledge transfer as "the process through which one unit is affected by the experience of another." In contrast, we specifically examine intrafirm replication (which occurs after the end of a co-creation relation) of knowledge that originated in an interfirm new product development relationship between a supplier and a customer ${ }^{14}$.

\subsubsection{Mechanisms Underlying Transferability}

The nature of knowledge substantially affects knowledge ambiguity and the chances for knowledge transfer (e.g., Mowery et al. 1996; Simonin 1999a; Zander and Kogut 1995). Generally, knowledge inertness, knowledge immobility, and the degree to which knowledge is tacit, context specific, and complex represent factors that can hamper its efficient transfer (e.g., Reed and deFillippi 1990). Winter (1987) finds that knowledge transfer is less problematic when the knowledge is observable in use, teachable, articulated, and independent (versus embedded in a system of interdependent information).

\footnotetext{
14 Transferability is an intrafirm variable in the sense that it is measured as the extent to which the focal firm (one of the partners) can use marketing knowledge outside its original context. Note, however, that this is both within and outside the focal firm in, for example, new and other relationships, NPD projects, or processes.
} 
Literature on knowledge transfer suggests two broad descriptive mechanisms that underlie co-creation knowledge transferability: efficiency and scope (see, for example, Edmondson et al. 2003). First, although many explanations are available for decreased knowledge transfer potential within relationships, most point to efficiency losses caused by increases in (mental) costs and the related transfer difficulty and slowness. Several authors (e.g., Hansen 1999; Winter and Szulanski 2001) argue that knowledge transfer from one context to another can involve substantial costs and time, especially when the knowledge is complex, because the interactions between the different knowledge components are poorly understood. Knowledge specificity (e.g., to the relationship) creates new problems for the transfer, whose solution requires learning by doing (Simonin 1999a). Similar reasoning applies to inert or sticky knowledge, which depends on its context and therefore calls for knowledge reconstruction and adaptation (Szulanski 2000). In addition to the nature of the knowledge, collaborations between firms can increase interactive complexity and dampen the decomposability of causal linkages between actions and results (Kotabe et al. 2003). Thus, firms may find that the likelihood of knowledge transfer depends on the time and costs involved, which in turn affect the reapplication of co-creation knowledge in other situations.

Second, the scope of transferability, or the degree to which co-creation knowledge suitably may be reapplied to a wide range of contexts, depends largely on the degree to which the transferred knowledge is specific to a particular situation, relationship, or environment (Kotabe et al. 2003; Nonaka 1994; Szulanski 2000; Winter and Szulanski 2001). Transferability scope has particular importance in vertical co-creation relations because co-creation knowledge might serve not only firm-specific purposes such as idea generation but also relations with other customers or suppliers (Song et al. 2005). Developing knowledge and skills unique to a relationship benefits knowledge transfer in the co-creation relation in terms of uncertainty reduction and increased specialization (Fichman and Levinthal 1991; Kotabe et al. 2003, respectively), but may be of limited use in contexts outside that relationship after the co-creation relation ends (e.g., product launches).

\subsection{Conceptual Framework}

In line with the conceptual framework in Figure 4.1, we develop hypotheses on the basis of a brief review of the literature pertaining to the relationships among the key constructs. 
Figure 4.1: CoNCEPTUAL FramewORK

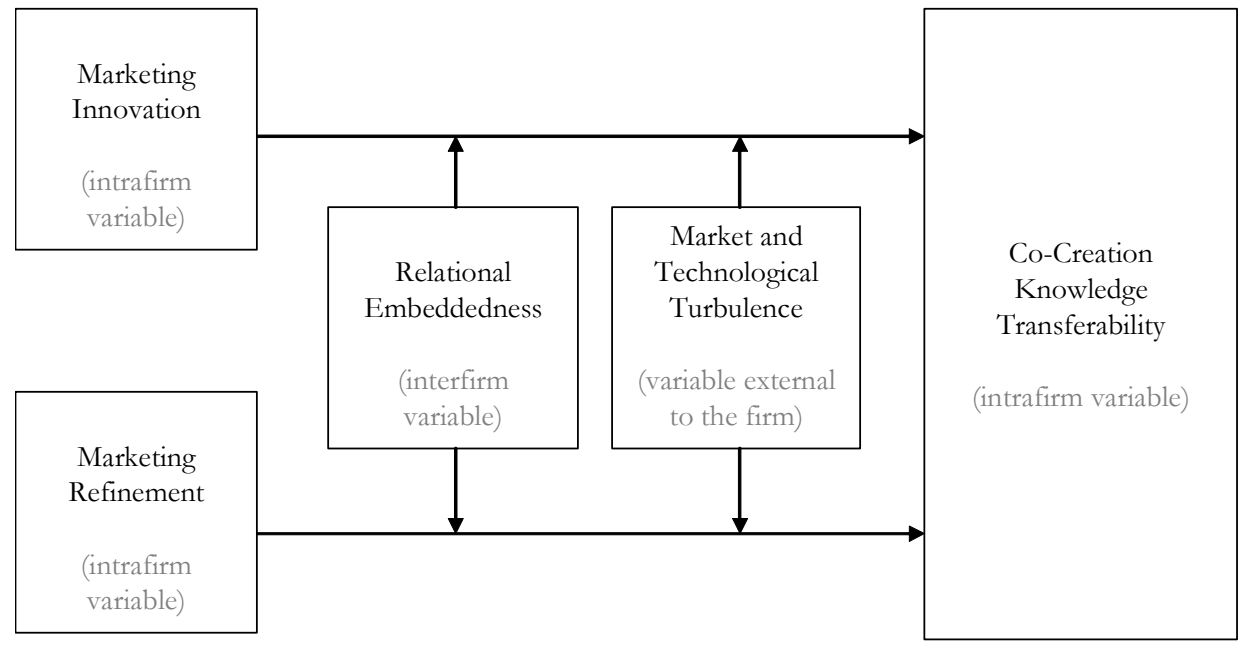

\subsubsection{Co-Creation Knowledge: Marketing Innovation and Marketing Refinement}

The (inter)organizational learning theory contains plentiful learning typologies (e.g., Argyris 1976; Holmqvist 2003; Huber 1991; March 1991). To conceptualize and define the two knowledge types of interest here (i.e., marketing innovation and marketing refinement), we draw on the distinction between exploratory and exploitative learning (e.g. Kyriakopoulos and Moorman 2004; March 1991), also commonly referred to as single- and double-loop learning (Argyris 1976). We define marketing innovation and refinement according to the outcome view of learning (producing new knowledge) rather than the process view (e.g., experimentation, open-minded search, creative problem solving). Marketing innovation, then, consists of new marketing knowledge that challenges existing approaches to interfacing with the market (i.e., the established mental market model). For example, marketing innovation can encompass new positioning strategies, new ways of serving customers, new channels, or other marketing mix elements (Kyriakopoulos and Moorman 2004). In contrast, marketing refinement refers to new marketing knowledge that improves existing mental models of the market, such as improved product features (e.g., a similar but slightly smaller mobile phone), sharpened segmentation, or efficiency increases in the distribution channel.

Both marketing innovation and marketing refinement represent suitable candidates for knowledge transfer, because both affect knowledge transferability 
through underlying mechanisms described previously. Thus, both co-creation knowledge types can transfer to contexts outside the relationship, because transfer costs are low (efficiency) or because they apply to a multitude of areas (scope). We discuss the arguments associated with each knowledge type next.

Marketing innovation constitutes a complex system of multiple, interdependent pieces of knowledge embedded in a larger system (Arora and Gambardella 1994), which means that to understand what knowledge should be transferred, we must first understand the larger system. Moreover, to understand and integrate the causal linkages in new contexts, additional learning efforts are required (Hansen 1999). This problem gets aggravated when the larger system in which the marketing innovation is embedded is diffused across people, departments, or firms (Simonin 1999a). In this case, time and effort must be expended on extensive dialogue and interactions to uncouple the knowledge from its application (Nonaka and Takeuchi 1995; Spender 1996). The transfer of marketing innovation from an interfirm to an intrafirm application therefore involves substantial costs.

In contrast, marketing refinement involves more readily useable knowledge because it is based on refining and optimizing existing routines (March 1991). Therefore, the (mental) costs, difficulty, and time involved in decomposing the knowledge into interpretable chunks of information, before transferring it to contexts outside the relationship, remain rather low (Levinthal and March 1993; Szulanski 2000). That is, the unambiguous nature of marketing refinement allows for fast, easy, and inexpensive transfer, which enhances efficiency. In summary, the transferability of marketing refinement should be more efficient than that of marketing innovation, because its characteristics make the transfer faster, easier, and less costly.

Furthermore, the characteristics of marketing refinement and innovation affect transferability through the scope of the process. Marketing innovation results from experimentation and extensive information search during conscious attempts to challenge mental market models (e.g., finding new ways to bring products to market), which means it is broad in nature and consists of multiple, interdependent sets of knowledge (Kotabe et al. 2003). Consequently, several elements of the total set of co-creation knowledge (or even the entire set of knowledge) may be useful in multiple situations (Mowery et al. 1996). Thus, marketing innovation is not likely to be specific to a certain context and therefore suitable for transfers of broad scope. 
Marketing refinement, however, results from local search processes (Rosenkopf and Nerkar 2001) or firms' search for solutions that are closely related to their current expertise or knowledge (Stuart and Podolny 1996). Furthermore, marketing refinement involves sequential adaptations to optimize processes (Fleming and Sorenson 2004). Therefore, it likely relates to a specific product adaptation brought about by a supplier and customer. In terms of transferability scope then, marketing refinement may have limited potential for other relationships, environments, or products of the firm.

On the basis of these rationales, we may conclude that the effect of marketing innovation on transferability is positive through its impact on transferability scope, as is the effect of marketing refinement but, in this case, because of its impact on efficiency. In turn, we hypothesize the following:

$\mathrm{H}_{1}$ : The effect of (a) marketing innovation and (b) marketing refinement on transferability is positive.

\subsubsection{The Moderating Role of Relational Embeddedness}

Transferability depends on the degree of (interactive) complexity, that is, the degree to which causes can be attributed to effects (Levinthal and March 1993). Social network theory claims that partnerships with high levels of relational embeddedness (i.e., the degree of closeness in the social relationship between the supplier and the customer) develop relationship-specific knowledge and assets (e.g., shared understanding, routines) (e.g., Galbraith 1990; Kotabe et al. 2003; Wasserman and Faust 1994). Although tie strength accelerates knowledge transfer in interfirm relationships (e.g., Dyer and Singh 1998; Hansen 1999), its effect differs for the subsequent intrafirm transfer of interfirm knowledge to situations outside the relationship.

For marketing innovation, relationship-specific knowledge should complicate the attribution of actions to results (i.e., increase ambiguity) because the actions of the companies get intertwined (Lounamaa and March 1987). Therefore, close relationships cause marketing innovation to separate from the individual firm and become more embedded in the relationship (Brown and Duguid 1991; Selnes and Sallis 2003). Knowledge thus takes the form of interfirm rather than intrafirm know-how. This context dependence makes it even harder to turn marketing innovation into actionable knowledge for future applications. The combination of marketing innovation and close relationships further decreases efficiency and cancels potential scope benefits. 
In contrast, close relationships should boost the transfer of marketing refinement, which entails developing knowledge about existing routines and processes. Close relationships increase the observability of the cause-and-effect relationships of routines created within the collaborative context (Hansen 1999), so marketing refinements may be transferred more efficiently when knowledge originates from close relationships. Moreover, higher levels of relationship-specific knowledge enable partners to benefit from refining their routines associated with, for example, NPD (Dyer and Singh 1998). Therefore, relational embeddedness should make marketing refinements relatively less mundane, and the resulting routine variety should make marketing refinements more broadly applicable in other contexts.

These arguments imply conflicting effects of strong ties on the transferability of marketing innovations versus marketing refinements:

$\mathrm{H}_{2}$ : Relational embeddedness (a) attenuates the effect of marketing innovation on transferability and (b) strengthens the effect of marketing refinement on transferability.

\subsubsection{The Moderating Role of Environmental Turbulence}

Turbulence reflects the rate of change in an environment; more specifically, market turbulence refers to the perceived rate of change in customers and customer preferences (Jaworski and Kohli 1993), whereas technological turbulence refers to the rate of change in technological processes (Jaworski and Kohli 1993). We posit that the degree of change in an environment can influence the transferability of both co-creation knowledge types.

Literature on the effect of environmental turbulence suggests two competing effects. First, attributions about the cause-and-effect relationships for marketing innovation involve an effortful, frustrating, and time-consuming task (Szulanski 2000; Winter and Szulanski 2001). High market turbulence complicates the issue by requiring fast responses (Urban et al. 1986) and introducing an additional source of ambiguity (Winter and Szulanski 2001). Such turbulence demands additional trial-and-error processes and is therefore more costly in terms of time and efficiency. These arguments suggest a negative effect of turbulence on the transferability of marketing innovations.

However, highly turbulent environments also might have positive effects. Marketing innovation consists of multiple, interdependent pieces of knowledge and therefore tends to encompass an overall capability (Mowery et al. 1996), such 
that the firm learns how to do things rather than learning about certain facts in a specific situation (Edmondson et al. 2003; Grant 1996). Knowledge about how to do things increases firms' flexibility (Achrol 1991) and idea diversity (Song et al. 2005) when they respond to rapidly changing environments. Therefore, the scope benefits that derive from environmental turbulence could have positive effects on marketing innovation.

Both arguments pertaining to the effect of environmental turbulence on the transferability of marketing innovations are compelling, so we propose:

$\mathrm{H}_{3 \mathrm{a}}$ : Environmental turbulence attenuates the positive effect of marketing innovation on transferability.

$\mathrm{H}_{3 a(a \mathrm{lt})}$ : Environmental turbulence strengthens the positive effect of marketing innovation on transferability.

Marketing refinement, which is specific to a situation, requires firms to learn what to do to solve a situation but not more general capabilities (Mowery et al. 1996). Because refinement results from local search processes and is specific to its context (Fleming and Sorenson 2004), rapidly changing environmental conditions may compound the difficulties of transferring marketing refinement to a broad range of contexts and thus render such knowledge obsolete. In stable markets, marketing refinement should be easy to decompose into different pieces of knowledge and thus efficiently transfer to other contexts. However, when environments change quickly, co-creation knowledge pertaining to marketing refinements may be too specific to be reapplied in other circumstances. Therefore, we propose:

$\mathrm{H}_{3 \mathrm{~b}}$ : Environmental turbulence attenuates the positive effect of marketing refinement on transferability.

\subsection{Research Method}

In elaborating on the steps we have undertaken to investigate the role of knowledge type, relational embeddedness, and environmental turbulence on transferability, we next present our empirical analyses.

\subsubsection{Empirical Context}

This chapter examines the extent to which knowledge developed previously in cocreation relations can be applied to (or is relevant in) contexts outside that relationship or the new product developed. We test our model using a cross- 
sectional survey methodology and 246 Dutch manufacturing firms that had taken part in a co-creation relation. Each firm received an individualized management report in return for its participation.

We used Dun \& Bradstreet's Market Direct database to obtain the telephone numbers and mailing addresses of all Dutch manufacturing firms with more than 50 employees, which gave us a list of 3,146 companies that we contacted by phone to determine whether they met the sample requirements and verify their mailing addresses. Participants must have been engaged in a vertical (customer-supplier) co-creation relation from at least the development stage; we excluded companies that did not meet this requirement $(n=1,376)$ or that we could not be contact for other reasons (e.g., independent subdivisions of parent companies with central NPD departments, bankruptcy, outdated telephone numbers) $(\mathrm{n}=910)$. The sampling frame for the final survey therefore consists of 860 firms, from which we collected 246 responses, for a response rate of $28.6 \%$. When we test for nonresponse bias by comparing early respondents (ER) and late respondents (LR) (Armstrong and Overton 1977), we find no differences on the measures we use in this study ${ }^{15}$. An additional test that considers the objective observation of the number of employees (categorized from 1 to 7 ) in the respondent's business unit also reveals no differences across ER and LR ${ }^{16}$.

We targeted as our key informants the team leaders of the co-creation project, who have high levels of knowledge about the firm and play boundaryspanning roles with the partner. In terms of their direct involvement in the cocreation project, respondents scored an average of $6(\mathrm{SD}=1.33$ ) (scale of $1=$ low to $7=$ high). The mean score for cooperation with the partner across the five stages of NPD was $5.1(1=$ low, $7=$ high $)(\mathrm{SD}=1.6)$. Long-standing relationships with the partner (mean $=11$ years, $\mathrm{SD}=12$ years) and respondents' extensive experience in their position as a co-creation team leader (mean $=9$ years, $\mathrm{SD}=8$ years) enhance our confidence in the data.

\subsubsection{Measurement of Key Model Constructs}

After in-depth interviews with five co-creation team leaders regarding the relevance and prevalence of co-creation knowledge transferability in practice, we

\footnotetext{
15 Transferability $\mathrm{ER}=4.91, \mathrm{LR}=4.84, \mathrm{t}_{(222)}=.51$, n.s.; marketing innovation $\mathrm{ER}=4.66, \mathrm{LR}=4.62$, $\mathrm{t}_{(222)}=.29$, n.s.; marketing refinement $\mathrm{ER}=4.97, \mathrm{LR}=4.92, \mathrm{t}_{(222)}=.31$, n.s.; relational embeddedness $\mathrm{ER}=5.48, \mathrm{LR}=5.52, \mathrm{t}_{(222)}=-.32$, n.s.; market turbulence $\mathrm{ER}=4.09, \mathrm{LR}=4.26$, $\mathrm{t}_{(222)}=-.99$, n.s.; technological turbulence $\mathrm{ER}=4.58, \mathrm{LR}=4.79, \mathrm{t}_{(222)}=-1.41$, n.s.

${ }^{16}$ Number of employees ER $=4.01, \mathrm{LR}=3.83, \mathrm{t}_{(191)}=1.02$, n.s.
} 
developed our survey instrument. To corroborate the measurement scales, we test and retest the survey instrument with business managers $(n=6)$ and a research panel $(n=10)$. Four persons fluent in both English and Dutch cross-checked the (back) translations of the survey to ensure the meanings and interpretations of both questionnaires were compatible, though we only used the Dutch questionnaires for our data collection. The items used in the survey instrument appear in Appendix C.

Transferability. To the best of our knowledge, no existing scale describes the transferability construct within our research context. Therefore, we combine scales from other relevant empirical work to create a preliminary list of scale items (e.g., Gatignon et al. 2002; Kyriakopoulos and Moorman 2004). Specifically, we use Kyriakopoulos and Moorman's (2004) scale to identify critical aspects in marketing strategies and Gatignon et al.'s (2002) scales to gain an idea of how to conceptualize applied learning outcomes in terms of knowledge areas. On the basis of our in-depth interviews, we eliminated several items from the preliminary set of questions. The six items we retained assess the relevance of the following co-creation knowledge elements outside the initial relationship: (1) new knowledge concerning the firm's communication strategy, (2) new knowledge with regard to marketing concepts, (3) knowledge with regard to marketing skills, (4) knowledge from a new or different knowledge base, (5) knowledge on the application of marketing tactics, and (6) knowledge resulting from retraining.

Marketing innovation. We adapt Kyriakopoulos and Moorman's (2004) measurement scale to measure marketing innovation and thus ask respondents to indicate the extent to which their firm has learned to take different and more effective marketing actions as a result of working with the partner. This approach enables us to capture two key characteristics of "thinking outside the box," namely, novelty and usefulness (Amabile 1983; Lubart 1994). Usefulness often appears as a part of measures of innovation and creativity because it implies the knowledge can be used and thus does not suffer from a lack of practical relevance (e.g., Amabile 1983). The final scale version consists of the following marketing actions: (1) targeting and segmentation, (2) product positioning and differentiation, (3) distribution, and (4) communication and promotion.

Marketing refinement. The scale for marketing refinement mirrors that for marketing innovation, except for the instructions we provided to respondents. That is, we ask respondents to rate the degree to which existing marketing actions were optimized during the co-creation project. This approach falls in line with the generally accepted view of refinement as comprising efficiency increases and 
improvements over existing practices within the firm (e.g., Auh and Menguc 2005; March 1991).

Relational embeddedness. The measurement scale for our first moderator is based on Rindfleisch and Moorman's (2001) four-item scale. The items tap the degree to which partners in co-creation relations share close social relations and consist of the following items: (1) Our new product development team members share close social relations with our partner's new product development team members, (2) The relationship with our partner can be defined as "mutually gratifying," (3) We expect that we will be working with our partner in the future, and (4) We expect that we will be working with our customer in the future.

Market and technological turbulence. We measure environmental turbulence, the second moderator, according to two contexts, namely, market and technological turbulence. Market turbulence refers to respondents' perceived rate of change in customer sets and customer preferences, whereas technological turbulence refers to the rate of change in the technological processes of the industry. We operationalize the two measures on the basis of Kohli and Jaworski's (1993) measurement scales.

In addition to these key model constructs, we include the following control variables: (1) marketing memory, or the amount of prior knowledge, insights, and information about marketing aspects of the product category, which may affect transferability as a result of the prior experiences or routines stored by the firm; (2) technology memory, or prior knowledge, insights, and information about research and development in the product category; and (3) knowledge redundancy, or the similarity of partners' NPD-related knowledge bases. Firms need prior knowledge about marketing and technological processes to understand the link between routines and processes (Moorman and Miner 1997), and when they understand those links, their transfer potential may increase, because transfer requires the application of knowledge from one situation to another. Knowledge redundancy between partners, serves as a control variable because it may affect the degree to which the partners have managed to understand the co-creation knowledge.

\subsubsection{Construct Validation}

We assess measure validity by conducting exploratory and confirmatory factor analyses. For the exploratory factor analysis, we apply the principle component extraction method with Varimax rotation. The KMO Bartlett test shows a $p$-value 
of .00. On the basis of the results of this step, we delete several items whose loading is too low or that load on more than one factor. We also delete several items on the basis of high modification indices in the confirmatory factor analysis. The resulting goodness-of-fit measures are satisfactory $\left(\chi^{2}=1020\right.$, NNFI $=.94$, CFI $=.94$, SRMR $=.05$, RMSEA $=.05)$. The composite reliabilities for the scales are .90 for transferability, .94 for marketing innovation, .88 for marketing refinement. .71 for relational embeddedness .75 for market turbulence, and .73 for technological turbulence (see Table 4.1).

We use two different approaches to determine discriminant validity. We first compare the AVE of each variable with the squared correlations of the constructs and find substantial positive differences between the AVE and the squared correlations. Next, we construct baseline and constrained measurement models for all possible pairs of variables and use a chi-square difference test to compare their performance. The chi-square differences between the two solutions are significant $(p<.001)$, which confirms the discriminant validity between the constructs, except for that between marketing innovation and marketing refinement, whose chi-square difference test is significant only at the .10 level $(p$ value $=.08)$.

To check for potential common method bias, we subject the results of the principal components factor analysis to Harman's one-factor test. In the unrotated factor structure, we identify multiple factors and find no evidence of a general factor. Factors with an eigenvalue greater than 1 explain $69 \%$ of the total variance, and the first factor does not account for the majority of the variance $(17 \%)$. Following Podsakoff and Organ (1986), we conclude that common method variance is not a concern.

\subsubsection{Analysis Procedure}

A chi-square test ensures that all possible combinations between the two knowledge types and relational embeddedness are well represented in the sample of co-creation relations. This test requires nominal data, so we create dummy variables by applying a median split to the constructs (marketing innovation, marketing refinement, and relational embeddedness). The results from the test show a Pearson chi-square value of .28 , with a two-sided asymptotic significance level of .61. Thus, we can safely assume that the expected frequencies equal the observed frequencies across the four types of cooperation.

To estimate our hypotheses we use ordinary least square regression. We correct the model for heteroskedasticity of unknown form to ensure the standard 


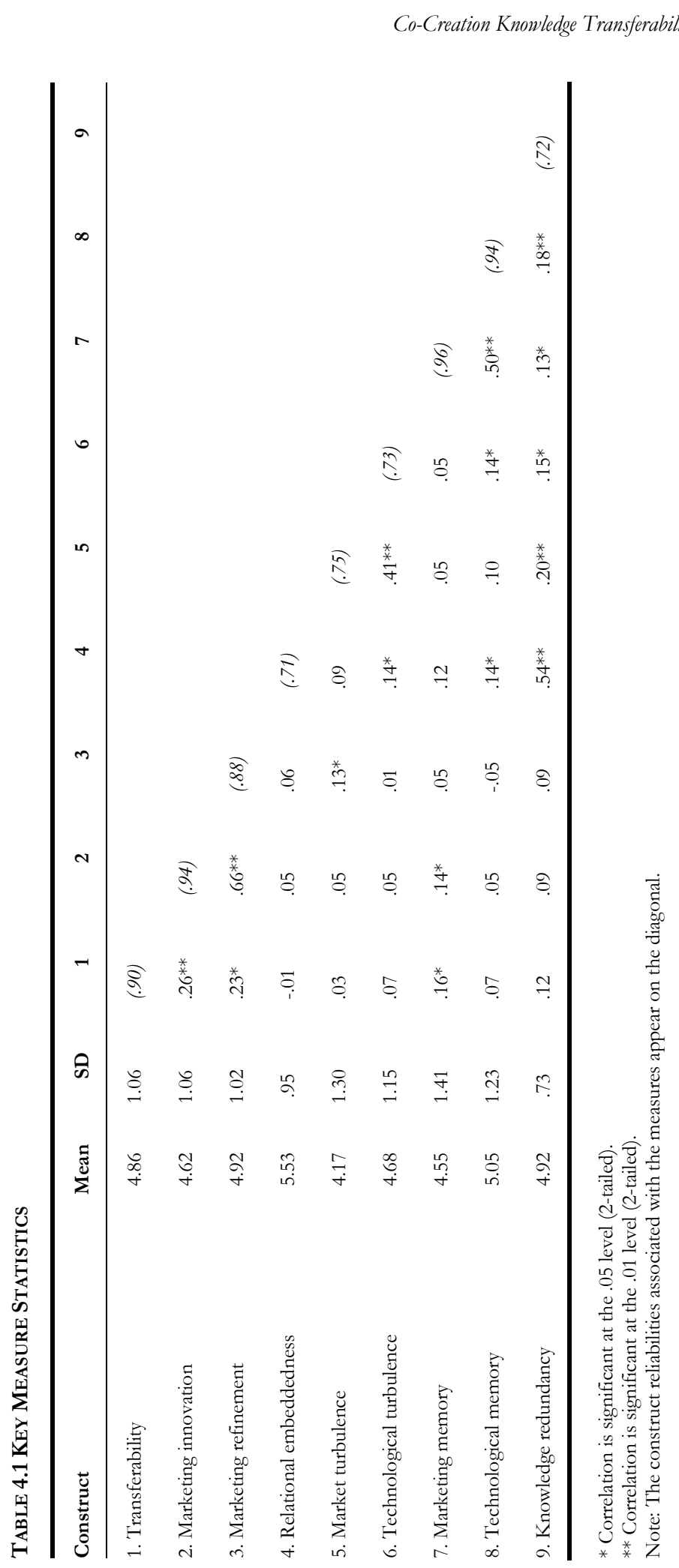


errors are robust; we also mean-center all variables before creating interaction terms to avoid multicollinearity (Aiken and West 1991). The variance inflation factors of the variables, which all fall below 3, provide no indication of multicollinearity problems (Neter et al. 1985).

\subsection{Results}

Our first hypothesis examines the effect of co-creation knowledge types on transferability and posits that the effects of both marketing innovation and marketing refinement will be positive. The results show a beta-coefficient of 24 ( $p$ $\leq .01)$ for marketing innovation, and the effect marketing refinement is also positive $(\beta=.16, p \leq .05)$ (see Table 4.2). This provides support for $\mathrm{H}_{1 \mathrm{a}}$ and $\mathrm{H}_{1 \mathrm{~b}}$ at mean levels of the moderators in the model.

In $\mathrm{H}_{2}$, we predict a negative moderating effect of relational embeddedness on marketing innovation and a positive moderating effect on marketing refinement. The results support these predictions $(\beta=-.15, p \leq .05 ; \beta=.14, p \leq$ .05 , respectively). Figures 4.2 and 4.3 contain the graphical representations of the interaction effects of $\mathrm{H}_{2}$. The slopes of the regression lines of the two moderating effects (relational embeddedness $x$ marketing innovation and refinement) differ significantly in the post-hoc analyses in which we constrain the difference of the slopes to $0(p \leq .05)$. Therefore, the interaction of relational embeddedness and marketing innovation is significantly different than that of relational embeddedness and marketing refinement.

Additional probing (as recommended by Preacher et al. 2006) shows that the slope of marketing innovation is positive $(\beta=.39, p \leq .01)$ for low levels $(-1$ $\mathrm{SD})$ and insignificant $(\beta=.10, p \geq .05)$ for high levels $(+1 \mathrm{SD})$ of the moderator. Marketing refinement is insignificant $(\beta=.03, p \geq .05)$ for low levels and positive $(\beta=.30, p \leq .01)$ for high levels of relational embeddedness ${ }^{17}$.

We hypothesize that environmental turbulence would attenuate $\left(\mathrm{H}_{3 \mathrm{a}}\right)$ or strengthen $\left(\mathrm{H}_{3 \mathrm{a}(\mathrm{alt})}\right)$ the relationship between marketing innovation and knowledge transferability. We find a negative moderating effect of market turbulence $(\beta=$ $.22, p \leq .01)$ and no effect of technological turbulence $(\beta=.11, p \geq .05)$. We thus find partial support for $\mathrm{H}_{3 \mathrm{a}}$ but not for $\mathrm{H}_{3 \mathrm{a}(\mathrm{alt})}$. Figure 4.4 depicts the positive effect of marketing innovation on transferability for low market turbulence and the

\footnotetext{
17 The range of observed values for the moderator (relational embeddedness) is [-4.20, 1.47]. Marketing innovation is significant between -4.20 and .45. Marketing refinement is significant between -.12 and 1.47 .
} 
TABLE 4.2: REgRESSION RESULTS (ROBUST ESTIMATION)

Dependent Variable

Transferability

Independent Variables

Coeff.

SE

\section{Control Variables}

Marketing memory

.08

.06

Technology memory

.02

.06

Knowledge redundancy

$.19 *$

.10

\section{Main Effects}

Marketing innovation (MI)

Marketing refinement (MR)

Relational embeddedness (RE)

Market turbulence (MT)

Technological turbulence (T'T)

\section{Interaction Effects}

RE*MI

$\mathrm{RE} * \mathrm{MR}$

MT*MI

TT*MI

MT*MR

TT*MR

$\begin{array}{ll}-.15^{* *} & .06 \\ .14^{* *} & .06 \\ -.22^{* * *} & .09 \\ .11 & .08 \\ .09 & .06 \\ -.12^{*} & .07\end{array}$

\section{Overall Model}

R-squared

$* p \leq .10$.

$* * p \leq .05$.

$* * * p \leq .01$.

Notes: The $\Delta \mathrm{F}$-statistics are significant for the addition of the main effects and, consequently, the interaction effects to the model (Significance F-change model $1 p=.02$, model $2 p=.00$, $\operatorname{model} 3 p=.02$ ).

negative effect when market turbulence is high. The slope of marketing innovation is significant for low levels of market turbulence $(\beta=.53, p \leq .01)$, but not for high levels $(\beta=-.04, p \geq .05)$.

The moderating effect of market turbulence on refinement is not significant $(\beta=.09, p \geq .05)$, and the interaction between technological turbulence and marketing refinement relates negatively related to transferability, though only at the $10 \%$ significance level $(\beta=-.12, p \leq .10)$. Thus, we find only partial support 
Figure 4.2 Moderating Effect of Relational Embeddedness on Marketing INNOVATION

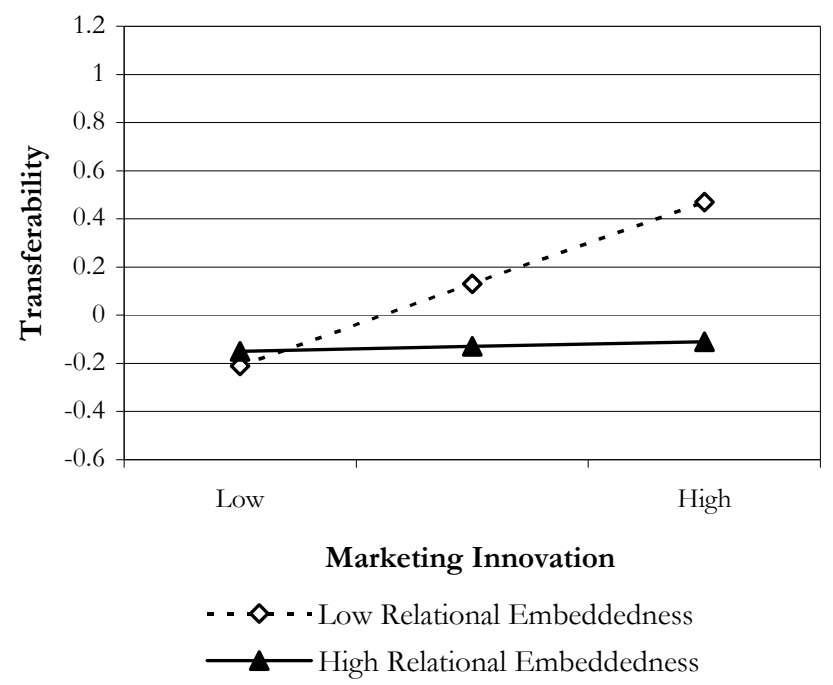

Figure 4.3 Moderating EfFect of Relational EmbedDEDNESS ON MARKETing REFINEMENT

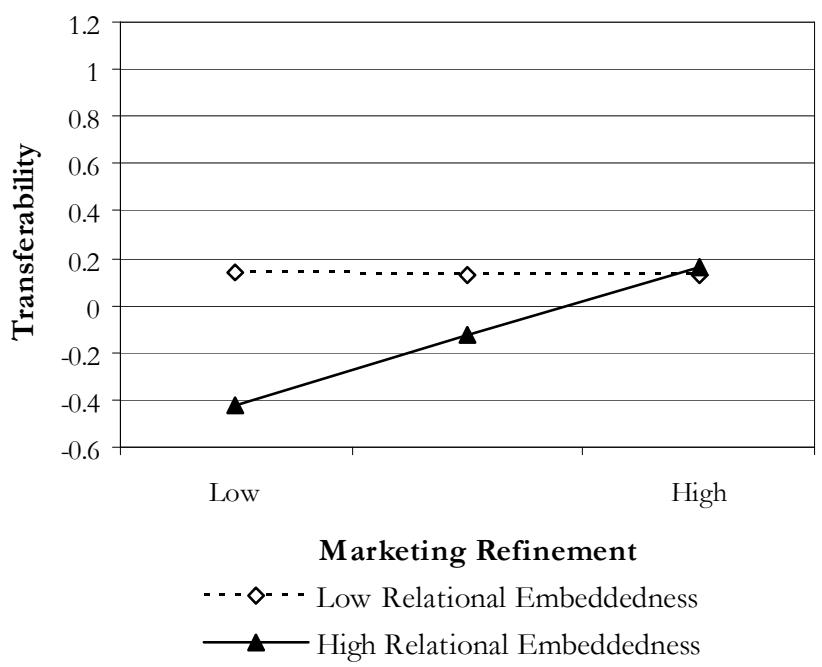


Figure 4.4 Moderating EfFECT OF MARKet TurbulenCE ON MARKETING INNOVATION

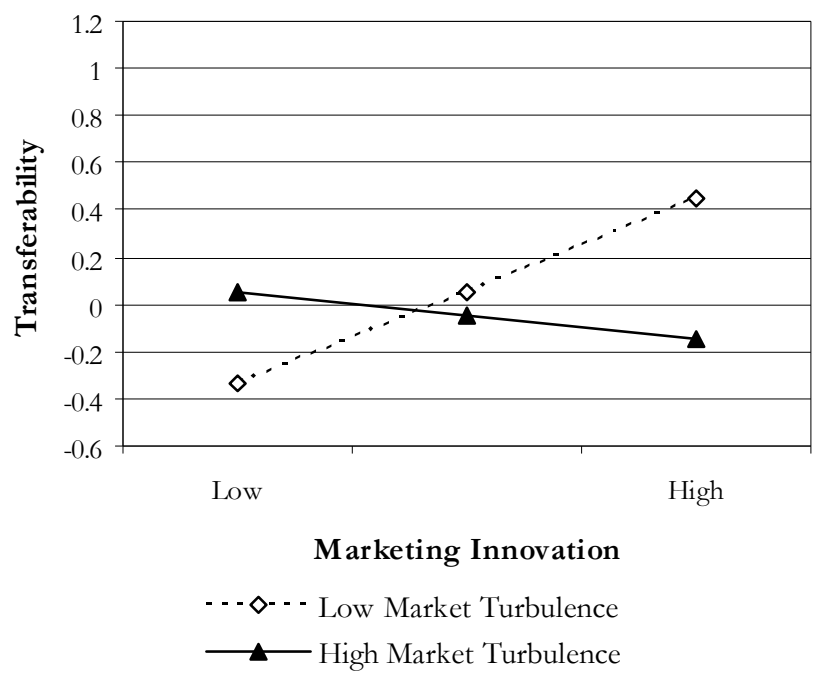

Figure 4.5 Moderating Effect of Technological Turbulence on Marketing REFINEMENT

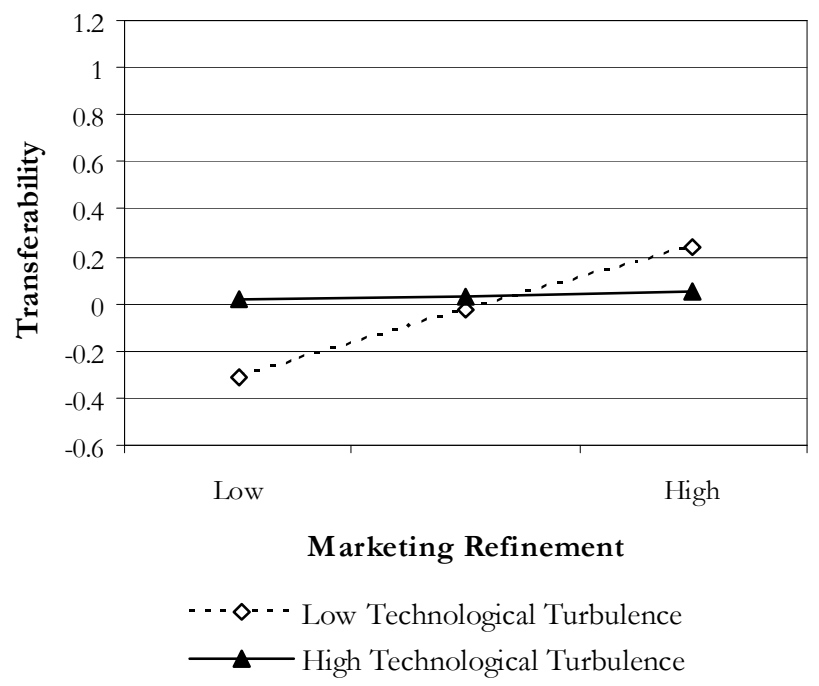


for $\mathrm{H}_{3 \mathrm{~b}}$. As the graph in Figure 4.5 shows, the impact of marketing refinement and transferability grows stronger when technological turbulence is low compared with when it is high. The slope of marketing refinement is positive and significant at low levels of technological turbulence $(\beta=.30, p \leq .01)$ and insignificant at high levels $(\beta=.02, p \geq .05)$. Table 4.3 summarizes the results of this chapter.

TABLE 4.3 Summary OF RESUlts

\begin{tabular}{lcc}
$\begin{array}{l}\text { Hypothesized relationship } \\
\text { Dependent variable: transferability }\end{array}$ & $\begin{array}{c}\text { Expected } \\
\text { sign }\end{array}$ & $\begin{array}{c}\text { Results } \\
\text { (significance level) }\end{array}$ \\
\hline Marketing innovation & + & $+(.01)$ \\
Marketing refinement & + & $+(.05)$ \\
Relational embeddedness $\times$ Marketing innovation & - & $-(.05)$ \\
Relational embeddedness $\times$ Marketing refinement & + & $+(.05)$ \\
Market turbulence $\times$ Marketing innovation & + or - & $-(.01)$ \\
Technological turbulence $\times$ Marketing innovation & + or - & n.s. \\
Market turbulence $\times$ Marketing refinement & - & n.s. \\
Technological turbulence $\times$ Marketing refinement & - & $-(.10)$ \\
\hline
\end{tabular}

\subsection{Discussion and Implications}

Whereas prior research focuses on knowledge transfer within business partnerships or firms, we unite research on interfirm and intrafirm transfer to examine the transfer potential of knowledge generated through co-creation relations to intrafirm applications that extend beyond the initial relation. This research therefore has implications for literature on both intra- and interfirm learning, in that it empirically shows that co-creation relations generate rents that extend beyond the relationship itself. This finding complements existing literature, which mainly focuses on factors within the firm or within the relationship (for an exception, see Mowery et al. 1996), with insights into the future value of knowledge gained from co-creation relations, even after the product has been launched and the co-creation relation terminated.

We next elaborate on our findings regarding the determinants of cocreation knowledge transferability and discuss some implications of this research. In addition, we acknowledge some limitations and provide recommendations for further research. 


\subsubsection{Implications}

Should firms be concerned with the type of knowledge they gain during a cocreation relation and the future value they might derive from it? We recognize that the impact of co-creation knowledge manifests itself through two routes or underlying mechanisms. Specifically, the positive main effect of marketing innovation on transferability operates through advantages derived from the transferability scope, whereas marketing refinement positively and directly affects transferability through efficiency. Because marketing innovation and marketing refinement are equally suitable for knowledge transfer, at first glance, firms should not be concerned with the knowledge types they gain from co-creation relations.

However, when we also consider the moderating effect of the knowledge development context, we observe that firms must be concerned with the type of knowledge and carefully manage their co-creation knowledge outcomes. Whereas "conventional wisdom often assumes that transferred practices are fully understood and transferred without difficulty" (Szulanski and Jensen 2006, p. 938), we show such transfer is not necessarily the norm. Instead, relational embeddedness has a dual effect on the transferability of co-creation knowledge, such that knowledge developed in close relationships hinders the transferability of marketing innovations but benefits that of marketing refinements. This pattern mimics Szulanski and Jensen's (2006) findings that the trustworthiness of knowledge sources can both increase and decrease transfer accuracy. Taken together, this research increasingly confirms relational embeddedness as a doubleedged sword with both bright and dark sides (see also Anderson and Jap 2005; Grayson and Ambler 1999).

Furthermore, our results show that the joint impact of knowledge and social ties differs during versus after a relationship. Hansen (1999) finds that noncodified, dependent knowledge (which we call innovation) is best transferred within companies that enjoy strong ties. However, codified, independent knowledge (i.e., refinement) is best transferred in weak tie conditions. We contribute to literature on knowledge transfer by demonstrating that after product launch, strong ties do not facilitate the transfer of marketing innovation; rather weak ties facilitate this transfer. In addition, we observe that increasing levels of marketing refinement benefit from strong ties rather than weak ties. Thus, the context that is beneficial during a relationship may lead to suboptimal value generation subsequent to the relationship. For example, generating marketing innovations may require close relationships, so the partners grow close enough to absorb knowledge (Lane and Lubatkin 1998). However, this relationship trait 
inhibits the transferability of that knowledge to contexts outside the relationship. Therefore, companies should not automatically assume that collaborative projects are valuable because they can transfer the associated knowledge to their other operations. Although co-creation knowledge transfer is a viable option, it is not by any means costless or effortless.

Another context effect -that of environmental turbulence- emerges as less significant than we expected. Although this finding represents good news for firms, because the environment is beyond their span of control, the results still seem surprising. Previous research has widely claimed that greater turbulence increases ambiguity about the cause-and-effect relationships of knowledge and its outcomes. In providing one of the first studies of intrafirm co-creation knowledge transfer, we explore transferability in general and do not distinguish between internal and external knowledge transferability. This generalization may explain why we fail to find a significant negative moderating effect of market turbulence on the relationship between marketing refinement and transferability. That is, marketing refinement may be transferred mainly to contexts that are internal to firms, not external relationships with other customers or suppliers. To validate this explanation, additional research should distinguish between internal and external transferability.

Furthermore, we expected technological turbulence to affect the transferability of co-creation knowledge negatively because of the greater ambiguity caused by rapid changes in technological issues. Our results, however, suggest that technological turbulence may be distant enough from marketing processes that we cannot recognize its effects on marketing innovation. In contrast to marketing refinement, marketing innovation may be broad enough to avoid the negative effects of technological changes.

Finally, the significant impact of the control variable knowledge redundancy merits attention. This finding confirms that the relationship characteristics of co-creation relations affect the degree to which learning outcomes may be transferred by individual firms. Knowledge redundancy between partners builds a common understanding and appreciation of "outside knowledge" (Sapienza et al. 2004), which then enables those individual firms to relate better to what they have learned and achieve a better position from which they can appropriate and generalize this knowledge. 


\subsubsection{Limitations and Further Research}

Several limitations of this study merit further discussion. We aimed to provide initial insights into the extent to which companies perceive knowledge from cocreation relations as useful in contexts other than the initial relationship. We opted to measure the transferability potential of co-creation knowledge for two reasons. First, to limit the effect of memory decay, we asked respondents to refer to products resulting from co-creation relations that had been launched no more than two years prior. Therefore, measuring transfer potential enables us to capture the full range of opportunities that may not have been executed at the time of our data collection. Second, firms might not exploit certain transfer opportunities for reasons other than time, such as prioritizing other projects or lacking sufficient human resources. Despite these clear rationales, we acknowledge that this field could benefit from an empirical examination of co-creation knowledge with regard to actual, rather than potential, transfer.

For our dependent variable, we use transferability; further research might extend our scope to obtain insights about the financial consequences of cocreation knowledge transfer. March (1991) predicts that innovation may be more risky but also is more attractive from a financial point of view; in parallel, marketing refinement may be less risky and less radical and therefore less profitable. Does this prediction hold when research takes into account relationship characteristics? Consistent with previous research (e.g., Hansen 1999), we note that social relations significantly influence the generation and transfer of knowledge, but the optimal combination of relational ties and knowledge characteristics appears to differ (and even conflict) during and after co-creation relations. Therefore, additional research should examine the net effect of financial gains (losses) associated with knowledge generation during co-creation relations and with co-creation knowledge transfer while simultaneously taking into account the characteristics of the relationship. Insights into these effects would improve our understanding of extended financial consequences, beyond those related to the new product.

We acknowledge that this chapter provides only a first step in exploring co-creation knowledge transferability and is limited to the interaction between knowledge and context (relational embeddedness and environmental turbulence). We exclude, for example, firm characteristics and firm capabilities, which may play significant roles in knowledge transfer (Simonin 1999b). Although we incorporate several firm-level variables as covariates, the effects of these and other variables require explicit consideration in further research. 
Finally, our study is limited to the examination of knowledge transferability in vertical co-creation relations. We encourage researchers to examine the extent to which our findings generalize to other types of co-creation relations, such as those between competitors, to determine if our results extend to these relationships. 
Chapter 5: Conclusion 


\subsection{Introduction}

The overall aim of this dissertation is to examine the determinants and consequences of knowledge development and knowledge competencies in cocreation relations. To achieve this goal, each chapter presents an empirical assessment of aspects of this issue. Across the three main chapters, the research context pertains to co-creation relations, or projects in which a business customer and a supplier jointly develop a new product. Chapter 2 focuses on the combined effect of firm and relationship traits on knowledge development. Specifically, it assesses the impact of relational embeddedness on the degree to which firmspecific learning abilities lead to marketing innovation. Chapter 3 focuses on the ambiguous role of firm memory in developing new competencies during cocreation relations and analyzes the role of knowledge redundancy in overcoming the liabilities of increasing levels of firm memory. Not only do Chapters 2 and 3 consider the determinants of knowledge development and knowledge development competencies, they also examine consequences in terms of firm financial performance and firm strategic advantage. Finally, Chapter 4 focuses exclusively on the consequences of knowledge development in co-creation relations by studying co-creation knowledge as a candidate for future value generation, expressed as the potential to transfer knowledge to applications beyond that of the initial interfirm relationship.

This chapter serves to conclude this dissertation by providing a brief recap of the findings of the empirical studies and discussing implications for theory and practice. The next two sections predominantly focus on the determinants of knowledge development through co-creation relations, whereas the subsequent section emphasizes its consequences. We end this chapter with a set of recommendations for further research.

\subsection{Discussion}

This dissertation contributes to literature on knowledge development and competencies in several important ways. In response to the increasing need for firms to collaborate with customers, we focus on a highly interactive context for knowledge development: co-creation relations between business customers and suppliers. As a consequence, we acknowledge that knowledge development involves a social process (rather than a purely cognitive process) that gets reflected in the contexts studied and the constructs included in research on this topic. 
Existing studies that include intra- and interfirm effects on knowledge development (capabilities) simultaneously remain scarce but are necessary to provide a more complete portrait of the benefits and liabilities of social learning processes (Uzzi and Lancaster 2003). The three empirical studies of this dissertation thus provide deeper insights into various aspects of such processes. We summarize the findings of each study next.

\subsubsection{Partners' Learning Abilities and Relational Embeddedness}

Firms increasingly engage in knowledge development through co-creation relations, among other reasons, to hedge against uncertainties in their environments. At the same time however, many of these relationships result in failures. Therefore, we consider the conditions in which a relationship with a partner constrains and those in which it spurs knowledge development.

We show that the learning abilities of both the supplier (proactive market orientation) and the customer (lead-user status) enhance marketing innovations in vertical co-creation relations. Active engagement of lead users in NPD has strategic importance for the supplier firm, because it bridges the market knowledge gap of that supplier. The tie strength between the partners affects firmlevel learning abilities in an important and surprising way; that is, tie strength turns out to have both bright and dark sides. Whereas relational embeddedness hampers marketing innovation when the customer-partner is lead user, it helps a proactive supplier glean and develop radical marketing knowledge. In summary, firms should evaluate the (mis)fit between their firm-level learning abilities and tie strength instead of assuming that strong ties provide a cure-all for learning and successful new product outcomes. Because new product managers can control these factors, intentional stimulation of marketing innovation is possible.

Marketing innovations have substantial impacts not only on the financial performance of a new product but also the strategic position of the firm. Although marketing innovation involves costs, it leads to strategic advantages that translate into healthy financial performance by the new product. Thus, marketing innovation offers great value for companies that desire strategic or value innovation.

\subsubsection{Knowledge Redundancy and Focal Firm Memory}

The role of firm memory in new competence development represents a hotly debated issue in literature on innovation and (inter)organizational learning. The debate springs from mixed results, which point to both the essence of 
organizational learning for organizational renewal and the constraints it places on deviations from existing technological and market models. We show that this ambiguity can be overcome by adding knowledge redundancy into the equation. Because vertical relations expose firms to divergent knowledge, beliefs, and mental models, success or failure in new competence development can be explained through knowledge redundancy and its capacity to break established routines. Redundancy unlocks the potential of prior experience to find new linkages between old and new information and prevents the firm from experiencing ineffective communication or suffering a lack of cross-fertilization of both partners' knowledge stocks.

Companies therefore should not justify the use of existing knowledge by their fear of losing potential future value from their previous investments in knowledge development. Our results show that existing knowledge has a direct negative effect on competence development but can be unleashed most effectively when firms select partners that hold knowledge related to their own. Managers can match their own knowledge with that of their partner and thus anticipate the projected level of new competence development. Therefore, knowledge redundancy provides an important selection criterion for co-creation partners among channel members.

\subsubsection{Co-Creation Knowledge Transferability}

The last empirical chapter focuses on the firm-level benefits of knowledge developed through co-creation relations in terms of knowledge transferability. Knowledge transferability relates to firms' capacity to reuse knowledge from cocreation relations in situations outside the initial relationship between the customer and the supplier, which has particular importance for these firms because it provides them an opportunity to maximize the value of their previously developed knowledge in their relationships with other suppliers or customers. We argue that co-creation knowledge depends on its relational and environmental context and therefore does not allow costless transfers to alternative applications. Consistent with this claim, we examine whether both marketing innovation and marketing refinement exhibit the same transfer potential.

The results indicate that marketing innovation and marketing refinement both are suitable candidates for transferability, which might appear to suggest firms do not need to be concerned about differences in the future value of knowledge outcomes from co-creation relations. However, this initial assumption turns out to be incorrect when we also consider the characteristics of the 
relationship (i.e., relational embeddedness) in which the knowledge was developed and the turbulence of the environment. Although individual firms likely have trouble influencing their external environments, they should recognize that increasing levels of turbulence can be disadvantageous for transferability.

We also extend literature on interfirm relations and intrafirm knowledge transfer by explicitly showing that the context of the co-creation relation has implications for the transferability of knowledge outcomes, even after the product has been developed and launched. The results therefore provide additional support for the assertion that relational embeddedness involves a double-edged sword. Again, it reveals a positive and a negative moderating impact, such that close relationships facilitate the transfer of marketing refinement but hinder the transfer of marketing innovation. Therefore, firms should include an upfront evaluation, during the project definition process, of the potential transferability of knowledge that they expect to gain from the relationship.

\subsubsection{Relevance of combining knowledge and social relationship factors for studies of knowledge development}

The results of the three empirical chapters also lead to a more general conclusion. Exploring the antecedents and consequences of knowledge development and competencies has shown that the interaction between firm knowledge aspects and social relationship aspects plays an important role in studies on knowledge development and usage. Sole reliance, therefore, on either firm or relationship factors foregoes the opportunity to draw a more complete picture on the complex, moderating role of social ties.

We have combined organizational learning theory and social network theory to show that relational embeddedness (the first dimension of tie strength) between co-creation partners significantly affects the generation of marketing innovations. Not only do we observe a significant effect, we also see that this effect can be both positive and negative depending on the learning capabilities of the partners. Hence, the high failure rates of interfirm collaborations may be partly explained by the risks involved in having close relationships with a partner.

The value of combining insights from organizational learning theory and social network theory has also proven to be worthwhile in our study on the transferability of co-creation knowledge. Here, again, we observe that relational embeddedness is a double-edged sword in affecting co-creation knowledge; it negatively affects the relationship between marketing innovation and 
transferability, but it positively affects the relationship between marketing refinement and transferability.

The resources based view (or, more specifically, knowledge based view) of the firm has been used in this dissertation to generate insights in the role of memory in new competence development. In addition, we use social network theory to establish the role of knowledge redundancy (the second dimension of tie strength) in unlocking existing firm knowledge (i.e., memory) for recombination with new knowledge. We observe that firm memory blocks new competence development, but also that increases in knowledge redundancy between supply chain partners help firms to successfully use prior knowledge for recombination in new competence development. Hence, this study of both firm knowledge and relationship aspects may be helpful in explaining the mixed findings on the role of memory in previous studies.

\subsection{Perspectives on Further Research}

In addition to the directions for future research provided at the end of each chapter, we include in this section some general directions in the areas of interfirm relations, marketing knowledge development, competence development, and the firm benefits of co-creation relations.

Throughout this dissertation, we have elaborated on the knowledge outcomes of co-creation relations between suppliers and customers. Yet modern environments are characterized by increasingly rapid diffusion of technologies, greater globalization, and more and more demanding customers. Therefore, research should also examine knowledge outcomes in (in)formal co-creation networks, which provide firms with an alternative, or potentially complementary, source of knowledge input (Achrol and Kotler 1999). Social network theory could benefit from research that examines the impact of firm- and relationship-level variables on the knowledge development of the firms involved.

We also illustrate the light and dark sides of relational embeddedness in different situations, which implies its dual (positive and negative) function in both the generation and transfer of co-creation knowledge outcomes. However, it is not clear what drives these two sides of close relationships. Therefore, future research should advance our understanding of the bright and dark side of close relations by identifying (the lack of) a consistent pattern of circumstances or traits that might clarify its dual role.

High levels of knowledge redundancy unlock previously existing knowledge for new competence development, but this method might not be the 
only way to counter the negative effects of organizational memory. Individual managers may be more or less suitable in terms of their ability to break with current routines. Researchers therefore should investigate the effects of managers' (economic, social, cognitive, psychological) reasons for adhering to organizational memory, as well as their tendency to improvise and recombine old and new knowledge. Such investigations would provide insight in those managerial (decision-making) traits that are most suitable for new competence development.

Information processing typically consists of three steps: knowledge exchange or acquisition, knowledge interpretation, and knowledge integration (Jaworski and Kohli 1993). An important related issue involves understanding the relative effect of knowledge redundancy in unlocking organizational memory for new competence development in terms of this information processing approach. In which of the three stages is knowledge redundancy most effective in unlocking organizational memory -knowledge exchange, knowledge interpretation, or knowledge integration?

Finally, in the three empirical studies, we investigate several effects of knowledge outcomes, namely, new product financial performance, strategic advantages, and co-creation knowledge transferability. However, other consequences of learning also are important for firm strategy. What, for example, are the effects of firm-level traits (learning abilities, memory) on outcomes such as product radicalness and product creativity? What impact does organizational memory have on strategic innovation versus technological innovation? Does a relationship exist between product-level outcomes and knowledge outcomes? Are radical innovations or incremental new products more effective in developing marketing knowledge? 


\section{APPENDICES}

\section{APPENDIX A: SCALE ITEMS, CHAPTER 2}

All variables use seven-point Likert scales, where 1 indicates a negative response (e.g., strongly disagree) and 7 a positive response (e.g., strongly agree), unless noted otherwise.

Supplier marketing innovation (adapted from Kyriakopoulos and Moorman 2004)

Please indicate to which extent your company has learned to do other and better things during the co-creation project with regard to the marketing issues mentioned.

- Targeting and segmentation

- Customer service

- Product positioning and differentiation

- Distribution

- Communication and promotion

Customer lead-user status (operationalized from von Hippel 1986; 1988; 1994; 2002)

Please consider your customer's characteristics with regard to behavior in the market and indicate the degree to which you agree with the following statements:

The customer...

- tends to conduct thorough research for the available options offered by suppliers to identify new marketing possibilities that could address their own and their customers' needs.

- has, in the past three years, invested a substantial amount of time and money in identifying leading-edge marketing trends.

- is positioned at the leading edge of marketing trends and related needs.

- has, in the past three years, applied existing solutions in ways not anticipated by suppliers.

Supplier proactive market orientation (adapted from Narver et al. 2004)

Please consider your company's characteristics with regard to behavior in the market and indicate the degree to which you agree with the following statements:

Our company ...

- helps customers anticipate developments in their markets.

- continuously tries to discover additional customer needs of which they are unaware.

- incorporates solutions to unarticulated customer needs in its new products and services. 
- brainstorms on how customers (could) use its products and services.

- introduces new products even at the risk of making its own products obsolete.*

- searches for opportunities in areas where customers have a difficult time expressing their needs.*

- works closely with lead users who try to recognize customer needs months or even years before the majority of the market may recognize them.*

- extrapolates key trends to gain insight into what users in a current market will need in the future.

Relational embeddedness (adapted from Rindfleisch and Moorman 2001)

Please indicate the extent to which the following statements are an accurate reflection of the nature of the relationship between your company and your partner:

- We feel indebted to our customer for what it has done for us.*

- Our new product development team members share close social relations with our customer's new product development team members.

- The relationship with our customer can be defined as "mutually gratifying".

- We expect that we will be working with our customer in the future.

Supplier financial performance (Moorman 1995)

Please rate the extent to which the product has achieved the following outcomes during the first 12 months of its life in the marketplace:

- Market share relative to its stated objective.

- Sales relative to its stated objective.

- Return on assets relative to its stated objective.

- Profit margin relative to its stated objective.

- Return on investment relative to its stated objective.*

\section{Supplier strategic advantage (Jap 1999)}

Please indicate the extent to which you agree with the following statements about the consequences of the co-creation relation for your company:

- Our firm has gained strategic advantages over our competitors.*

- The relationship has not resulted in strategic advantages for our firm. (r)

- Our firm has gained benefits that enable us to compete more effectively in the marketplace.

- The relationship has not resulted in strategically important outcomes for our firm. (r)

Partner goal congruency (Jap 1999)

- Customer has different goals. (r)

- The firms share the same goals in the relationship.

- The partners support each other's objectives.

- Customer has comparable goals. 
Relationship formalization (Adapted from Sivadas and Dwyer 2000)

- We rely extensively upon contractual rules and policies in controlling dayto-day operations of the relationship with our customer.

- We follow written procedures in most aspects of business in the relationship with our customer.

Market turbulence (adapted from Jaworski and Kohli 1993)

Please indicate the extent to which you agree with the following statements concerning the industry of the new product developed:

- Customers' product preferences change quite a bit over time.

- Our customers tend to look for new products all the time.

- We are witnessing demand for our products and services from customers who never bought them before.

- New customers tend to have product-related needs that are different from those of our existing customers.

- We cater to many of the same customers that we used to in the past ( $\mathrm{r})^{*}$

Technological turbulence (adapted from Jaworski and Kohli 1993)

Please indicate the extent to which you agree with the following statements concerning the industry of the newly developed product:

- The technology in this industry is changing rapidly.

- Technological changes provide big opportunities in this industry.

- It is very difficult to forecast where the technology in this industry will be in the next 2 to 3 years.*

- A large number of new product ideas have been made possible through technological breakthroughs in our industry.

- Technological developments in this industry are rather minor. (r)

Notes:

(r) indicates that the item is a reverse-scored item.

* indicates that the item is deleted during the scale purification process. 


\section{APPENDIX B: SCALE ITEMS, CHAPTER 3}

All variables use seven-point Likert scales, where 1 indicates a negative response (e.g., strongly disagree) and 7 a positive response (e.g., strongly agree), unless noted otherwise.

New competence development (Based on Gatignon et al. 2002)

Please indicate the extent to which you agree with the following statements about the vertical cocreation relation.

The vertical co-creation relation...

- involved fundamentally new concepts or principles for our company.

- required new skills which we did not possess before the project.*

- required a great deal of retraining.

- required us to learn from completely new or different knowledge bases (i.e., car industry learns from airline industry).

- required us to adopt different methods and procedures.

- required us to develop many new skills.

Marketing memory (Based on Moorman and Miner 1997)

Prior to the vertical co-creation, compared to firms in our industry, my company had:

- A great deal of knowledge about the marketing aspects of this product category.

- A great deal of information and data about the marketing aspects of products in this product category.

- A lot of knowledge about marketing products in this product category.

- A lot of insight in the marketing aspects of this product category.

Technology memory (Based on Moorman and Miner 1997)

Prior to the vertical co-creation, compared to firms in our industry, my company had:

- A great deal of knowledge about research and development in this product category.

- A great deal of information and data about research and development aspects of products in this product category.

- A lot of knowledge about research and development in this product category.

- A lot of insight in research and development aspects of this product category.

Knowledge redundancy (Rindfleisch and Moorman 2001)

(seven-point semantic differential scale)

Please indicate the extent to which the following statements are an accurate reflection of the nature of the relationship between your company and your partner:

- Our partner produces very different products - produces very similar products. 
- Our partner has complementary NPD skills - has overlapping NPD skills.

- Our partner's NPD team members have different knowledge from ours have the same type of knowledge.

- Our partner has very different resources - has very similar resources.

Firm financial performance (Moorman 1995)

Please rate the extent to which the product has achieved the following outcomes during the first 12 months of its life in the marketplace:

- Market share relative to its stated objective.

- Sales relative to its stated objective.

- Return on assets relative to its stated objective.

- Profit margin relative to its stated objective.

- Return on investment relative to its stated objective.*

Firm strategic advantage (Jap 1999)

Please indicate the extent to which you agree with the following statements about the consequences of the co-creation relation for your company:

- Our firm has gained strategic advantages over our competitors.

- The relationship has not resulted in strategic advantages for our firm. (r)

- Our firm has gained benefits that enable us to compete more effectively in the marketplace.*

- The relationship has not resulted in strategically important outcomes for our firm (r)

Partner goal congruency (Jap 1999)

- Partner has different goals. (r)

- The partners share the same goals in the relationship.*

- The partners support each other's objectives.

- Partner has comparable goals.

Co-creation specific investments (Rokkan et al. 2003)

Please indicate the extent to which you agree with the following statements about your company:

- Significant investments in equipment dedicated to the relationship with the partner have been made.

- Extensive internal adjustments have been made in order to deal effectively with the partner.

- Training people to deal with the partner has involved substantial commitments of time and money.

- The logistics systems have been tailored to meet the requirements of dealing with the partner. 
Relational embeddedness (Rindfleisch and Moorman 2001)

Please indicate the extent to which the following statements are an accurate reflection of the nature of the relationship between your company and your partner:

- We feel indebted to our partner for what it has done for us.*

- Our new product development team members share close social relations with our partner's new product development team.

- The relationship with our partner can be defined as "mutually gratifying".

- We expect that we will be working with our partner in the future.

Market turbulence (adapted from Jaworski and Kohli 1993)

Please indicate the extent to which you agree with the following statements concerning the industry of the new product developed:

- Customers' product preferences change quite a bit over time.

- Our customers tend to look for new products all the time.

- We are witnessing demand for our products and services from customers who never bought them before.*

- New customers tend to have product-related needs that are different from those of our existing customers.

- We cater to many of the same customers that we used to in the past. (r)*

Technological turbulence (Jaworski and Kohli 1993)

Please indicate the extent to which you agree with the following statements concerning the industry of the newly developed product:

- The technology in this industry is changing rapidly.

- Technological changes provide big opportunities in this industry.

- It is very difficult to forecast where the technology in this industry will be in the next 2 to 3 years.*

- A large number of new product ideas have been made possible through technological breakthroughs in our industry.

- Technological developments in this industry are rather minor. (r)

Notes:

(r) indicates that the item is a reverse-scored item.

* indicates that the item is deleted during the scale purification process. 


\section{APPENDIX C: SCALE ITEMS, ChaPTER 4}

All variables use seven-point Likert scales, where 1 indicates a negative response (e.g., strongly disagree) and 7 a positive response (e.g., strongly agree), unless noted otherwise.

Transferability (Based on Kyriakopoulos and Moorman 2005; Gatignon et al 2002)

Please indicate to which extent the new marketing knowledge that resulted from the co-creation relation is applicable/ relevant in situations outside the relationship between you and your partner (e.g., when cooperating with another partner or for other products or applications).

- New knowledge concerning our firm's communication strategy.

- New knowledge with regard to marketing concepts for our firm.

- Knowledge with regard to marketing skills.

- Knowledge from a new or different knowledge base.

- Knowledge on the application of marketing tactics.

- Knowledge resulting from retraining.*

Marketing innovation (adapted from Kyriakopoulos and Moorman 2004)

Please indicate to which extent your company has learned to do other and better things during the co-creation project with regard to the marketing issues mentioned.

- Targeting and segmentation

- Customer service*

- Product positioning and differentiation

- Distribution

- Communication and promotion

Marketing refinement (adapted from Kyriakopoulos and Moorman 2004)

Please indicate to which extent your company has learned to do the same thing better during the co-creation project with regard to the marketing issues mentioned.

- Targeting and segmentation

- Customer service*

- Product positioning and differentiation

- Distribution

- Communication and promotion

Relational embeddedness (Rindfleisch and Moorman 2001)

Please indicate the extent to which the following statements are an accurate reflection of the nature of the relationship between your company and your partner:

- We feel indebted to our partner for what it has done for us.*

- Our new product development team members share close social relations with our partner's new product development team members.

- The relationship with our partner can be defined as "mutually gratifying".

- We expect that we will be working with our partner in the future. 
Market turbulence (adapted from Jaworski and Kohli 1993)

Please indicate the extent to which you agree with the following statements concerning the industry of the new product developed:

- Customers' product preferences change quite a bit over time.

- Our customers tend to look for new products all the time.

- We are witnessing demand for our products and services from customers who never bought them before.*

- New customers tend to have product-related needs that are different from those of our existing customers.

- We cater to many of the same customers that we used to in the past. (r)*

Technological turbulence (Jaworski and Kohli 1993)

Please indicate the extent to which you agree with the following statements concerning the industry of the newly developed product:

- The technology in this industry is changing rapidly.

- Technological changes provide big opportunities in this industry.

- It is very difficult to forecast where the technology in this industry will be in the next 2 to 3 years.*

- A large number of new product ideas have been made possible through technological breakthroughs in our industry.

- Technological developments in this industry are rather minor. (r)*

Marketing memory (Based on Moorman and Miner 1997)

Prior to the vertical co-creation, compared to firms in our industry, my company had:

- A great deal of knowledge about the marketing aspects of this product category.

- A great deal of information and data about the marketing aspects of products in this product category.

- A lot of knowledge about marketing products in this product category.

- A lot of insight in the marketing aspects of this product category.

Technology memory (Based on Moorman and Miner 1997)

Prior to the project, compared to firms in our industry, my company had:

- A great deal of knowledge about research and development in this product category.

- A great deal of information and data about research and development aspects of products in this product category.

- A lot of knowledge about research and development in this product category.

- A lot of insight in research and development aspects of this product category. 
Knowledge redundancy (Rindfleisch and Moorman 2001)

(seven-point semantic differential scale)

Please indicate the extent to which the following statements are an accurate reflection of the nature of the relationship between your company and your partner:

- Our partner produces very different products - produces very similar products.*

- Our partner has complementary NPD skills - has overlapping NPD skills.

- Our partner's NPD team members have different knowledge from ours have the same type of knowledge.

- Our partner has very different resources - has very similar resources.

\section{Notes:}

(r) indicates that the item is a reverse-scored item.

* indicates that the item is deleted during the scale purification process. 


\section{REFERENCES}

Achrol, Ravi S. (1991), "Evolution of the Marketing Organization: New Forms for Turbulent Environments," Journal of Marketing, 55 (4), 77-93.

Achrol, Ravi S. and Philip Kotler (1999), "Marketing in the Network Economy," Journal of Marketing, 63 (Special Issue), 146-63.

Aiken, Leona S. and Steve G. West (1991), Multiple Regression: Testing and Interpreting Interactions. Newbury Park, Ca: Sage.

Amabile, Teresa (1983), The Psychology of Creativity. New York: Springer.

Amit, R. and P. J. H. Schoemaker (1993), "Strategic Assets and Organizational Rent," Strategic Management Journal, 14 (1), 33-46.

Anderson, Erin and Sandy D. Jap (2005), "The Dark Side of Close Relationships," MIT Sloan Management Review, 46 (3), 75-82.

Anderson, P. and M.L. Tushman (1991), "Managing through Cycles of Technological Change," Research in Technology Management, 34 (4), 26-31.

Argote, Linda and Paul Ingram (2000), "Knowledge Transfer: A Basis for Competitive Advantage in Firms," Organizational Behavior \& Human Decision Processes, 82 (1), 150-69.

Argote, Linda, Bill McEvily, and Ray Reagans (2003), "Managing Knowledge in Organizations: An Integrative Framework and Review of Emerging Themes," Management Science, 49 (4), 571-82.

Argyris, C. (1976), "Single-Loop and Double-Loop Models in Research on Decision Making," Administrative Science Quarterly, 21 (3), 363-75.

Arkes, Hal R. and Peter Ayton (1999), "The Sunk Cost and Concorde Effects: Are Humans Less Rational Than Lower Animals?" Psychological Bulletin, 125 (5), 591-600.

Armstrong, J. Scott and Terry S. Overton (1977), "Estimating Nonresponse Bias in Mail Surveys," Journal of Marketing Research, 14 (3), 396-402.

Arora, Ashish and Alfonso Gambardella (1994), "Evaluating Technological Information and Utilizing It," Journal of Economic Behavior \& Organization, 24 (1), 91-114.

Auh, Seigyoung and Bulent Menguc (2005), "Balancing Exploration and Exploitation: The Moderating Role of Competitive Intensity," Journal of Business Research, 58 (12), 1652 61.

\section{B}

Baden-Fuller, Charles and M. Pitt (1996), "The Nature of Innovating Strategic Management," in Strategic Innovation, Charles Baden-Fuller and M. Pitt, Eds. London: Routledge, 3-42.

Bagozzi, Richard P. and Youjae Yi (1988), "On the Evaluation of Structural Equation Models," Journal of the Academy of Marketing Science, 16 (1), 74-94.

Barney, Jay (1991), "Firm Resources and Sustained Competitive Advantage," Journal of Management, 17 (1), 99-121. 
Baron, R. M. and D. A. Kenny (1986), "The Moderator-Mediator Variable Distinction in Social Psychological Research: Conceptual, Strategic, and Statistical Considerations," Journal of Personality and Social Psychology, 51 (6), 1173-82.

Barton, Sidney L., Dennis Duchon, and Kenneth J. Dunegan (1989), "An Empirical Test of Staw and Ross's Prescriptions for the Management of Escalation of Commitment Behavior in Organizations," Decision Sciences, 20 (3), 532-44.

Benner, Mary J. and Michael L. Tushman (2003), "Exploitation, Exploration, and Process Management: The Productivity Dilemma Revised," Academy of Management Review, 28 (2), 238-56.

Bentler, P. M. (1992), "On the Fit of Models to Covariances and Methodology to the Bulletin," Psychological Bulletin, 112 (3), 400-04.

Bidault, Francis, Charles Despres, and Christina Butler (1998), "The Drivers of Cooperation between Buyers and Suppliers," Research Policy, 26 (7/8), 719-32.

Bonner, Joseph M. and Orville C. Walker, Jr. (2004), "Selecting Influential Business-toBusiness Customers in New Product Development: Relational Embeddedness and Knowledge Heterogeneity Considerations," Journal of Product Innovation Management, 21 (3), 155-69.

Brown, John Seely and Paul Duguid (1991), "Organizational Learning and Communitiesof-Practice: Toward a Unified View of Working, Learning, and Innovating," Organization Science, 2 (1), 40-57.

\section{C}

Campbell, Donald T. and Donald W. Fiske (1959), "Convergent and Discriminant Validation by the Multitrait-Multimethod Matrix," Psychological Bulletin, 56 (2), 81-105.

Chandy, Rajesh K. and Gerard J. Tellis (2000), "The Incumbent's Curse? Incumbency, Size, and Radical Product Innovation," Journal of Marketing, 64 (3), 1-17.

---- (1998), "Organizing for Radical Product Innovation: The Overlooked Role of Willingness to Cannibalize," Journal of Marketing Research, 35 (4), 474-87.

Christensen, Clayton M. and Joseph L. Bower (1996), "Customer Power, Strategic Investment, and the Failure of Leading Firms," Strategic Management Journal, 17 (3), $197-$ 218.

Cohen, Wesley M. and Daniel A. Levinthal (1990), "Absorptive Capacity: A New Perspective on Learning and Innovation," Administrative Science Quarterly, 35 (1), 128-52.

Cool, K. O., I. Dierickx, and G. Szulanski (1997), "Diffusion of Innovations within Organizations: Electronic Switching in the Bell System, 1971-1982," Organization Science, 8 (5), 543-59.

Cross, Rob and Lee Sproull (2004), "More Than an Answer: Information Relationships for Actionable Knowledge," Organization Science, 15 (4), 446-62.

Cyert, Richard M. and James G. March (1963), A Behavioral Theory of the Firm. Englewood Cliffs, New York: Prentice Hall, Inc.

Danneels, Erwin (2002), "The Dynamics of Product Innovation and Firm Competences," Strategic Management Journal, 23 (12), 1095-121. 
Day, George S. (1999), "Creating a Market-Driven Organization," MIT Sloan Management Review, 41 (1), 11-22.

---- (1998), "What Does It Mean to Be Market-Driven?" Business Strategy Review, 9 (1), 1-14.

---- (1994), "The Capabilities of Market-Driven Organizations," Journal of Marketing, 58 (4), 37-52.

Denrell, Jerker and James G. March (2001), "Adaptation as Information Restriction: The Hot Stove Effect," Organization Science, 12 (5), 523-37.

Deshpandé, Rohit, John U. Farley, and Frederick E. Webster Jr. (1993), "Corporate Culture, Customer Orientation, and Innovativeness in Japanese Firms: A Quadrad Analysis," Journal of Marketing, 57 (1), 23-27.

Dougherty, Deborah (1992), "A Practice-Centered Model of Organizational Renewal through Product Innovation,” Strategic Management Journal, 13 (Special Issue), 77-92.

Dowling, Michael J., William R. Boulton, and Sidney W. Elliott (1994), "Strategies for Change in the Service Sector: The Global Telecommunications Industry," California Management Review, 36 (3), 57-88.

Dutta, Shantanu, Om Narasimhan and Surendra Rajiv (1999), "Success in HighTechnology Markets: Is Marketing Capability Critical?" Marketing Science, 18 (4), 54768.

Dutta, Shantanu and Allen M. Weiss (1997), "Technological Innovativeness and its Pattern of Partnership Agreements," Management Science, 43 (3), 343-56.

Dwyer, F.R. and S. Oh (1988), "A Transaction Cost Perspective on Vertical Contractual Structure and Interchannel Competitive Strategies," Journal of Marketing, 52 (2), 21-24.

Dyer, Jeffrey H. and Harbir Singh (1998), "The Relational View: Cooperative Strategy and Sources of Interorganizational Competitive Advantage," Academy of Management Review, 23 (4), 660-79.

$\mathbf{E}$

Easterby-Smith, Mark and Luis Araujo (1999), “Organizational Learning: Current Debates and Opportunities," in Organizational Learning and the Learning Organization. Developments in Theory and Practice, Mark Easterby-Smith, John Burgoyne and Luis Araujo Eds. London: Sage.

Edmondson, Amy C., Ann B. Winslow, Richard M.J. Bohmer, and Gary P. Pisano (2003), "Learning How and Learning What: Effects of Tacit and Codified Knowledge on Performance Improvement Following Technology Adoption," Decision Sciences, 34 (2), 197-223.

Eisenhardt, Kathleen M. and Jeffrey A. Martin (2000), "Dynamic Capabilities: What Are They?" Strategic Management Journal, 21 (10/11), 1105-31.

Eisenhardt, Kathleen M. and Behna N. Tabrizi (1995), "Accelerating Adaptive Processes: Product Innovation in the Global Computer Industry," Administrative Science Quarterly, 40 (1), 84-110.

Eliashberg, Jehoshua and Donald A. Michie (1984), "Multiple Business Goals Sets as Determinants of Marketing Channel Conflict: An Empirical Study," Journal of Marketing Research, 21 (1), 75-88.

Eurostat (2002), "European Community Innovation Survey," Retrieved 17 August 2004, available at http://epp.eurostat.cec.eu.int/portal/ 
Feldman, Martha S. and Brian T. Pentland (2003), "Reconceptualizing Organizational Routines as a Source of Flexibility and Change," Administrative Science Quarterly, 48, 94118.

Fichman, Mark and Daniel A. Levinthal (1991), "Honeymoons and the Liability of Adolescence: A New Perspective on Duration Dependence in Social and Organizational Relationships," Academy of Management Review, 16 (2), 442-68.

Fleming, Lee and Olav Sorenson (2004), "Science as a Map in Technological Search," Strategic Management Journal, 25 (8/9), 909-28.

Fornell, Claes and David F. Larcker (1981), "Evaluating Structural Equation Models with Unobservable Variables and Measurement Error," Journal of Marketing Research, 18 (1), $39-50$.

\section{G}

Galbraith, C.S. (1990), "Transferring Core Manufacturing Technologies in High Technology Firms," California Management Review, 32 (4), 56-70.

Garud, Raghu and Michael A. Rappa (1994), "A Socio-Cognitive Model of Technology Evolution: The Case of Cochlear Implants," Organization Science, 5 (3), 344-62.

Gatignon, Hubert, Michael L. Tushman, Wendy Smith, and Philip Anderson (2002), "A Structural Approach to Assessing Innovation: Construct Development of Innovation Locus, Type, and Characteristics," Management Science, 48 (9), 1103-22.

Ghosh, Mrinal and George John (1999), "Governance Value Analysis and Marketing Strategy," Journal of Marketing, 63 (Special Issue), 131-45.

Granovetter, Mark (1973), "The Strength of Weak Ties," American Journal of Sociology, 78 (6), 1360-80.

Grant, Robert M. (1996), "Prospering in Dynamically-Competitive Environments: Organizational Capability as Knowledge Integration," Organization Science, 7 (4), 375-87.

Grant, Robert M. and C. Baden-Fuller (2004), "A Knowledge Accessing Theory of Strategic Alliances," Journal of Management Studies, 41 (1), 61-84.

Grayson, Kent and Tim Ambler (1999), "The Dark Side of Long-Term Relationships in Marketing Services," Journal of Marketing Research, 36 (1), 132-41.

Greene, W. H. (2002), Limdep Econometric Modeling Guide: Version 8.0. Plainview, NY: Econometric Software Inc.

Gulati, R. (1999), "Network Location and Learning: The Influence of Network Resources and Firm Capabilities on Alliance Formation," Strategic Management Journal, 20 (5), 397 420 .

\section{$\mathbf{H}$}

Halinen, Aino (1997), Relationship Marketing in Professional Services: A Study of AgencyClient Dynamics in the Advertising Sector. New York: Routledge.

Hamel, Gary (1991), "Competition for Competence and Inter-partner Learning within International Strategic Alliances," Strategic Management Journal, 12 (Special Issue), 83103. 
Hamel, Gary, Yves L. Doz, and C.K. Prahalad (1989), "Collaborate with Your Competitors -- and Win," Harvard Business Review, 67 (1), 133-39.

Han, Jin K., Namwoon Kim, and Rajendra K. Srivastava (1998), "Market Orientation and Organizational Performance: Is Innovation the Missing Link?" Journal of Marketing (4), $30-45$.

Hannan, Michael T. and John R. Freeman (1983), "Structural Inertia and Organizational Change," American Sociological Review, 29 (2), 149-64.

Hansen, Morten T. (1999), "The Search-Transfer Problem: The Role of Weak Ties in Sharing Knowledge across Organization Subunits," Administrative Science Quarterly, 44 (1), 82-111.

Hanvanich, Sangphet, K. Sivakumar, and G. Tomas M. Hult (2006), "The Relationship of Learning and Memory with Organizational Performance: The Moderating Role of Turbulence," Journal of the Academy of Marketing Science, 34 (4), 600-12.

Harrison, Jeffrey S., Michael A. Hitt, Robert E. Hoskisson, and R. Duane Ireland (2001), "Resource Complementarity in Business Combinations: Extending the Logic to Organizational Alliances," Journal of Management, 27 (6), 679-90.

Helfat, Constance E. (2000), "Guest Editor's Introduction to the Special Issue: The Evolution of Firm Capabilities," Strategic Management Journal, 21 (10-11), 955-59.

Henderson, Rebecca M. and Kim B. Clark (1990), "Architectural Innovation: The Reconfiguration of Existing Product Technologies and the Failure of Established Firms," Administrative Science Quarterly, 35 (1), 9-30.

Henderson, Rebecca M. and Iain Cockburn (1994), "Measuring Competence? Exploring Firm Effects in Pharmaceutical Research," Strategic Management Journal, 15 (Special Issue), 63-84.

Hill, C. W. L. and D. L. Deeds (1996), "The Importance of Industry Structure for the Determination of Firm Profitability: A Neo-Austrian Perspective," Journal of Management Studies, 33 (4), 429-51.

Hitt, Michael A., M. Tina Dacin, Edward Levitas, Jean-Luc Arregle, and Anca Borza (2000), "Partner Selection in Emerging and Developed Market Contexts: ResourceBased and Organizational Learning Perspectives," Academy of Management Journal, 43 (3), 449-67.

Holmqvist, Mikael (2003), "A Dynamic Model of Intra- and Interorganizational Learning," Organization Studies, 24 (1), 95-123.

Huber, George P. (1991), "Organizational Learning: The Contributing Processes and Literatures," Organization Science, 2 (1), 88-115.

\section{I}

Im, Subin and John P. Workman, Jr. (2004), "Market Orientation, Creativity, and New Product Performance in High-Technology Firms," Journal of Marketing, 68 (2), 114-32.

Inkpen, Andrew C. (1996), "Creating Knowledge through Collaboration," California Management Review, 39 (1), 123-40.

$\mathrm{J}$

Jap, Sandy D. (2001), "Perspectives on Joint Competitive Advantages in Buyer-Supplier Relationships," International Journal of Research in Marketing, 18 (1/2), 19-35. 
---- (1999), "Pie-Expansion Efforts: Collaboration Processes in Buyer-Supplier Relationships," Journal of Marketing Research, 36 (4), 461-75.

Jaworski, Bernard J. and Ajay K. Kohli (1993), "Market Orientation: Antecedents and Consequences," Journal of Marketing, 57 (3), 53-70.

Jaworski, Bernard J., Ajay K. Kohli, and Arvind Sahay (2000), "Market-Driven Versus

Driving Markets," Journal of the Academy of Marketing Science, 28 (1), 45-54.

\section{K}

Kahneman, Daniel, Paul Slovic, and Amos Tversky (1982), Judgment under Uncertainty: Heuristics and Biases. New York: Cambridge University Press.

Kale, Prashant and Harbir Singh (2000), "Learning and Protection of Proprietary Assets in Strategic Alliances: Building Relational Capital," Strategic Management Journal, 21 (3), 217-37.

Kaplan, R. S. and D. P. Norton (1996), "Using the Balanced Scorecard as a Strategic Management System," Harvard Business Review, 74 (1), 75-85.

Kessler, Eric H., Paul E. Bierly, and Shanti Gopalakrishnan (2000), "Internal vs. External Learning in New Product Development: Effects on Speed, Costs and Competitive Advantage," R\&D Management, 30 (3), 213-24.

Khanna, Tarun, Ranjay Gulati, and Nitin Nohria (1998), "The Dynamics of Learning Alliances: Competition, Cooperation, and Relative Scope," Strategic Management Journal, 19 (3), 193-210.

Kim, W. Chan and R. Mauborgne (1999), "Creating New Market Space," Harvard Business Review, 77 (1), 83-93.

Knudsen, Mette Praest (2007), "The Relative Importance of Interfirm Relationships and Knowledge Transfer for New Product Development Success," Journal of Product Innovation Management, 24 (2), 117-38.

Kogut, Bruce (1988), "Joint Ventures: Theoretical and Empirical Perspectives," Strategic Management Journal, 9 (4), 319-32.

Kogut, Bruce and Udo Zander (1992), "Knowledge of the Firm, Combinative Capabilities, and the Replication of Technology," Organization Science, 3 (3), 383-97.

Kohli, Ajay K. and Bernard J. Jaworski (1990), "Market Orientation: The Construct, Research Propositions, and Managerial Implications," Journal of Marketing, 54 (2), 1-18.

Kotabe, Masaaki, Xavier Martin, and Hiroshi Domoto (2003), "Gaining from Vertical Partnerships: Knowledge Transfer, Relationship Duration and Supplier Performance Improvement in the U.S. And Japanese Automotive Industries," Strategic Management Journal, 24 (4), 293-316.

Koufteros, Xenophon A. (1999), "Testing a Model of Pull Production: A Paradigm for Manufacturing Research Using Structural Equation Modeling," Journal of Operations Management, 17 (4), 467-88.

Kyriakopoulos, Kyriakos and Ko de Ruyter (2004), "Knowledge Stocks and Information Flows in New Product Development," Journal of Management Studies, 41 (8), 1469-98.

Kyriakopoulos, Kyriakos and Christine Moorman (2004), "Tradeoffs in Marketing Exploitation and Exploration Strategies: The Overlooked Role of Market Orientation," International Journal of Research in Marketing, 21 (3), 219-40. 
Lane, Peter J. and Michael Lubatkin (1998), "Relative Absorptive Capacity and Interorganizational Learning," Strategic Management Journal, 19 (5), 461-77.

Leonard-Barton, Dorothy (1992), "Core Capabilities and Core Rigidities: A Paradox in Managing New Product Development," Strategic Management Journal, 13 (5), 111-25.

Levinthal, Daniel A. and James G. March (1993), "The Myopia of Learning," Strategic Management Journal, 14 (8), 95-112.

Levitt, B and J.G. March (1988), "Organizational Learning," Annual Review of Sociology, 14, 314-40.

Liebeskind, Julia Porter (1996), "Knowledge, Strategy, and the Theory of the Firm," Strategic Management Journal, 17, 93-107.

Lilien, Gary L., Pamela D. Morrison, Kathleen Searls, Mary Sonnack, and Eric von Hippel (2002), "Performance Assessment of the Lead User Idea-Generation Process for New Product Development," Management Science, 48 (8), 1042-59.

Lorenzoni, Gianni and Andrea Lipparini (1999) "The Leveraging of Interfirm Relationships as a Distinctive Organizational Capability: A Longitudinal Study," Strategic Management Journal, 20 (4), 317-38.

Lounamaa, Pertti, H. and James G. March (1987), "Adaptive Coordination of a Learning Team," Management Science, 33 (1), 107-23.

Lubart, Todd I. (1994), "Creativity," in Handbook of Perception and Cognition: Thinking and Problem Solving, Robert J. Sternberg, Ed. New York: Academic Press, 289-332.

Lukas, Bryan A., G. Tomas M. Hult and O.C. Ferrell (1996), “A Theoretical Perspective of the Antecedents and Consequences of Organizational Learning in Marketing Channels," Journal of Business Research, 36 (3), 233-44.

Lusch, R. F. and S. L. Vargo (2006), "Service-Dominant Logic: Reactions, Reflections and Refinements," Marketing Theory, 6 (3), 281-88.

\section{M}

MacKinnon, David P. and James H. Dwyer (1993), "Estimating Mediated Effects in Prevention Studies," Evaluation Review, 17 (2), 144-58.

Madhavan, Ravindranath and Rajiv Grover (1998), "From Embedded Knowledge to Embodied Knowledge: New Product Development as Knowledge Management," Journal of Marketing, 62 (4), 1-12.

March, James G. (1991), "Exploration and Exploitation in Organizational Learning," Organization Science, 2 (1), 71-87.

Marketing Science Institute (2006), "Research Priorities: A Guide to MSI Research Programs and Procedures," Retrieved 4 September 2006, available at www.msi.org.

Markides, Constantinos C. (1999), "A Dynamic View of Strategy," MIT Sloan Management Review, 40 (3), 55-63.

McEvily, Bill and Alfred Marcus (2005), "Dynamic Capabilities," Strategic Management Journal, 26 (11), 1033-55.

McEvily, Bill and Akbar Zaheer (1999), "Bridging ties: A Source of Firm Heterogeneity in Competitive Capabilities," Strategic Management Journal, 20 (12), 1133-56. 
Moorman, Christine (1995), "Organizational Market Information Processes: Cultural Antecedents and New Product Outcomes," Journal of Marketing Research, 32 (3), 318-35.

Moorman, Christine and Anne S. Miner (1997), "The Impact of Organizational Memory on New Product Performance and Creativity," Journal of Marketing Research, 34 (1), 91 106.

Moorman, Christine and Anne S. Miner (1998), "Organizational Improvisation and Organizational Memory," Academy of Management Review, 23 (4), 698-723.

Moorman, Christine and Rebecca J. Slotegraaf (1999), "The Contingency Value of Complementary Capabilities in Product Development," Journal of Marketing Research, 36 (2), 239-57.

Moorman, Christine, Gerald Zaltman, and Rohit Deshpandé (1992), "Relationships between Providers and Users of Market Research: The Dynamics of Trust within and between Organizations," Journal of Marketing Research, 29 (3), 314-28.

Morrison, Pamela D., John H. Roberts, and Eric von Hippel (2000), "Determinants of User Innovation and Innovation Sharing in a Local Market," Management Science, 46 (12), 1513-27.

Mowery, David C., Joan E. Oxley, and Brian S. Silverman (1996), "Strategic Alliances and Interfirm Knowledge Transfer," Strategic Management Journal, 17 (Special Issue), 77-91.

\section{$\mathbf{N}$}

Narver, John C., Stanley F. Slater, and Douglas L. MacLachlan (2004), "Responsive and Proactive Market Orientation and New-Product Success," Journal of Product Innovation Management, 21 (5), 334-47.

Nelson, Richard R. and Sidney G. Winter (1982), "The Schumpeterian Tradeoff Revisited," American Economic Review, 72 (1), 114-32.

Neter, John, William Wasserman, and Michael Kutner (1985), Applied Linear Statistical Models (2nd ed.). Homewood, IL: Irwin.

Nielsen, Bo Bernhard (2005), "The Role of Knowledge Embeddedness in the Creation of Synergies in Strategic Alliances," Journal of Business Research, 58 (9), 1194-204.

Nijssen, Edwin J., Bas Hillebrand, and Patrick A. M. Vermeulen (2005), "Unraveling Willingness to Cannibalize: A Closer Look at the Barrier to Radical Innovation," Technovation, 25 (12), 1400-09.

Noble, Charles H., Rajiv K. Sinha, and Ajith Kumar (2002), "Market Orientation and Alternative Strategic Orientations: A Longitudinal Assessment of Performance Implications," Journal of Marketing, 66 (4), 25-39.

Nonaka, Ikujiro (1994), "A Dynamic Theory of Organizational Knowledge Creation," Organization Science, 5 (1), 14-37.

Nonaka, Ikujiro and H. Takeuchi (1995), The Knowledge-Creating Company: How Japanese Companies Create the Dynamics of Innovation. New York, NY: Oxford University Press. 
O'Connor, Gina Colarelli (1998), "Market Learning and Radical Innovation: A Cross Case Comparison of Eight Radical Innovation Projects," Journal of Product Innovation and Management, 15 (2), 151-66.

Olson, Eric M., Orville C. Walker, Jr., and Robert W. Ruekert (1995), "Organizing for Effective New Product Development: The Moderating Role of Product Innovativeness," Journal of Marketing, 59 (1), 48-62.

\section{$\mathbf{P}$}

Parkhe, Arvind (1991), "Interfirm Diversity, Organizational Learning, and Longevity in Global Strategic Alliances," Journal of International Business Studies, 22 (4), 579-601.

Perks, Helen (2004), "Exploring Processes of Resource Exchange and Co-Creation in Strategic Partnering for New Product Development," International Journal of Innovation Management, 8 (1), 37-61.

Podsakoff, Philip M. and Dennis W. Organ (1986), "Self-Reports in Organizational Research: Problems and Prospects," Journal of Management, 12 (4), 531-44.

Powell, Walter W. (1998), "Learning from Collaboration: Knowledge and Networks in the Biotechnology and Pharmaceutical Industries," California Management Review, 40 (3), 228-40.

Powell, Walter W. and P. Brantley (1992), "Competitive Cooperation in Biotechnology: Learning through Networks," in Networks and Organizations: Structure, Form and Action, N. Nohria and R. Eccles, Eds. Boston, MA: Harvard Business School Press, 366-94.

Powell, Walter W., Kenneth W. Koput, and Larel Smith-Doerr (1996), "Interorganizational Collaboration and the Locus of Innovation: Networks of Learning in Biotechnology," Administrative Science Quarterly, 41 (1), 116-45.

Prahalad, C. K. and Venkat Ramaswamy (2004), "Co-Creation Experiences: The Next Practice in Value Creation," Journal of Interactive Marketing, 18 (3), 5-14.

Preacher, K. J. and A. F. Hayes (2004), "SPSS and SAS Procedures for Estimating Indirect Effects in Simple Mediation Models," Behavior Research Methods, Instruments, \& Computers, 36 (4), 717-31.

Preacher, K.J., P.J. Curran, and D.J. Bauer (2006), "Computational Tools for Probing Interactions in Multiple Linear Regression, Multilevel Modeling, and Latent Curve Analysis," Journal of Educational and Behavioral Statistics, 31 (3), 437-48.

\section{$\mathbf{R}$}

Reagans, Ray and Bill McEvily (2003), "Network Structure and Knowledge Transfer: The Effects of Cohesion and Range," Administrative Science Quarterly, 48 (2), 240-67.

Reed, R. and R.J. deFillippi (1990), "Causal Ambiguity, Barriers to Imitation, and Sustainable Competitive Advantage," Academy of Management Review, 15 (1), 88-102.

Rindfleisch, Aric and Jan B. Heide (1997), "Transaction Cost Analysis: Past, Present, and Future Applications," Journal of Marketing, 61 (4), 30-54. 
Rindfleisch, Aric and Christine Moorman (2001), "The Acquisition and Utilization of Information in New Product Alliances: A Strength-of-Ties Perspective," Journal of Marketing, 65 (2), 1-18.

Rokkan, Aksel I., Jan B. Heide, and Kenneth H. Wathne (2003), "Specific Investments in Marketing Relationships: Expropriation and Bonding Effects," Journal of Marketing Research, 40 (2), 210-24.

Rosenkopf, Lori and Atul Nerkar (2001), "Beyond Local Search: Boundary-Spanning, Exploration, and Impact in the Optical Disc Industry," Strategic Management Journal, 22 (4), 287-306.

Sapienza, Harry J., Annaleena Parhankangas, and Erkko Autio (2004), "Knowledge Relatedness and Post-Spin-Off Growth," Journal of Business Venturing, 19 (6), 809-29.

Schumpeter, Joseph A. (1939), Business Cycles: A Theoretical, Historical, and Statistical Analysis of the Capitalist Process. New York: McGraw-Hill.

Selnes, Fred and James Sallis (2003), "Promoting Relationship Learning," Journal of Marketing, 67 (3), 80-95.

Sharma, S.R.M. and Gur-Arie O. Durand (1981), "Identification and Analysis of Moderator Variables," Journal of Marketing Research, 18 (3), 291-300.

Shrout, Patrick E. and Niall Bolger (2002), "Mediation in Experimental and Nonexperimental Studies: New Procedures and Recommendations," Psychological Methods, 7 (4), 422-45.

Simonin, Bernard L. (1999a), "Ambiguity and the Process of Knowledge Transfer in Strategic Alliances," Strategic Management Journal, 20 (7), 595-623.

--- (1999b), "Transfer of Marketing Know-How in International Strategic Alliances: An Empirical Investigation of the Role and Antecedents of Knowledge Ambiguity," Journal of International Business Studies, 30 (3), 463-90.

Sivadas, Eugene and Jamie L. Baker-Prewitt (2000), "An Examination of the Relationship between Service Quality, Customer Satisfaction, and Store Loyalty," International Journal of Retail and Distribution Management, 28 (2), 73-82.

Sivadas, Eugene and F.R. Dwyer (2000), "An Examination of Organizational Factors Influencing New Product Success in Internal and Alliance-Based Processes," Journal of Marketing, 64 (1), 31-49.

Slater, Stanley F. and John C. Narver (1995), "Market Orientation and the Learning Organization," Journal of Marketing, 59 (3), 63-74.

Smith, Ken G., Stephen J. Carroll, and Susan J. Ashford (1995), "Intra- and Interorganizational Cooperation: Toward a Research Agenda," Academy of Management Journal, 38 (1), 7-23.

Sobel, M. E. (1982), "Asymptotic Intervals for Indirect Effects in Structural Equations Models," in Sociological Methodology, S. Leinhart, Ed. San Francisco: Jossey-Bass, 290312.

---- (1986), "Some New Results on Indirect Effects and Their Standard Errors in Covariance Structure Models," in Sociological Methodology, N. Tuma, Ed. Washington, DC: American Sociological Association, 159-86. 
Song, Michael, Cornelia Droge, Sangphet Hanvanich, and Roger Calantone (2005), "Marketing and Technology Resource Complementarity: An Analysis of Their Interaction Effect in Two Environmental Contexts," Strategic Management Journal, 26 (3), 259-76.

Sorescu, Alina B., Rajesh K. Chandy, and Jaideep C. Prabhu (2003), "Sources and Financial Consequences of Radical Innovation: Insights from Pharmaceuticals," Journal of Marketing, 67 (4), 82-102.

Spender, J.-C. (1996), "Making Knowledge the Basis of a Dynamic Theory of the Firm," Strategic Management Journal, 17 (Special Issue), 45-62.

Staw, Barry M. and Jerry Ross (1987), "Understanding Escalation Situations: Antecedents, Prototypes, and Solutions," in Research in Organizational Behavior, B.M. Staw and L.L. Cummings, Eds. Vol. 9. Greenwich, CT: JAI Press, 39-78.

Stuart, Toby E. and Joel M. Podolny (1996), "Local Search and the Evolution of Technological Capabilities," Strategic Management Journal, 17 (7), 21-38.

Szulanski, Gabriel (2000), "The Process of Knowledge Transfer: A Diachronic Analysis of Stickiness," Organizational Behavior \& Human Decision Processes, 82 (1), 9-27.

Szulanski, Gabriel, Rossella Cappetta, and Robert J. Jensen (2004), "When and How Trustworthiness Matters: Knowledge Transfer and the Moderating Effect of Causal Ambiguity," Organization Science, 15 (5), 600-13.

Szulanski, Gabriel and Robert J. Jensen (2006), "Presumptive Adaptation and the Effectiveness of Knowledge Transfer," Strategic Management Journal, 27 (10), 937-57.

$\mathbf{T}$

Teece, David J., Gary Pisano, and Amy Shuen (1997), "Dynamic Capabilities and Strategic Management," Strategic Management Journal, 18 (7), 509-33.

Thomke, Stefan and Eric von Hippel (2002), "Customers as Innovators: A New Way to Create Value," Harvard Business Review, 80 (4), 74-81.

Thomke, Stefan, Eric von Hippel, and Roland Franke (1998), "Modes of Experimentation: An Innovation Process-and Competitive-Variable," Research Policy, 27 (3), 315-32.

Tyre, Marcie J. and Eric von Hippel (1997), "The Situated Nature of Adaptive Learning in

Organizations," Organization Science, 8 (1), 71-83.

$\mathbf{U}$

Ulrich, Dave and Norm Smallwood (2004), "Capitalizing on Capabilities," Harvard Business Review, 82 (6), 119-27.

Urban, Glen L., Theresa Carter, Steven Gaskin, and Zofia Mucha (1986), "Market Share Rewards to Pioneering Brands: An Empirical Analysis and Strategic Implications," Management Science, 32 (6), 645-59.

Urban, Glen L. and Eric von Hippel (1988), "Lead User Analyses for the Development of New Industrial Products," Management Science, 34 (5), 569-82.

Uzzi, Brian (1999), "Embeddedness in the Making of Financial Capital: How Social Relations and Networks Benefit Firms Seeking Financing," American Sociological Review, 64 (4), 481-505. 
---- (1997), "Social Structure and Competition in Interfirm Networks: The Paradox of Embeddedness," Administrative Science Quarterly, 42 (1), 37-69.

--- (1996), "The Sources and Consequences of Embeddedness for the Economic Performance of Organizations: The Network Effect," American Sociological Review, 61 (4), 674-98.

Uzzi, Brian and Ryon Lancaster (2003), "Relational Embeddedness and Learning: The Case of Bank Loan Managers and Their Clients," Management Science, 49 (4), 383-99.

\section{V}

Vargo, Stephen L. and Robert F. Lusch (2004), "Evolving to a New Dominant Logic for Marketing," Journal of Marketing, 68 (1), 1-17.

Vlaar, Paul, Paul de Vries, and Mattijs Willenborg (2005), "Why Incumbents Struggle to Extract Value from New Strategic Options: Case of the European Airline Industry," European Management Journal, 23 (2), 154-69.

von Hippel, Eric (1998), "Economics of Product Development by Users: The Impact of "Sticky" Local Information," Management Science, 44 (5), 629-44.

--- (1994), "'Sticky Information" and the Locus of Problem Solving: Implications for Innovation," Management Science, 40 (4), 429-39.

---- (1988), "The Sources of Innovation," McKinsey Quarterly, 1, 72-79.

---- (1986), "Lead Users: A Source of Novel Product Concepts," Management Science, 32 (7), 791-805.

von Hippel, Eric and Ralph Katz (2002), "Shifting Innovation to Users Via Toolkits," Management Science, 48 (7), 821-33.

Vorhies, Douglas W. and Neil A. Morgan (2005), "Benchmarking Marketing Capabilities for Sustainable Competitive Advantage," Journal of Marketing, 69 (1), 80-94.

W

Walsh, J. P. (1995), "Managerial and Organizational Cognition: Notes from a Trip Down Memory Lane," Organization Science, 6 (3), 280-321.

Walsh, James P. and Gerardo Rivera Ungson (1991), "Organizational Memory," Academy of Management Review, 16 (1), 57-91.

Wasserman, S. and K. Faust (1994), Social Networks Analysis: Methods and Applications. United Kingdom: Cambridge University Press.

Williamson, O.E. (1985), The Economic Institutions of Capitalism. New York: The Free Press.

Winter, Sidney (1987), "Knowledge and Competence as Strategic Assets," in The Competitive

Challenge: Strategies for Industrial Innovation and Renewal, D. Teece, Ed. Cambridge, MA: Ballinger, 159-84.

Winter, Sidney G. and Gabriel Szulanski (2001), "Replication as Strategy," Organization Science, 12 (6), 730-43.

\section{$\mathrm{Z}$}

Zahra, Shaker A. and Gerard George (2002), "Absorptive Capacity: A Review, Reconceptualization, and Extension," Academy of Management Review, 27 (2), 185-203. 
Zahra, Shaker A., R. Isil Yavuz, and Deniz Ucbasaran (2006), "How Much Do You Trust Me? The Dark Side of Relational Trust in New Business Creation in Established Companies," Entrepreneurship: Theory \& Practice, 30 (4), 541-59.

Kogut, Bruce and Udo Zander (1992), "Knowledge of the Firm, Combinative Capabilities, and the Replication of Technology," Organization Science, 3 (3), 383-97.

Zander, Udo and Bruce Kogut (1995), "Knowledge and the Speed of the Transfer and Imitation of Organizational Capabilities: An Empirical Test," Organization Science, 6 (1), 76-92.

Zheng Zhou, Kevin, Chi Kin Yim, and David K. Tse (2005), "The Effects of Strategic Orientations on Technology- and Market-Based Breakthrough Innovations," Journal of Marketing, 69 (2), 42-60. 


\section{NEDERLANDSE SAMENVATTING}

\section{Marketing knowledge and competencies in co-creation relationships}

Steeds meer worden kennis en kennisontwikkelingsprocessen aangeduid als verklarende factoren van het succes of falen van bedrijven. Een steeds vaker toegepaste manier om kennis te ontwikkelen is de samenwerking tussen bedrijven om voor hen relevante kennis te verwerven. Daarnaast vindt waardecreatie steeds meer plaats op basis van de dialoog tussen bedrijven en hun klanten. Leveranciers investeren bijvoorbeeld steeds meer in het gezamenlijk ontwikkelen van producten met hun afnemers om zo hun eigen kennis te verrijken met die van een partij die dichter bij de consument staat.

De hierboven beschreven relaties waarbij betrokkenheid en interactie tussen leverancier en afnemer centraal staan, worden ook wel co-creatierelaties genoemd. Deze relatie vormt de context voor de empirische studies in dit proefschrift. Binnen deze context richt dit onderzoek zich op a) de invloed van bedrijfs- en relatiekenmerken op de ontwikkeling van kennis en kenniscompetenties en b) de waarde van kennis(competenties) voor bijvoorbeeld de financiële en strategische positie van bedrijven. De gebruikte gegevens zijn verzameld via een vragenlijst aan managers van co-creatierelaties. Deze managers zijn allen werkzaam in de Nederlandse productiesector.

De toenemende mate waarin bedrijven samenwerken om nieuwe kennis te verwerven en nieuwe producten te ontwikkelen is één van de drijfveren om in dit onderzoek uit te zoeken in welke mate de relatie op zich bepalend is voor de ontwikkeling van nieuwe kennis en kenniscompetenties. De resultaten van dit onderzoek bevestigen de verwachting dat het niet langer geheel terecht is om de uitkomsten van leerprocessen toe te schrijven aan kennisaspecten alleen. Ondanks het nog altijd grote belang van kennis, blijkt dat ook sociale dimensies van de relatie van belang zijn om een completer beeld te krijgen van de mogelijkheden en beperkingen van kennisontwikkeling tijdens co-creatierelaties.

In hoofdstuk 2, het eerste empirische hoofdstuk, wordt bekeken hoe een leverancier in een co-creatierelatie het beste marketinginnovaties kan ontwikkelen. Marketinginnovaties ontstaan wanneer het samenwerkingsproces heeft geleid tot kennis die het huidige marktmodel in vraag stelt. Hierbij kan gedacht worden aan het introduceren van een nieuw distributiekanaal of een nieuwe manier van klant- 
benadering. Als eerste wordt bestudeerd in hoeverre de ontwikkeling van marketinginnovaties wordt bepaald door de mate waarin de leverancier en de afnemer ieder apart het vermogen bezitten om te leren over de latente wensen van hun klanten. Daarnaast wordt aandacht besteed aan de rol van sociale invloeden. Dit wordt gedaan door te kijken naar het modererende effect van de sterkte van de band tussen de leverancier en de afnemer.

De resultaten laten zien dat zowel het leervermogen van de leverancier als dat van de afnemer de kans op marketinginnovaties van de leverancier vergroten. Voor een leverancier is het samenwerken met een afnemer dan ook van groot belang omdat dit het 'kennisgat' met de markt kan dichten. Wat betreft de invloed van de sociale aspecten is gebleken dat een sterke band tussen de twee bestudeerde partijen zowel positief als negatief kan uitpakken. Terwijl een sterke band de ontwikkeling van marketinginnovaties belemmert wanneer de afnemer veel kennis heeft van marketingtrends (een zogeheten 'lead-user'), werkt deze juist stimulerend wanneer de leverancier veel kennis over (de latente wensen van) de markt bezit.

Door niet enkel te kijken naar de kennisaspecten of naar de sociale aspecten apart maar deze juist te combineren, blijkt dat de invloed van de sterkte van de band binnen de relatie complexer is dan voorheen gedacht werd. Deze bevinding is in overeenstemming met een klein, maar groeiend aantal publicaties dat duidt op de tweeslachtigheid van een aantal factoren waaronder bijvoorbeeld 'vertrouwen' en 'sterkte van de band binnen relaties'.

Ook hoofdstuk 3 staat stil bij de interactie tussen kennis en sociale factoren. In dit hoofdstuk wordt specifiek gekeken naar een manier voor bedrijven om valkuilen, ten gevolge van eerdere successen en kennisgaring, te vermijden in het ontwikkelen van nieuwe competenties. De literatuur is verdeeld over de effecten van bestaande kennis ('geheugen'). Eén opvatting in de literatuur stelt dat bestaande kennis een belangrijk ingrediënt is voor het ontwikkelen van nieuwe competenties. Een andere opvatting is juist dat bestaande kennis bedrijven hierin hindert.

Dit hoofdstuk laat zien dat deze schijnbaar tegenstrijdige bevindingen verklaard kunnen worden. In overeenstemming met de visie die stelt dat bestaande kennis bedrijven hindert, vinden wij een direct negatief effect van bestaande kennis op de ontwikkeling van nieuwe competenties. Echter, in overeenstemming met de visie die de positieve effecten van bestaande kennis benadrukt, vinden wij ook dat de kennisoverlap tussen de leverancier en de afnemer ervoor zorgt dat de co-creatiepartners deels 'dezelfde taal spreken' en hierdoor het potentieel van bestaande (bedrijfs)kennis ontsluit om verbanden te kunnen leggen met nieuwe 
kennis. Tevens zorgt kennisoverlap ervoor dat de partners gebruik kunnen maken van de kruisbestuiving tussen de kennisbases en in staat zijn nieuwe competenties te ontwikkelen.

Bedrijven die deelnemen in co-creatierelaties zouden zich bij het selecteren van een partner daarom niet alleen moeten laten leiden door het type of de hoeveelheid kennis die de partner bezit, maar ook door de mate waarin de kennis van de partner gerelateerd is aan de eigen kennis. Daarnaast blijkt uit dit onderzoek dat het niet gerechtvaardigd is om routines en processen te handhaven vanwege eerdere (financiële) investeringen. Om zich continu te kunnen blijven aanpassen aan de markt en de concurrentie is het verstandiger om bestaande kennis, routines en processen te combineren met nieuwe kennis. Dit wordt vergemakkelijkt door co-creatie met partners uit de waardeketen die gerelateerde kennis bezitten.

Terwijl hoofdstuk 2 en 3 zich voornamelijk richten op het ontrafelen van de antecedenten van kennisontwikkeling $(\mathrm{H} 2)$ en van nieuwe competenties $(\mathrm{H} 3)$, richt de derde studie zich geheel op de gevolgen van kennisontwikkeling. De vraag in hoofdstuk 4 is of kennis die voortkomt uit een co-creatie haar waarde behoudt nadat de relatie is beëindigd. Bedrijven kunnen extra waarde halen uit de samenwerking als deze kennis kan worden hergebruikt in processen of producten buiten het gezamenlijk ontwikkelde product. Dit hoofdstuk onderzoekt of de herbruikbaarheid van deze kennis afhankelijk is van de context (relatie- en omgevingsfactoren) waarin het is ontwikkeld. Meer specifiek wordt onderzocht of de herbruikbaarheid van twee kennissoorten -marketinginnovaties en marketingverfijningen- afhankelijk zijn van a) de sterkte van de band tussen de bedrijven in een co-creatierelatie en b) de omgevingsfactoren. Mocht dit zo blijken, dan kan worden aangenomen dat kennishergebruik niet zo vanzelfsprekend is als regelmatig in de literatuur wordt verondersteld.

De resultaten wijzen uit dat beide kennissoorten in principe herbruikbaar zijn door de individuele deelnemers nadat de relatie is beëindigd. Echter, wanneer de sterkte van de band tussen de leverancier en de afnemer in ogenschouw wordt genomen, blijkt dat herbruikbaarheid niet zo vanzelfsprekend is. Wanneer de band tussen de bedrijven niet uitgesproken sterk is, dan blijkt de herbruikbaarheid van marketinginnovaties (nieuwe marketingkennis die bestaande manieren om in de markt te opereren betwist en verandert) hoog en eerder laag voor marketingverfijning (verbeteringen van bestaande mentale marktmodellen). Wat betreft de omgevingsfactoren blijkt dat veranderende klantbehoeften (hoge marktturbulentie) een hinderende werking hebben op het positieve effect van marktinnovaties op de 
herbruikbaarheid van co-creatiekennis. Technologische turbulentie hindert vooral de herbruikbaarheid van marketingverfijningen.

De resultaten beschreven in dit proefschrift leveren een belangrijke bijdrage aan een completer overzicht en een dieper inzicht in het samenspel van relatie- en kennisfactoren in co-creatierelaties. De combinatie van inter- en intrabedrijfsprocessen blijkt een relatief onontgonnen terrein dat verheldering kan brengen aan zowel theorie als beleid. Verder heeft het toelichten van tegenstrijdigheden in de literatuur geleid tot inzichten in het belang en de stuurbaarheid van de uitkomsten van co-creatierelaties. 


\section{Curriculum Vitae}

Corine Noordhoff was born on the $12^{\text {th }}$ of June 1979 in Bussum, The Netherlands. After completion of the secondary school (Baarnsch Lyceum, Baarn) in 1997, she started her International Business Studies at the Faculty of Economics and Business Administration at Maastricht University. During her studies, she spent one semester at the National University of Singapore. She received her Master's degree of Business Administration in August 2001 after which she joined the Departments of Marketing and Strategy and Organization at Maastricht University where she worked as a junior lecturer for a year and became employed as a Ph.D. candidate in September 2002. During her time as a Ph.D. candidate she was a visiting scholar at the Carlson School of Management, Minneapolis, USA.

Since September 2006 she is working as an Assistant Professor at the Department of Marketing at the Vrije Universiteit Amsterdam. Her main research interests lie in the area of marketing strategy, innovation, and interfirm relationships. 